\title{
The effects of aquaculture production noise on the growth, hearing, disease resistance, and survival of rainbow trout (Oncorhynchus mykiss) and methods for minimizing noise in fiberglass aquaculture tanks
}

John W. Davidson III West Virginia University

Follow this and additional works at: https://researchrepository.wvu.edu/etd

\section{Recommended Citation}

Davidson, John W. III, "The effects of aquaculture production noise on the growth, hearing, disease resistance, and survival of rainbow trout (Oncorhynchus mykiss) and methods for minimizing noise in fiberglass aquaculture tanks" (2009). Graduate Theses, Dissertations, and Problem Reports. 4455. https://researchrepository.wvu.edu/etd/4455

This Thesis is protected by copyright and/or related rights. It has been brought to you by the The Research Repository @ WVU with permission from the rights-holder(s). You are free to use this Thesis in any way that is permitted by the copyright and related rights legislation that applies to your use. For other uses you must obtain permission from the rights-holder(s) directly, unless additional rights are indicated by a Creative Commons license in the record and/ or on the work itself. This Thesis has been accepted for inclusion in WVU Graduate Theses, Dissertations, and Problem Reports collection by an authorized administrator of The Research Repository @ WVU. For more information, please contact researchrepository@mail.wvu.edu. 


\title{
The Effects of Aquaculture Production Noise on the Growth, Hearing, Disease \\ Resistance, and Survival of Rainbow Trout (Oncorhynchus mykiss) and Methods for Minimizing Noise in Fiberglass Aquaculture Tanks
}

\author{
John W. Davidson III
}

\author{
Thesis submitted to the \\ College of Agriculture, Forestry and Consumer Sciences \\ at West Virginia University \\ in partial fulfillment of the requirements \\ for the degree of
}

\author{
Master of Science \\ in \\ Wildlife and Fisheries Resources \\ Patricia M. Mazik, Ph.D., Chair \\ Julie Bebak-Williams, Ph.D. \\ Arthur N. Popper, Ph.D. \\ Kyle J. Hartman, Ph.D. \\ Christy M. Foran, Ph.D. \\ Department of Wildlife and Fisheries Resources \\ Morgantown, West Virginia \\ 2009
}

Key Words: Noise, Underwater Sound, Intensive Aquaculture Production, Rainbow Trout Growth, Fish Hearing

Copyright 2009 John W. Davidson III 


\begin{abstract}
The Effects of Aquaculture Production Noise on the Growth, Hearing, Disease Resistance, and Survival of Rainbow Trout (Oncorhynchus mykiss) and Methods for Minimizing Noise in Fiberglass Aquaculture Tanks
\end{abstract}

\title{
John W. Davidson III
}

Intensive aquaculture systems, particularly recirculating systems, often require noise producing equipment such as pumps, blowers, and filters that inadvertently increase sound levels within the culture environment. These systems are often very effective at culturing healthy, fast growing fish; however, the potential impacts of underwater noise on fish within intensive aquaculture systems have not been evaluated. Limited research suggests that subjecting fish to noise could result in impairment of the auditory system, reduced growth rates, and increased stress. The studies presented within this manuscript were conducted to gain a better understanding of aquaculture production noise and its potential impacts on rainbow trout growth, survival, and physiology.

Chapter 1. The objective of this study was to evaluate practical structural changes (retrofits) to reduce underwater noise within fiberglass fish culture tanks. Retrofits eliminated contact between PVC piping and tank surfaces and buffered sound transmission into tanks using insulated materials. Each retrofit contributed to a reduction of underwater sound. As retrofits were combined, a cumulative four-fold reduction in sound level was observed. Sound frequency spectra also indicated that nearby pumps and blowers created tonal frequencies that were transmitted into the tanks. The tank modifications used during this study were simple and inexpensive and could be applied to existing systems and designs. Optimal retrofits were applied to tanks used in subsequent studies to create "quiet" control tanks. 
Chapter 2. This study was conducted to evaluate the long term effects of aquaculture production noise on the hearing sensitivity, growth, survival, and disease susceptibility of rainbow trout. Two cohorts of rainbow trout were cultured for eight months in replicated tanks (n $=2$ ) consisting of three sound treatments: 115,130 , and $150 \mathrm{~dB}$ re $1 \mu \mathrm{Pa}$ RMS, representing sound levels that were lower than, similar to, and higher than mean sound levels recorded within commercial scale recirculating systems. There were no significant differences between sound treatments for hearing threshold, growth rate, mortality, and disease susceptibility. This study indicated that rainbow trout were not negatively impacted by noise levels common to recirculating aquaculture systems.

Chapter 3. Anecdotal evidence of slight (but non-significant) differences in growth between treatments during the Chapter 2 study, particularly over the first month, prompted additional research. The objective was to provide an in-depth evaluation of the long term effects of aquaculture production noise on the growth, condition factor, feed conversion efficiency, and survival of rainbow trout with increased replication $(n=4)$. Two sound treatments were used: 117 and $149 \mathrm{~dB}$ re $1 \mu \mathrm{Pa}$ RMS. No significant differences were identified between the treatments for mean weight, length, specific growth rates, condition factor, feed conversion, or survival $(\mathrm{n}=$ 4). Analysis of growth rates of individually tagged rainbow trout indicated that fish from the 149 $\mathrm{dB}$ tanks grew slower during the first month of noise exposure; however, fish acclimated to the noise thereafter. This study further suggests that rainbow trout growth and survival are unlikely to be affected over the long term by sound levels common to intensive aquaculture systems. 


\section{Acknowledgements}

First, I would like to say a special thank you to Dr. Pat Mazik for serving as my committee chair and for providing me with the unique opportunity to obtain a master's degree in Fisheries while still maintaining fulltime employment at the Freshwater Institute. I would like to thank everyone at West Virginia University and the National Conservation Training Center who made the extended learning degree program possible. I would also like to say a special thank you to Dr. Julie Bebak-Williams for her guidance and support as my on-site advisor and committee member throughout this project and for sticking with me when her career path took her elsewhere. I would like to thank all of my other committee members, Dr. Arthur Popper, Dr. Kyle Hartman, and Dr. Christy Foran, for their advice and assistance with this project. I would also like to extend my gratitude to all of the other coauthors that contributed to this work including: Dr. Adam Frankel and Dr. William Ellison for their expertise and assistance with acoustical setup and analysis, and Dr. Lidia (Eva) Wysocki and Dr. Michael Smith for their work with all aspects of the fish hearing portion of the study. I was very fortunate to have such a knowledgeable and experienced group of professionals to help me in this venture. I have benefited greatly from working with each of you and as a result I have grown tremendously as a scientific professional and as an individual.

I would also like to extend my gratitude to the many folks at the Freshwater Institute, who assisted with this project: Jacob Wilson, Michael Theis, and Michael Gearhart for technical assistance; Fred Ford, Brian Mason, and Daniel Coffinberger for tank construction and audio system setup; and to the many folks that assisted with length and weights and fish tagging. I would be remiss if I didn't thank Dr. Steven Summerfelt, who has been my mentor at the Freshwater Institute. Steve, thank you for urging me to pursue this degree. I would also like to 
thank Dr. Tim Welch from the National Center for Cool and Cold Water Aquaculture for assistance with the disease challenge and Dr. Alan Temple, Dr. Desta Fekedulegn, and the late Dr. George Seidel for statistical advice. Last but certainly not least, I would like to extend my gratitude to the Conservation Fund and the Freshwater Institute for supporting my professional advancement and providing the resources to carry out this research. This research was supported by the United States Department of Agriculture's Agricultural Research Service under Agreement 59-1930-5-510 and was conducted as part of the research program at the Conservation Fund's Freshwater Institute. 


\section{Table of Contents}

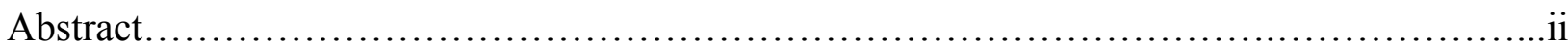

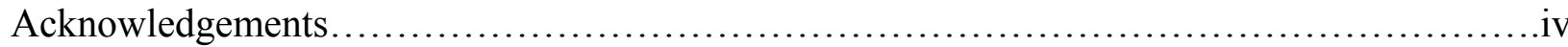

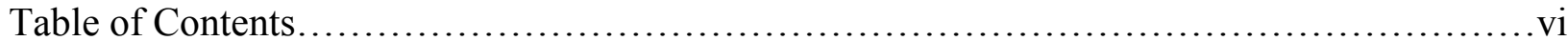

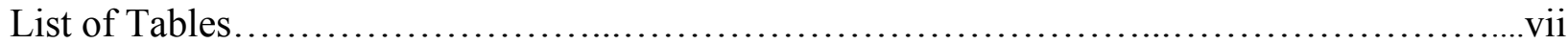

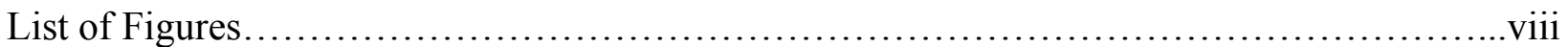

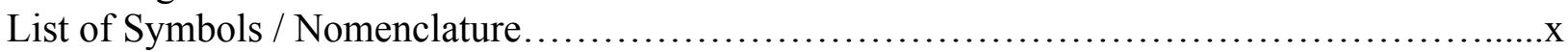

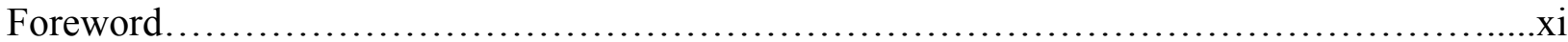

Chapter 1: Minimizing noise in fiberglass aquaculture tanks: Noise reduction potential

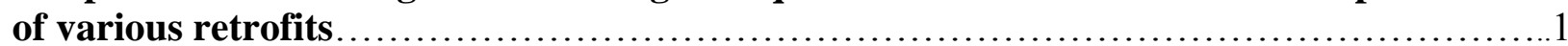

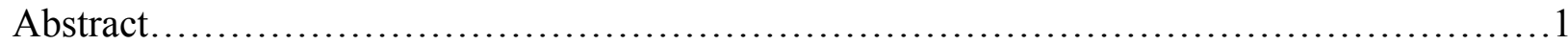

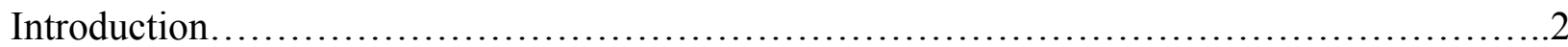

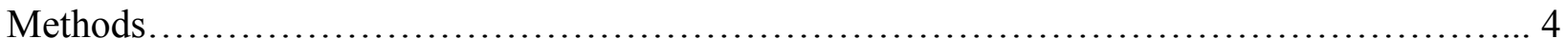

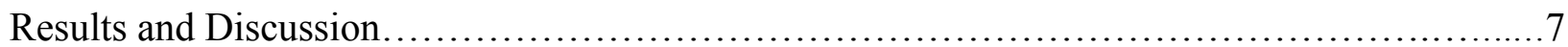

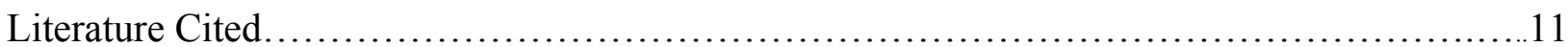

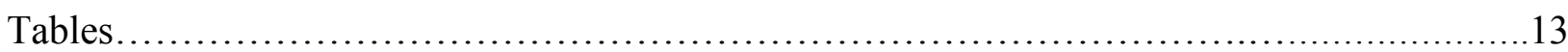

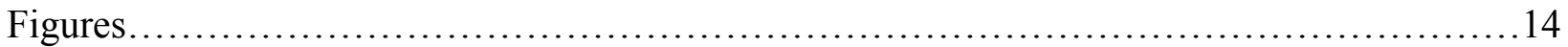

Chapter 2: The effects of aquaculture production noise on hearing, growth and disease resistance of rainbow trout Oncorhynchus mykiss....................................19

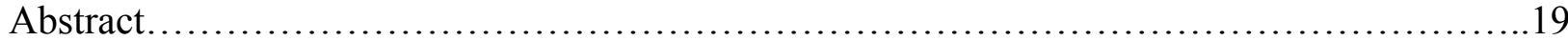

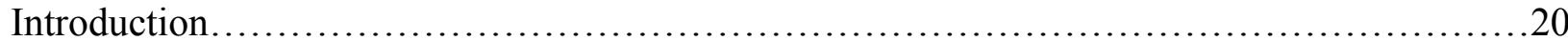

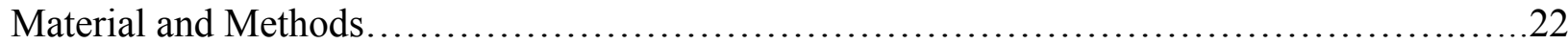

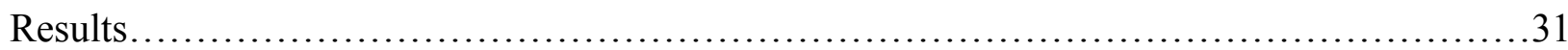

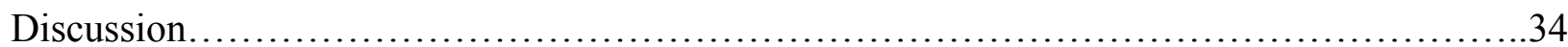

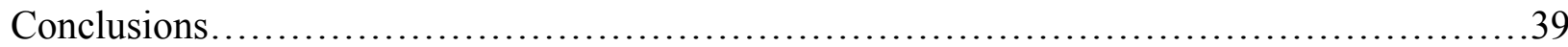

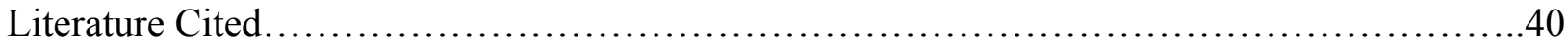

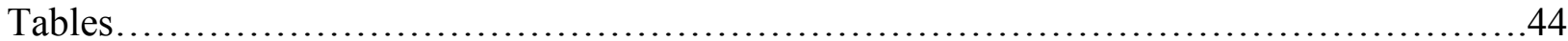

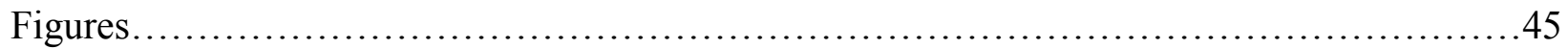

Chapter 3: The Effects of Aquaculture Production Noise on the Growth, Condition Factor, Feed Conversion, and Survival of Rainbow Trout, Oncorhynchus mykiss............52

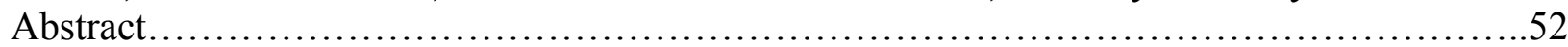

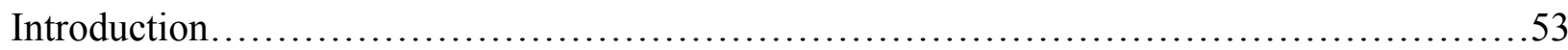

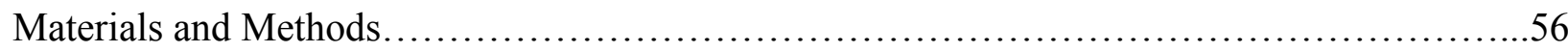

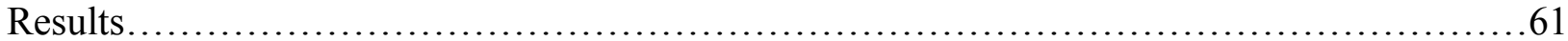

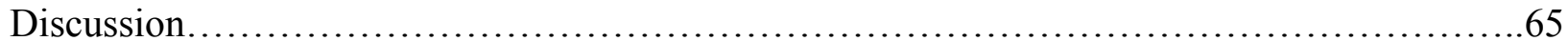

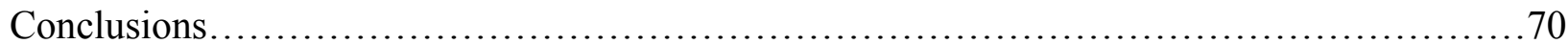

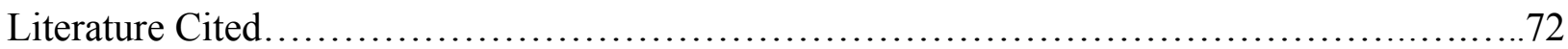

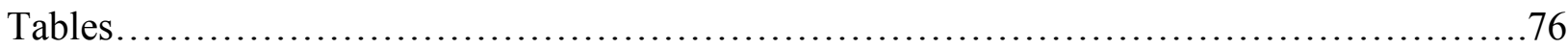

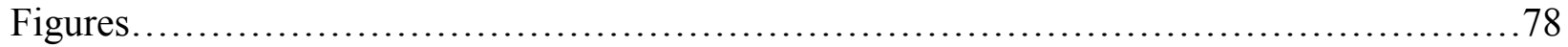

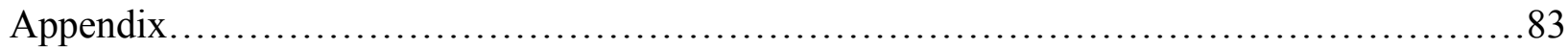

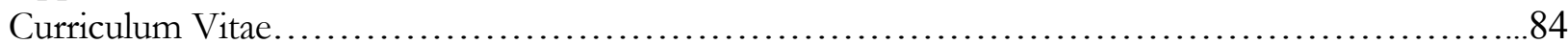




\section{List of Tables}

\section{Chapter 1}

Table 1. Modifications made, broadband sound levels ( $\mathrm{dB}$ re $1 \mu \mathrm{Pa})$, and mean sound pressures for each retrofit design

\section{Chapter 2}

Table 1. Percentage distribution of various saccular otolith crystalline structures from fish that were tested for hearing thresholds

Table 2. Percentage survival of trout from each sound treatment tank during the entire study period

\section{Chapter 3}

Table 1. Mean sound levels ( $\mathrm{dB}$ re $1 \mu \mathrm{Pa}$ RMS) for the $117 \mathrm{~dB}$ treatment

Table 2. Mean sound levels (dB re $1 \mu \mathrm{Pa}$ RMS) for the $149 \mathrm{~dB}$ treatment

Table 3. Mean water quality concentrations \pm 1 standard error for each sound treatment

Table 4. Mean \pm 1 standard error for various growth criteria for the 117 and $149 \mathrm{~dB}$ treatments following five months of noise exposure $(n=4)$. 


\section{List of Figures}

\section{Chapter 1}

Figure 1. Modification 1, SUSPEND INLET. Inlet piping designs before and after the retrofits.

Figure 2. Modifications 2a and 2b. DISCONNECT EFFLUENT and INSULATE EFFLUENT. Effluent piping designs before and after the retrofit.

Figure 3. Modification 3. ELEVATE/NEOPAD. Culture tank support designs before and after the retrofit.

Figure 4. Sound spectrum comparison of a water filled bucket seated directly on a gravel floor vs. a water filled bucket with foam insulation between the bucket and the gravel floor.

Figure 5. Percent sound pressure reduction for all retrofit modifications compared to sound pressure for the control tanks.

Figure 6. Sound spectrum comparison for control tanks and the retrofit design with Modifications 1, 2a, 2b, and 3 (SUSPEND INLET, DISCONNECT EFFLUENT, INSULATE EFFLUENT, and ELEVATE/NEOPAD).

Figure 7. Sound spectrogram indicating transmission of oxygen saturator pump and carbon dioxide blower frequencies into a culture tank.

Figure 8. A custom pump stand fabricated by Marine Biotech Inc. (Beverly, MA) installed at the USDA ARS, NCWMAC (Franklin, ME).

\section{Chapter 2}

Figure 1. Average sound density spectra of the three sound treatment tanks for cohort 1 (solid lines) and cohort 2 (dotted lines).

Figure 2. Tactile speaker attached to side wall of an experimental tank used to transmit aquaculture production noise into the tank.

Figure 3. Variability of sound pressure levels ( $\mathrm{dB}$ re $1 \mu \mathrm{Pa}$ broadband [2 $\mathrm{Hz}$ to $20 \mathrm{kHz}$ ] RMS) within the different sound treatment tanks.

Figure 4. Hearing thresholds of cohort 2 trout raised in $115 \mathrm{~dB}$ tanks (solid lines) and in $150 \mathrm{~dB}$ tanks (dashed lines) at the age of 16 weeks (A), 32 weeks (B), and 38 weeks (C).

Figure 5. Hearing thresholds of cohort 1 trout (age: 41 weeks) and cohort 2 trout (age: 38 weeks) measured on the same test days. 
Figure 6. Microscope photograph of a dissected fish ear with vaterite otolith.

Figure 7. Growth curves of cohort 1 trout raised in the three different sound treatment tanks.

Figure 8. Chloride (A), sodium (B), and glucose (C) blood concentrations of trout from cohort 1 (white bars) and cohort 2 (black bars) trout raised in different sound treatment tanks.

\section{Chapter 3}

Figure 1. Sound spectrum comparison of the holding tanks and the experimental control tanks used during the study (117 $\mathrm{dB}$ re $1 \mu \mathrm{Pa}$ RMS).

Figure 2. Mean sound spectrum levels for the two sound treatments.

Figure 3. Mean growth rates $(\mathrm{g})$ for the 149 and $117 \mathrm{~dB}$ treatments throughout the study with $95 \%$ confidence intervals.

Figure 4. Percentage difference in mean weights and lengths between treatments for each monthly sample.

Figure 5. Specific growth rates (\% growth/day) between each monthly sample for the 149 and $117 \mathrm{~dB}$ treatments with $95 \%$ confidence intervals.

Figure 6. Mean length $(\mathrm{mm})$ for the 149 and $117 \mathrm{~dB}$ treatments throughout the study with $95 \%$ confidence intervals.

Figure 7. Mean size distribution for each sound treatment at the beginning of the study.

Figure 8. Mean size distribution for each sound treatment after one month of exposure to experimental conditions.

Figure 9. Mean size distribution for each sound treatment at the end of the study.

\section{Appendix}

${ }^{1}$ Figure 1. Difference in mean weight (\%) between the 115 and the $150 \mathrm{~dB}$ re $1 \mu \mathrm{Pa}$ RMS treatments during each sampling event over the course of the study. 


\section{List of Symbols/Nomenclature}

1. AEP's.......................................................uditory evoked potentials

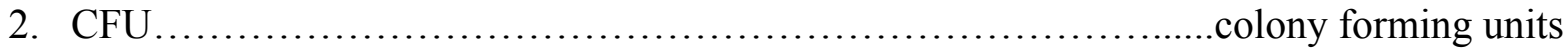

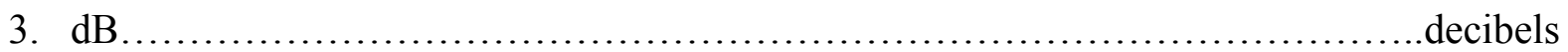

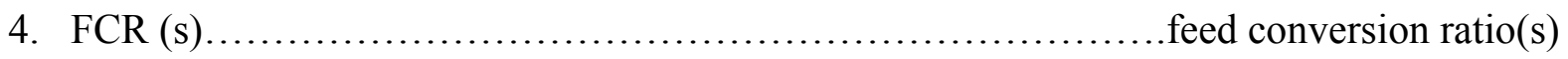

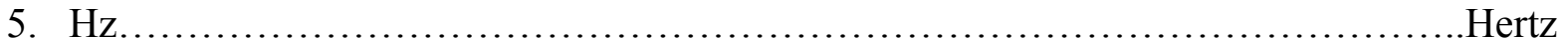

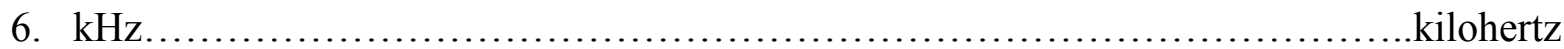

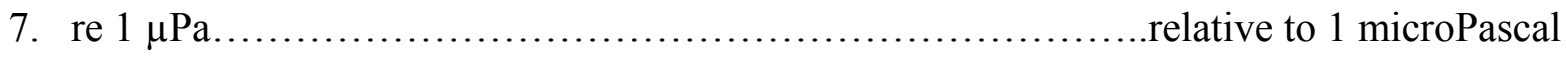

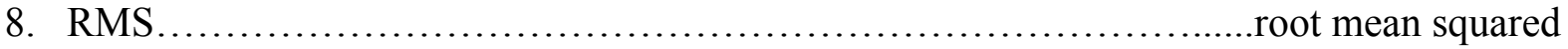

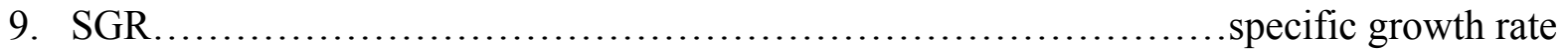

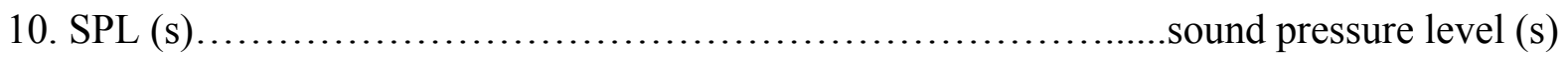




\section{Foreword}

This thesis was conducted as part of the research program at the Conservation Fund's Freshwater Institute in Shepherdstown, West Virginia and was funded by the United States Department of Agriculture. The contents of this thesis herein are written and formatted to the guidelines of the respective peer reviewed journals. Chapter 1 was written in the style required for Aquacultural Engineering, and chapters 2 and 3 for Aquaculture. 


\section{Chapter 1: Minimizing noise in fiberglass aquaculture tanks: Noise reduction potential of various retrofits}

\section{Abstract}

Equipment used in intensive aquaculture systems, such as pumps and blowers can produce underwater sound levels and frequencies within the range of fish hearing. The impacts of underwater noise on fish are not well known, but limited research suggests that subjecting fish to noise could result in impairment of the auditory system, reduced growth rates, and increased stress. Consequently, reducing sound in fish tanks could result in advantages for cultured species and increased productivity for the aquaculture industry. The objective of this study was to evaluate the noise reduction potential of various retrofits to fiberglass fish culture tanks. The following structural changes were applied to tanks to reduce underwater noise: 1) inlet piping was suspended to avoid contact with the tank, 2) effluent piping was disconnected from a common drain line, 3) effluent piping was insulated beneath tanks, and 4) tanks were elevated on cement blocks and seated on insulated padding. Four combinations of the aforementioned structural changes were evaluated in duplicate and two tanks were left unchanged as controls. Control tanks had sound levels of $120.6 \mathrm{~dB}$ re $1 \mu \mathrm{Pa}$. Each retrofit contributed to a reduction of underwater sound. As structural changes were combined, a cumulative reduction in sound level was observed. Tanks designed with a combination of retrofits had sound levels of $108.6 \mathrm{~dB}$ re 1 $\mu \mathrm{Pa}$, a four-fold reduction in sound pressure level. Sound frequency spectra indicated that the greatest sound reductions occurred between 2-100 Hz and demonstrated that nearby pumps and blowers created tonal frequencies that were transmitted into the tanks. The tank modifications 
used during this study were simple and inexpensive and could be applied to existing systems or considered when designing aquaculture facilities.

\section{Introduction}

Equipment such as aerators, pumps, blowers, filtration systems, and harvesting equipment that are required for intensive aquaculture production can increase noise in aquaculture systems, especially within recirculating systems that utilize these mechanical components (Bart et al., 2001; Timmons et al., 2001). Cascading flows associated with recirculating systems could also increase noise. Concerns have been raised that existing sound levels in the environment and in aquaculture facilities could negatively impact aquatic organisms (Richardson et al., 1995; Popper, 2003). Possible effects include impairment of the auditory system, increased stress, and reduced growth rates.

Noise can negatively affect fish hearing (Popper and Clarke, 1976; Scholik and Yan, 2002; Smith et al., 2004). Temporary hearing loss and stress responses occurred in goldfish, Carassius auratus, following exposure to white noise with a bandwidth of $0.1-10 \mathrm{kHz}$ and average sound pressure levels (SPL) of 160-170 dB re $1 \mu \mathrm{Pa}$ (Smith et al., 2004). Simulated boat engine noise $(0.3-4.0 \mathrm{kHz}, 142 \mathrm{~dB}$ re $1 \mu \mathrm{Pa})$ caused elevated auditory thresholds in the fathead minnow, Pimephales promelas (Scholik and Yan, 2002). Note: Due to the differences in density of air and water, sound levels must be referenced differently for the two media. In referencing underwater sound, an arbitrary reference value, 1 microPascal (re $1 \mu \mathrm{Pa}$ ), is used and in air 20 
$\mu \mathrm{Pa}$ is used (Hawkins and Myrberg, 1983; Popper, 2003). Thus the following equation is used to convert pressure to decibels: $\mathrm{dB}=20 \log _{10}(\mathrm{p}$ sound $/ \mathrm{p}$ reference $)$ where $\mathrm{p}=$ pressure.

Few studies have investigated the effects of noise on growth and reproduction, especially in regard to aquaculture species. Banner and Hyatt (1973) observed lower egg viability and reduced growth rates for longnose killifish, Fundulus similis, and the sheepshead minnow, Cyprinodon variegates, when sound levels within small aquarium tanks were approximately 20 $\mathrm{dB}$ higher than levels in the control tanks. Growth and reproductive rates of brown shrimp, Crangon crangon, were reduced when ambient SPL's were 30-40 dB higher than SPL's common to the natural habitat of the brown shrimp (Lagardère, 1982).

Teleost fishes are separated into two non-taxonomic groups based on hearing sensitivity: hearing specialists and hearing generalists (Popper, 2003). Hearing specialists such as channel catfish (Ictalurus punctatus) and goldfish have bony connections (Weberian ossicles) or other structures that bridge the swim bladder with the inner ear, enabling these species to detect high frequency sounds (Amoser and Ladich, 2003; Popper et al., 2003). Hearing specialists can detect sounds to over $3 \mathrm{kHz}$; with best sensitivity between $300-1000 \mathrm{~Hz}$ and most hearing specialists can detect sound pressure levels as low as $50-75 \mathrm{~dB}$ re $1 \mu \mathrm{Pa}$ and in the frequency range of 100 to $2000 \mathrm{~Hz}$ (Popper et al., 2003). The majority of fish species are hearing generalists. Hearing generalists lack specialized connections between the swim bladder and the inner ear and are therefore only able to detect low frequency sounds. Hearing generalists typically can only detect frequencies below $500-1000 \mathrm{~Hz}$ and are not as sensitive to sound pressure levels as hearing specialists (Popper et al., 2003).

Sound levels and frequencies recorded in commercial-scale aquaculture systems are within the hearing range of fish, including the less sensitive hearing generalists and range from 
125-135 dB re $1 \mu \mathrm{Pa}$ at 25-1000 Hz, and from $100-115 \mathrm{~dB}$ re $1 \mu \mathrm{Pa}$ at $1-2 \mathrm{kHz}$ (Bart et al., 2001). In a comparison of sound levels within recirculating systems with fiberglass tanks, concrete raceways, and earthen ponds; recirculating fiberglass tanks had the highest SPL's with maximum SPL's of $153 \mathrm{~dB}$ re $1 \mu \mathrm{Pa}$ (Bart et al., 2001). Sound pressure levels as high as $160 \mathrm{~dB}$ re $1 \mu \mathrm{Pa}$ have also been reported in aquaculture settings (Clark et al., 1996).

In natural aquatic environments, fish exposed to sounds that are significantly above ambient levels can move away from the sound source. However, fish in aquaculture settings are typically confined to individual culture tanks where avoidance of less than optimal sound is not possible. We theorize that reducing sound in tanks, particularly within recirculating systems, could benefit cultured species and potentially enhance productivity for the aquaculture industry. The objective of this study was to evaluate the noise reduction potential of various retrofits to fiberglass fish culture tanks. Retrofit designs focused on buffering sound and eliminating sound transmission pathways to tanks, which are proven techniques to reduce noise (Berendt et al., 1998).

\section{Methods}

Ten round fiberglass tanks ( $1.5 \mathrm{~m}$ inside diameter $\mathrm{x} 0.8 \mathrm{~m}$ deep) within a flow-through facility were used to examine the noise reduction potential of structural changes. Three avenues for possible sound transmission into the tanks were identified: (1) PVC inlet piping, (2) effluent piping, and (3) the gravel substrate under the tanks. Potential solutions for noise reduction include avoiding direct contact between vibrating units and other structural surfaces and applying 
noise dampening materials made of rubber or neoprene between vibrating surfaces (Berendt et al., 1998). Three tank structural modifications were developed and evaluated based on the possible avenues of sound transmission. Modification 1 - Inlet pipes, initially supported with a PVC fitting connected to the top of the tank wall, were elevated and supported from above to eliminate direct contact with the tank walls (SUSPEND INLET; Fig. 1). Modification 2a Effluent piping, initially connected to a central wastewater drain line fed by six tanks, was disconnected from the drain line so that water spilled into the pipe without direct contact (DISCONNECT EFFLUENT; Fig. 2). The intent of this modification was to prevent sound from traveling a reverse path from the wastewater drain back into the tanks. Modification $2 \mathrm{~b}$ - Effluent piping connected to the bottom center drain beneath the tanks and contacting the gravel floor was covered with black foam insulation (typically used in air conditioning and refrigeration applications) for some retrofit combinations (INSULATE EFFLUENT; Fig. 2). Modification 3 Culture tanks, originally seated on a gravel floor, were elevated on cement blocks and seated on neoprene isolation padding (Neopad, Isolation Technology, Inc., Massapequa, NY), to buffer sound transmission through the gravel floor (ELEVATE/NEOPAD; Fig. 3). Four retrofit designs consisting of combinations of modifications $1-3$ were used to evaluate sound reduction (Table 1). Two tanks were used for each retrofit design and two tanks were left unchanged as controls. Sound characteristics were measured using two methods. First, broadband sound level measurements were made using a calibrated hydrophone (HTI-94-SSQ, High Tech, Inc., Gulfport, MS) connected to a voltmeter. The hydrophone sensitivity was $-170.1 \mathrm{~dB}$ re: $1 \mathrm{~V} / \mu \mathrm{Pa}$ with a frequency response of $2 \mathrm{~Hz}$ to $30 \mathrm{kHz}$. The hydrophone was positioned midway between the sidewall and the center of each tank at depths of $38 \mathrm{~cm}$ (middle of the water column) and 66 $\mathrm{cm}$ (about $10 \mathrm{~cm}$ from the bottom of the tank). Water depth during normal operation was $76 \mathrm{~cm}$. 
Raw voltage values were mathematically converted to broadband sound pressure levels, also known as root-mean-squared (RMS) levels, using the following equation:

$$
\mathrm{SPL}(\mathrm{dB} \text { re } 1 \mu \mathrm{Pa} \mathrm{RMS})=20 \times \log _{10}\left(\left(\mathrm{X} \times 10^{3} / \mathrm{HCV}\right) * 10^{6}\right)
$$

where $\mathrm{X}=$ voltmeter reading in $\mathrm{mV} ; \mathrm{HCV}=3126 \mathrm{Volts} / \mu \mathrm{Pa}$ (hydrophone calibration value). Broadband sound pressure levels represent the average amplitude of a complex waveform that consists of many frequencies.

Second, sound recordings were collected using the calibrated hydrophone connected to a low-pass filter (Model 91149A, Precision Filters, Inc., Ithaca, NY), a pre-amplifier (Model WSB FP-11 \#1, Shure Inc., Niles, IL), and an analog-to-digital converter and data logger (Model USB9215, National Instruments, Austin, TX) connected to a lap top computer installed with NIDAQmx Base Software using a Labview 7.1 application (National Instruments, Austin, TX). Sound spectra were generated from the data collected with this equipment.

In most machines, vibrational energy from specific moving parts is transmitted through the machine structure causing other parts and surfaces to vibrate and radiate sound. For example, pipe vibration is often caused by motor driven pumps (Berendt et al., 1998). The majority of noise created by such sources usually exists as pure tones associated with the rotational speed of the pumps or motors (Cudina, et al., 1988; Berendt et al., 1998). A separate test was conducted to determine if nearby mechanical equipment contributed to sound within the tanks. A single recording was initiated and then an oxygen saturator pump and a carbon dioxide blower were sequentially turned off. Sound spectra were then analyzed to determine if tonal frequencies varied with unit operation. 


\section{Results and Discussion}

The structural changes evaluated during the study contributed to substantial noise reduction. The unmodified control tanks had the highest sound level, $120.6 \mathrm{~dB}$ re $1 \mu \mathrm{Pa}$. SUSPEND INLET tanks had a mean sound level of $116.0 \mathrm{~dB}$ re $1 \mu \mathrm{Pa}$; a reduction of $4.6 \mathrm{~dB}$

from the sound levels in the control tanks (Table 1). Since the decibel scale is logarithmic, a $6 \mathrm{~dB}$ decrease represents a 50\% reduction in sound level and a $20 \mathrm{~dB}$ decrease represents a $90 \%$ reduction in sound level. Therefore, the $4.6 \mathrm{~dB}$ reduction resulting from inlet piping modifications is a considerable decrease. Mean sound pressure levels expressed as microPascals $(\mu \mathrm{Pa})$ illustrate the magnitude of the sound reduction. Mean sound pressure decreased from $1.1 \mathrm{x}$ $10^{6} \mu \mathrm{Pa}$ in the control tanks to $6.3 \times 10^{5} \mu \mathrm{Pa}$ in the SUSPEND INLET tanks (Table 1 ).

As structural changes were combined, a cumulative sound reduction was observed. For example, tanks with SUSPEND INLET and DISCONNECT EFFLUENT had a mean sound level of $112.3 \mathrm{~dB}$ re $1 \mu \mathrm{Pa}$ compared to SUSPEND INLET only tanks that had a mean sound level of $116.0 \mathrm{~dB}$ re $1 \mu \mathrm{Pa}$ (Table 1). Eliminating contact between the effluent piping and the common wastewater drain resulted in an additional $3.7 \mathrm{~dB}$ decrease. The cumulative sound reduction of the SUSPEND INLET and DISCONNECT EFFLUENT modifications was $8.3 \mathrm{~dB}$. Mean sound pressure decreased from $1.1 \times 10^{6} \mu \mathrm{Pa}$ in the control tanks to $4.1 \times 10^{5} \mu \mathrm{Pa}$ in tanks with SUSPEND INLET and DISCONNECT EFFLUENT modifications.

Additional sound reduction was observed when effluent piping was insulated and tanks were elevated on cement blocks and seated on neoprene padding. The sound level measured within tanks having the SUSPEND INLET, INSULATE EFFLUENT, and ELEVATE/ NEOPAD modifications was $108.6 \mathrm{~dB}$ re $1 \mu \mathrm{Pa}$, which represents and additional sound level 
reduction of $3.7 \mathrm{~dB}$ and a cumulative sound level reduction of $12.0 \mathrm{~dB}$, approximately a fourfold decrease in sound pressure (Table 1). INSULATE EFFLUENT and ELEVATE/ NEOPAD modifications were both newly introduced for these tanks, therefore, the reduction in sound level could have resulted from one or both of these modifications. We speculate that the majority of the sound reduction for these tanks can be attributed to the ELEVATE/ NEOPAD modification. A preliminary test showed that placing a piece of foam insulation beneath a $120 \mathrm{~L}$ water-filled bucket seated on a gravel floor reduced in-water sound by as much as $20 \mathrm{~dB}$ across the frequency spectrum compared to sound levels recorded when the water-filled bucket was seated directly on the gravel floor (Fig. 4). Tanks modified with ELEVATE/NEOPAD used sections of neoprene insulation with a surface area of $200 \mathrm{~cm}^{2}$ between the tank and each cinder block. Using larger sections of neoprene insulation or cutting a circular piece of insulation to fit beneath the entire tank might have further reduced noise. Noise dampening materials dissipate the vibrational energy in the form of frictional heat that is generated by the flexing and bending of particles of the dampening material (Berendt et al., 1998). Therefore, the use of sound buffering materials beneath tanks should be considered, especially with tanks that are seated on metal or concrete platforms that could be more conducive to sound transmission than gravel.

Tanks that incorporated all structural changes: SUSPEND INLET, DISCONNECT EFFLUENT, INSULATE EFFLUENT, AND ELEVATE/ NEOPAD, also had a sound level of $108.6 \mathrm{~dB}$ re $1 \mu \mathrm{Pa}$, a cumulative sound level reduction of $12.0 \mathrm{~dB}$. Although additional sound reduction was not observed for these tanks, our findings clearly show that combinations of modifications caused cumulative decreases in underwater sound. The modifications to the culture tanks affected sound transmission pathways and substantially reduced noise within the tanks. SUSPEND INLET, DISCONNECT EFFLUENT, and ELEVATE/NEOPAD and/ or INSULATE 
EFFLUENT modifications each decreased sound levels. Sound pressure levels $(\mu \mathrm{Pa})$ were reduced by 41,62 , and $75 \%$ compared to the control tank values, as each modification was introduced (Fig. 5).

Sound spectrum data for all conditions showed that the highest sound levels, 105-130 dB re $1 \mu \mathrm{Pa}$, occurred at low frequencies $(2-100 \mathrm{~Hz})$. Sound levels declined steadily between $100-$ $500 \mathrm{~Hz}$ and stabilized between $75-85 \mathrm{~dB}$ re $1 \mu \mathrm{Pa}$ at 500-1000 Hz (Fig. 6). The largest mean sound reduction, 10-15 dB, occurred between 2-100 Hz (Fig. 6). Sound spectrum data also indicated that combined structural changes resulted in cumulative sound reductions and the largest sound decreases.

Sound recordings confirmed that mechanical equipment operating close to fish culture tanks could transmit sound into the control tanks. After sound recordings were initiated, a carbon dioxide blower and an oxygen saturator pump were turned off. A $29 \mathrm{~Hz}$ tonal frequency produced by a carbon dioxide blower and a $59 \mathrm{~Hz}$ frequency produced by an oxygen saturator pump disappeared from the sound spectrum after each unit was turned off (Fig. 7). The disappearance of the 29 and $59 \mathrm{~Hz}$ signals confirmed that these frequencies were being transmitted into the tanks when the equipment was operating.

A potential method to reduce sound is to control sound at the source (Berendt et al, 1998). Although methods to abate sounds originating from the oxygen saturator pump and carbon dioxide blower were not evaluated in this study, several sound buffering techniques could be utilized to diminish sound radiating from mechanical equipment. Underwater sound reduction in tanks could be achieved by setting large pumps and blowers on resilient mounts, such as neoprene padding or air mounts, to prevent transmission of vibrations through the supporting base and thus reduce the potential for radiation of noise into adjacent areas. Additionally, pumps 
and blowers could be partially enclosed or could be isolated from the tanks in separate rooms. Soundproofing walls and enclosures are commercially available. Engineers at the Freshwater Institute considered the findings of this study when designing recirculating aquaculture systems at the USDA ARS National Cold Water Marine Aquaculture Center (NCWMAC) in Franklin, ME. A custom pump stand (Marine Biotech Inc., Beverly, MA) with resilient pump mounts and rubber vibration isolation couplings on the pump inlet and outlet piping was installed in a separate water treatment room (Fig. 8).

This study demonstrated that sound levels within fish culture tanks could be substantially reduced using structural changes designed to eliminate sound transmission pathways. Eliminating contact between PVC inlet and effluent piping and the tanks effectively decreased the underwater sound levels within the tanks, indicating that PVC piping is a common sound transmission pathway to culture tanks. Other sound control techniques, not demonstrated in this study, can be utilized to reduce sound transmission through PVC pipe. Rubber fittings and couplings can be used on PVC pipe runs to dampen sound and specialized noise suppressors are available that can be installed within pipe runs or at pump outlets. In addition to PVC pipe, other sound transmission pathways could exist at aquaculture facilities. Anything directly contacting the culture tank walls could transmit sound into the tanks such as steel supports, walkways and stairways around and across tanks, and electrical conduit. The tank modifications and considerations used during this study were simple and inexpensive and could easily be incorporated into existing culture systems. However, sound reducing options should also be considered during the planning and design phase for aquaculture facilities. Although limited data exists regarding the effects of sound on fish in aquaculture facilities, taking steps to reduce sound 
within systems could reduce stress levels, enhance growth rates, and increase survival of aquaculture species, and could ultimately increase profitability.

\section{Literature Cited}

Amoser, S. and Ladich F., 2003. Diversity in noise-induced temporary hearing loss in otophysine fishes. Journal of the Acoustical Society of America 113, 2170-2179.

Banner, A. and Hyatt, M., 1973. Effects of noise on eggs and larvae of two estuarine fishes. Transactions of the American Fisheries Society 1, 134-136.

Bart, A.N., Clark, J., Young, J., and Zohar, Y., 2001. Underwater ambient noise measurements in aquaculture systems: a survey. Aquaculture Engineering 25, 99-110.

Berendt, R.D., Corliss, E., and Ojavo, M., 1998. Quieting: A Practical Guide to Noise Control. National Bureau of Standards Handbook 119. U.S. Environmental Protection Agency Office of Noise Abatement and Control, Washington D.C.

Clark, J., Young, J., Bart, A.N., Zohar, Y., 1996. Underwater ambient noise measurements. In: $30^{\text {th }}$ Proceedings of the Acoustical Society of America, St. Louis, MO. Nov. 27, p. 13.

Cudina, M., and Sterzaj, M., 1988. Noise reduction of a centrifugal pump. Noise-Con 88 Proceedings, National Conference on Noise and Control Engineering. West Lafayette, IN (USA), 69-74.

Hawkins, A.D., and Myrberg, A.A., 1983. Hearing and sound communication under water: In: Bioacoustics: A Comparative Approach (Lewis, B., ed.), pp. 347-405. London Academic Press.

Lagardère, J.P., 1982. Effects of noise on growth and reproduction of Crangon crangon in rearing tanks. Marine Biology 71, 177-185.

Popper, A.N., and Clarke, N.L. 1976. The auditory system of the goldfish (Carassius auratus): effects of intense acoustic stimulation. Comparative Biochemistry and Physiology 53A (1), 11-18.

Popper, A.N., 2003. Effects of anthropogenic sound on fishes. Fisheries 28(10), 24-31.

Popper, A.N., Fay, R.R., Platt, C., and Sand, O., 2003. Sound detection mechanisms and capabilities of teleost fishes. Pages 3-38 in S.P. Collin and N.J. Marshall, eds. Sensory processing in aquatic environments. Springer-Verlag, New York. 
Timmons, M.B., Ebeling, J.M., Wheaton, F.W., Summerfelt, S.T., and Vinci, B.J. 2001. Recirculating Aquaculture Systems. Cayuga Aqua Ventures. Ithaca, NY.

Richardson, W.J., Greene Jr., C.R., Malme, C.L., and Thomson, D.H., 1995. Marine mammals and noise. Academic Press, New York.

Scholik, A.R. and Yan, H.Y., 2002. Effects of boat engine noise on the auditory sensitivity of the fathead minnow, Pimephales promelas. Environmental Biology of Fishes 63, 203-209.

Smith, M.E., Kane A.S., and Popper, A.N., 2004. Noise induced stress response and hearing loss in goldfish (Carassius auratus). The Journal of Experimental Biology 207, 427-435. 


\section{Tables}

Table 1. Modifications made, broadband sound levels ( $\mathrm{dB}$ re $1 \mu \mathrm{Pa}$ ), and mean sound pressures for each retrofit design.

\begin{tabular}{|c|c|c|c|c|c|c|}
\hline $\begin{array}{l}\text { Retrofit } \\
\text { Design }\end{array}$ & $\begin{array}{l}\text { SUSPEND } \\
\text { INLET }\end{array}$ & $\begin{array}{l}\text { DISCONNECT } \\
\text { EFFLUENT }\end{array}$ & $\begin{array}{l}\text { INSULATE } \\
\text { EFFLUENT }\end{array}$ & ELEVATE/NEOPAD & 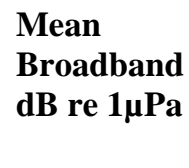 & $\begin{array}{l}\text { Mean } \\
\text { Sound } \\
\text { Pressure } \\
(\mu \mathrm{Pa})\end{array}$ \\
\hline Control & & & & & 120.6 & $1.1 \times 10^{6}$ \\
\hline 1 & $\checkmark$ & & & & 116.0 & $6.3 \times 10^{5}$ \\
\hline $1,2 \mathrm{a}$ & $\checkmark$ & $\checkmark$ & & & 112.3 & $4.1 \times 10^{5}$ \\
\hline $1,2 b, 3$ & $\checkmark$ & & $\checkmark$ & $\checkmark$ & 108.6 & $2.7 \times 10^{5}$ \\
\hline $1,2 \mathrm{a}, 2 \mathrm{~b}, 3$ & $\checkmark$ & $\checkmark$ & $\checkmark$ & $\checkmark$ & 108.6 & $2.7 \times 10^{5}$ \\
\hline
\end{tabular}




\section{Figures}

Inlet piping before retrofit

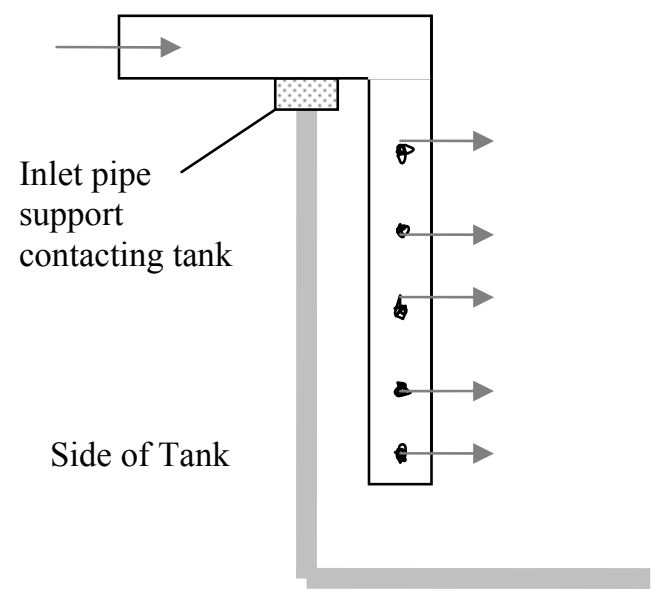

Inlet piping after retrofit

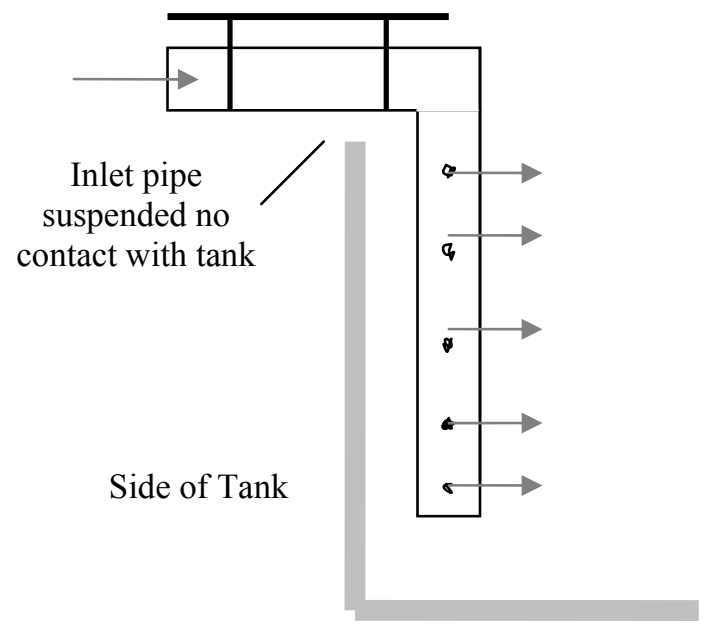

Figure 1. Modification 1, SUSPEND INLET. Inlet piping designs before and after the retrofits.

Culture Tank Outlet before Retrofit

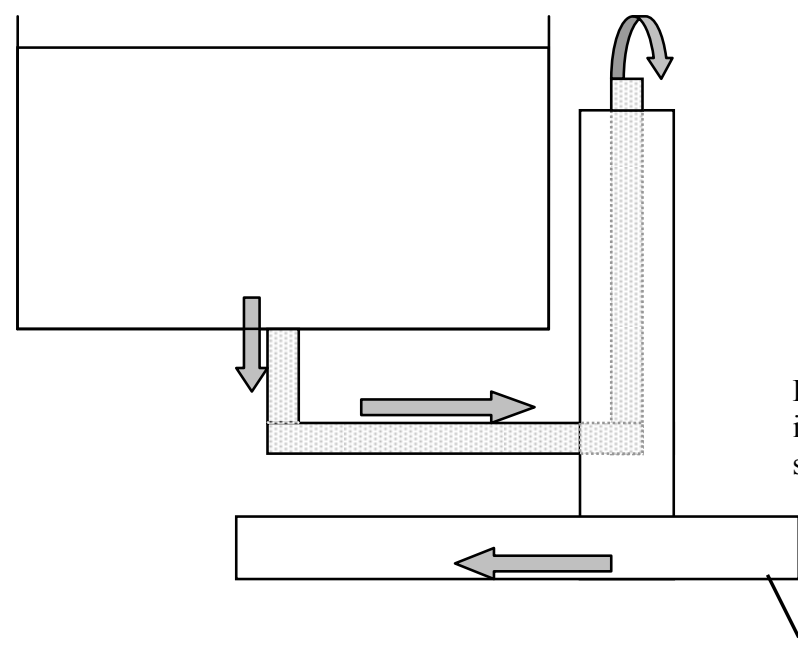

Culture Tank Outlet after Retrofit

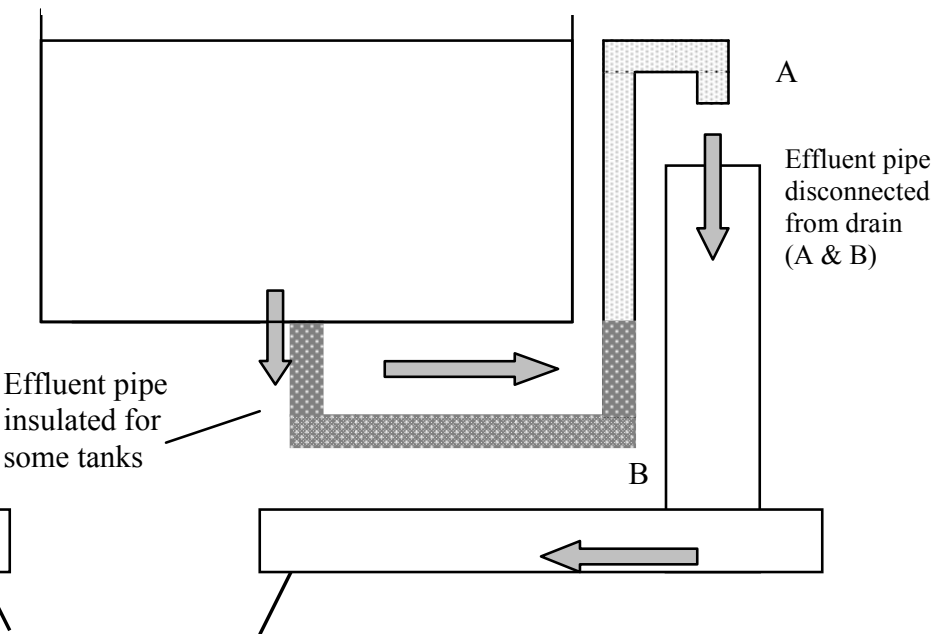

Common drain (carries water to filtration)

Figure 2. Modifications 2a and 2b. DISCONNECT EFFLUENT and INSULATE EFFLUENT. Effluent piping designs before and after the retrofit. 

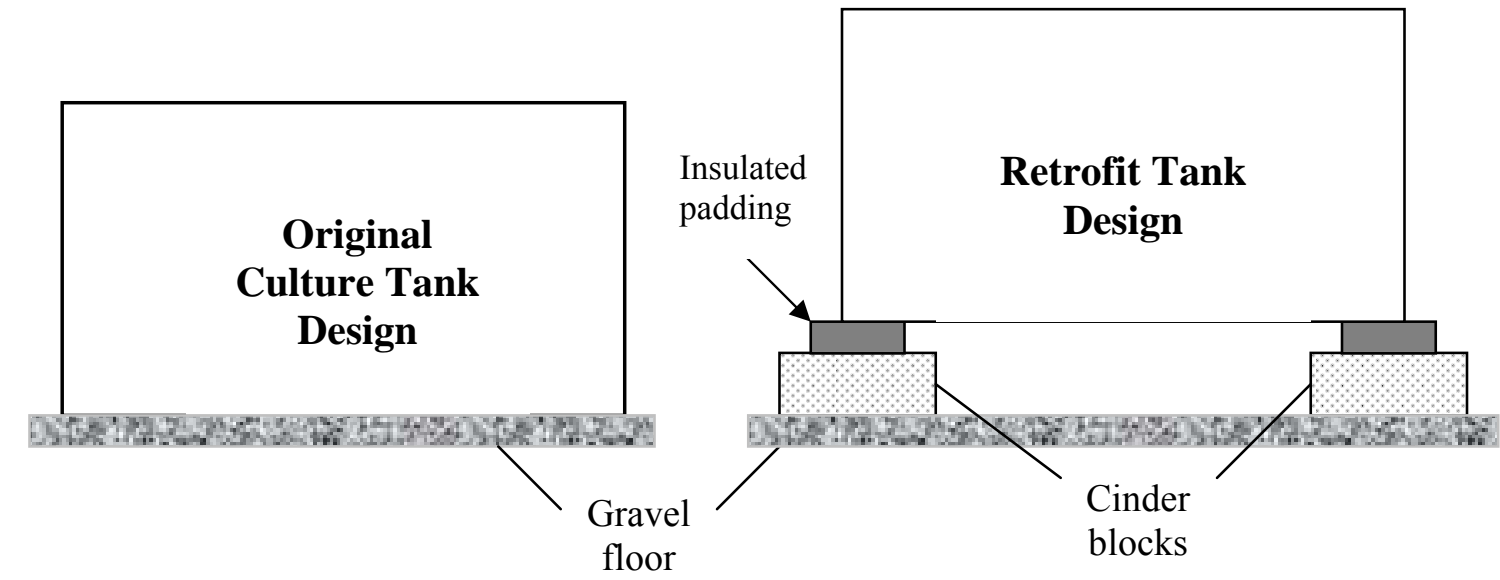

Figure 3. Modification 3. ELEVATE/NEOPAD. Culture tank support designs before and after the retrofit.

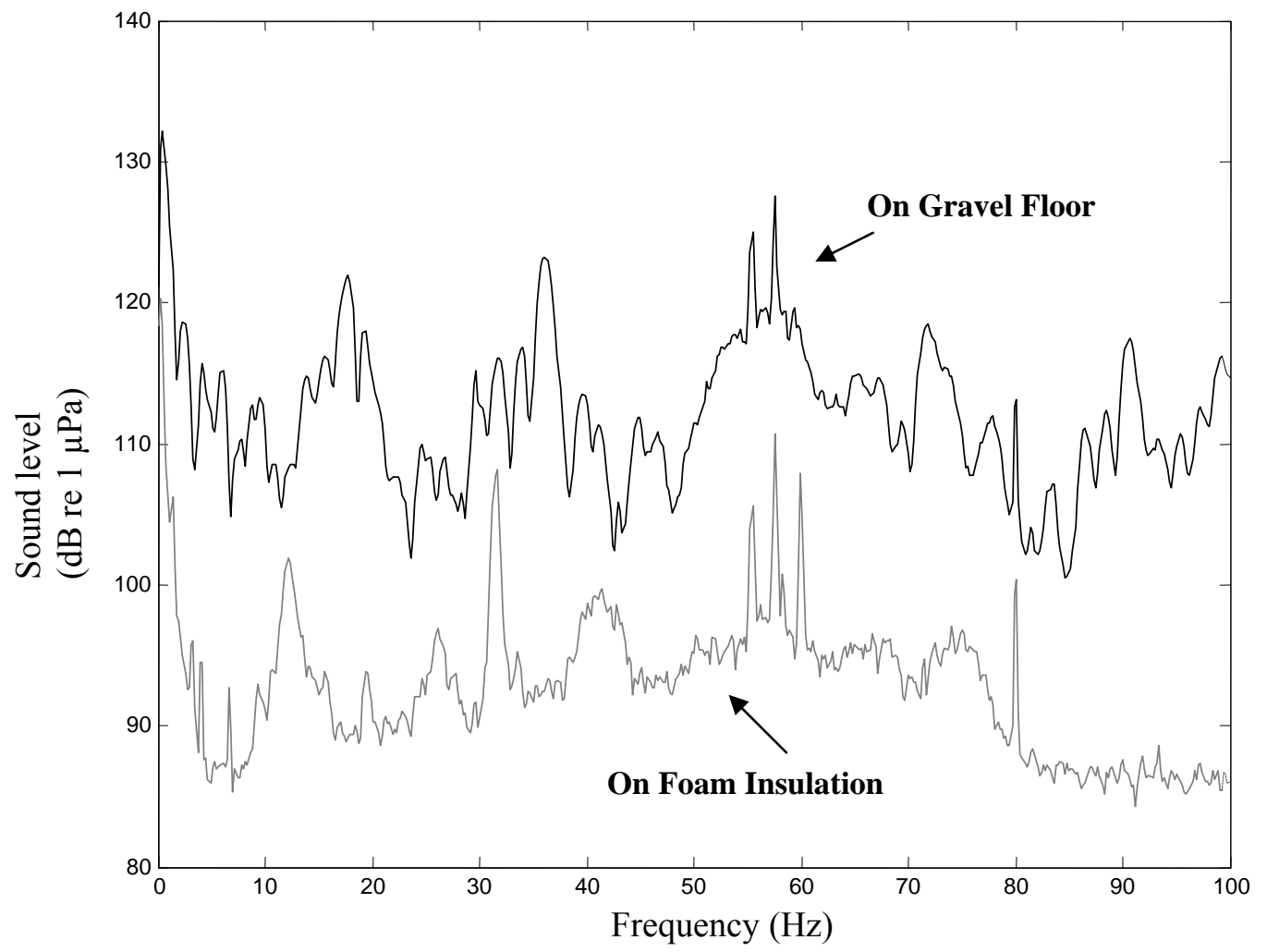

Figure 4. Sound spectrum comparison of a water filled bucket seated directly on a gravel floor vs. a water filled bucket with foam insulation between the bucket and the gravel floor. 


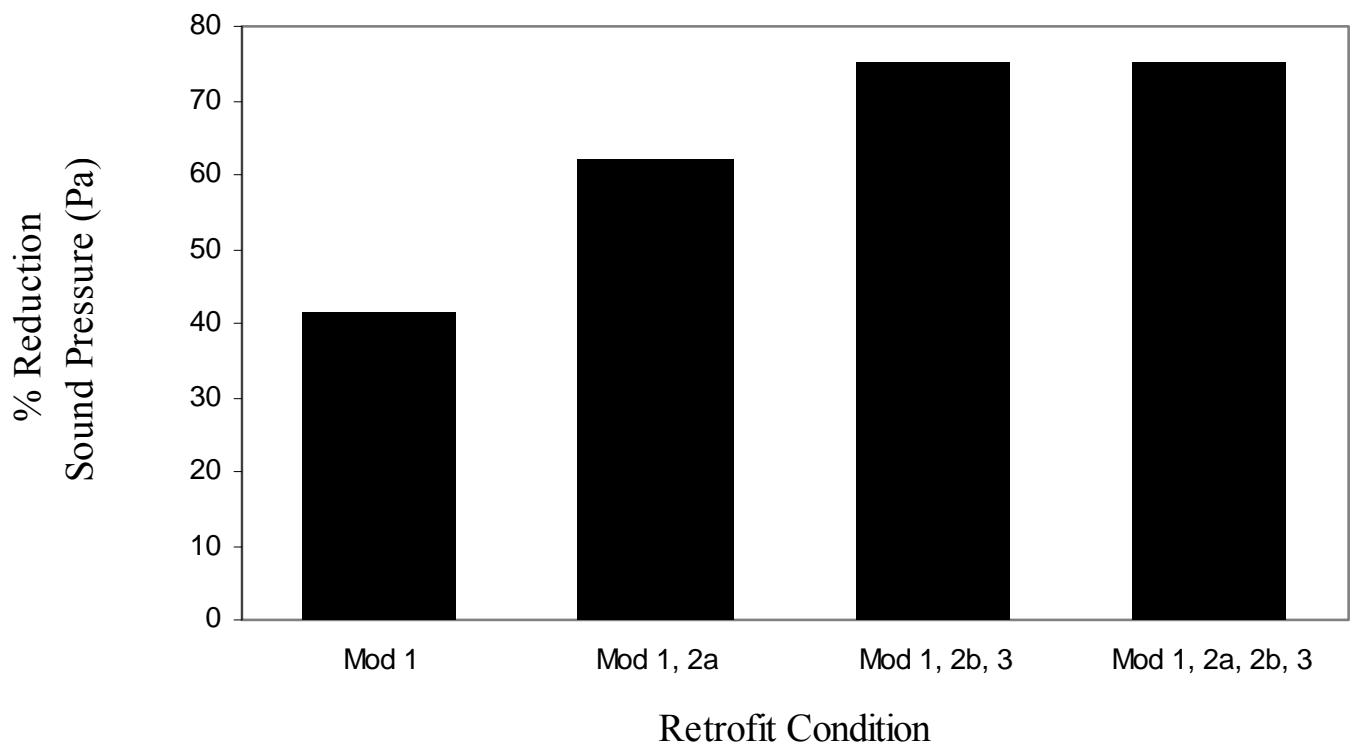

Figure 5. Percent sound pressure reduction for all retrofit modifications compared to sound pressure for the control tanks.

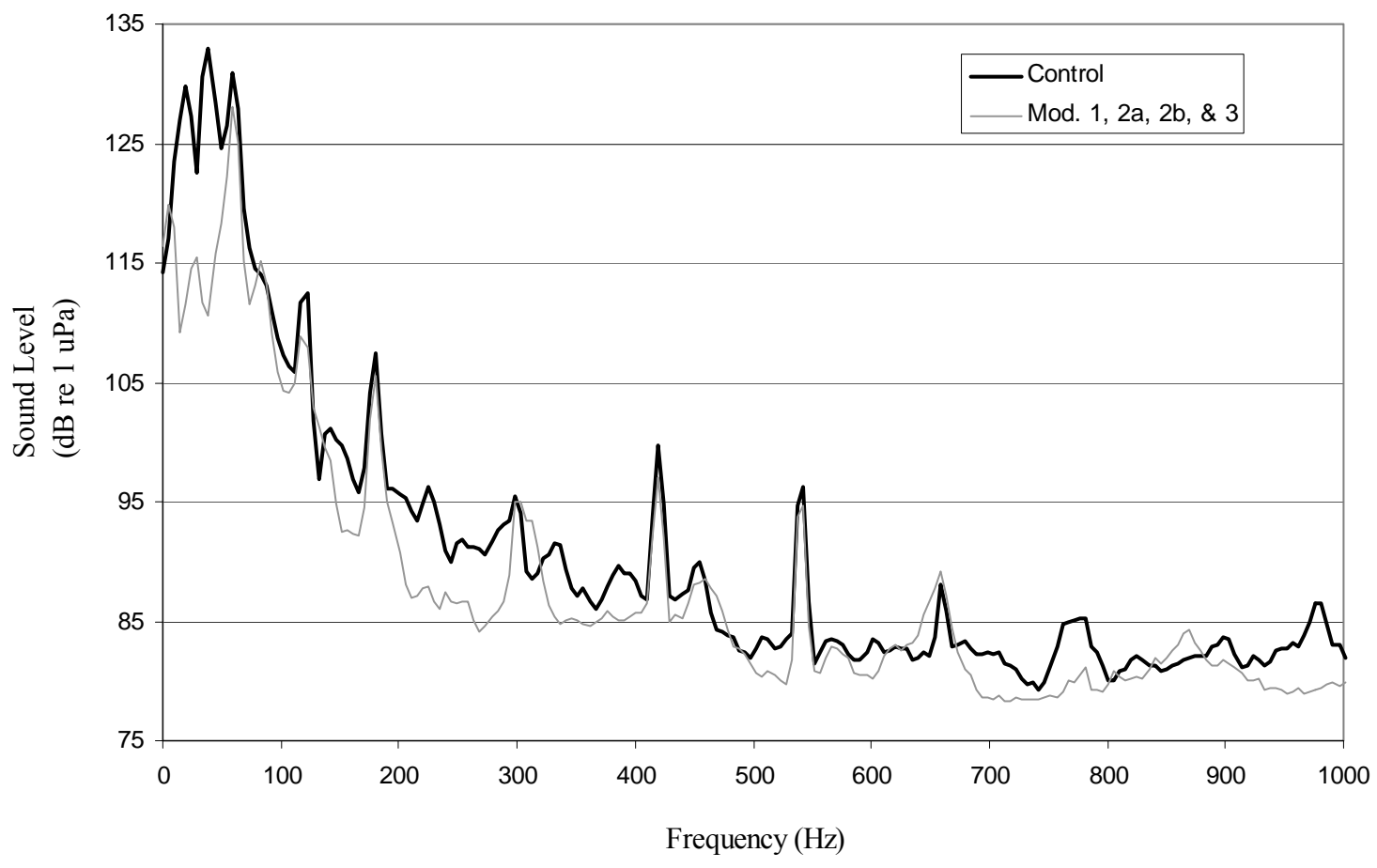

Figure 6. Sound spectrum comparison for control tanks and the retrofit design with Modifications 1, 2a, 2b, and 3 (SUSPEND INLET, DISCONNECT EFFLUENT, INSULATE EFFLUENT, and ELEVATE/NEOPAD). 


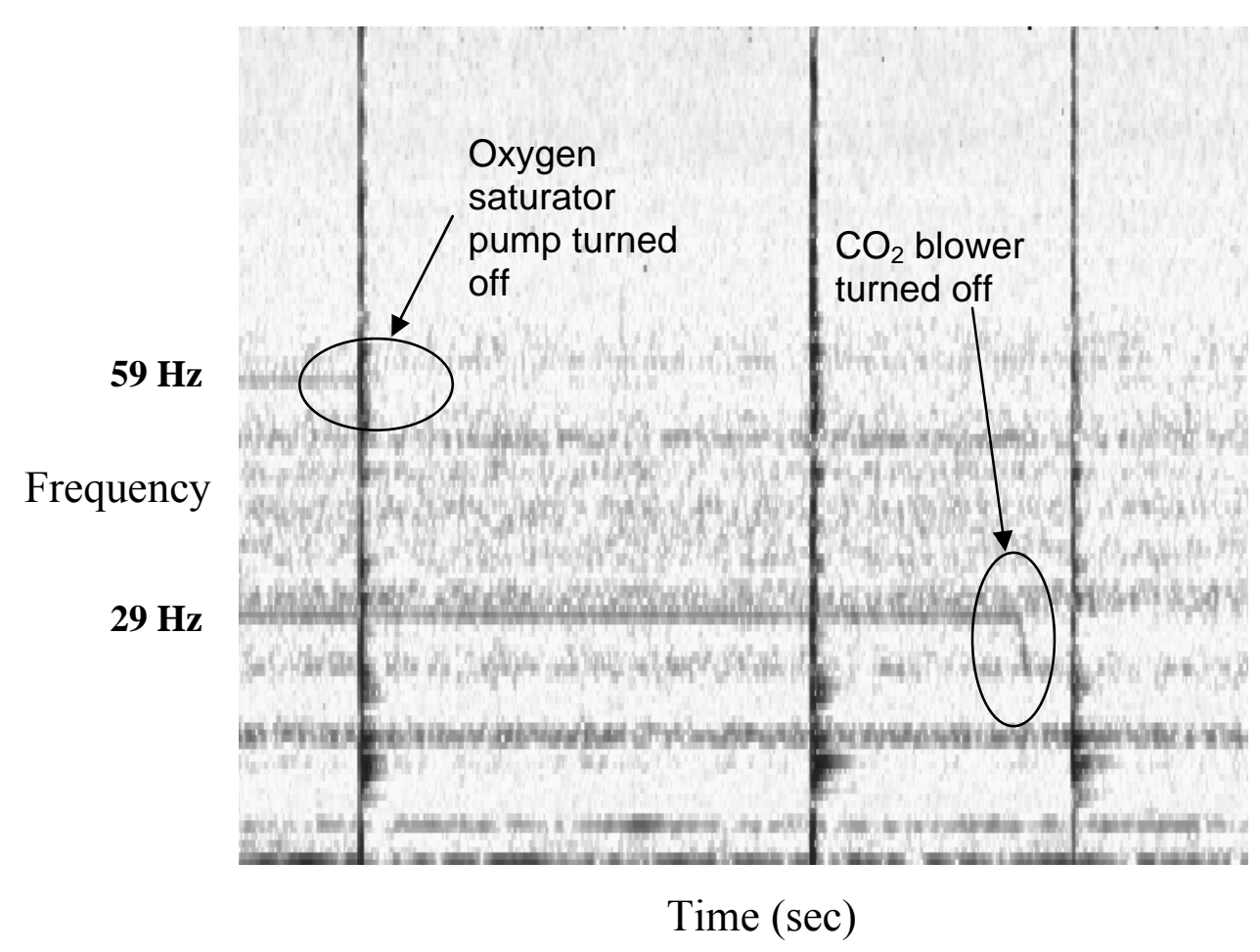

Figure 7. Sound spectrogram indicating transmission of oxygen saturator pump and carbon dioxide blower frequencies into a culture tank. Note: The dark horizontal bars indicate intense tonal frequencies. The dark vertical bars are transient sounds that were intentionally created to denote events in time during the test. 


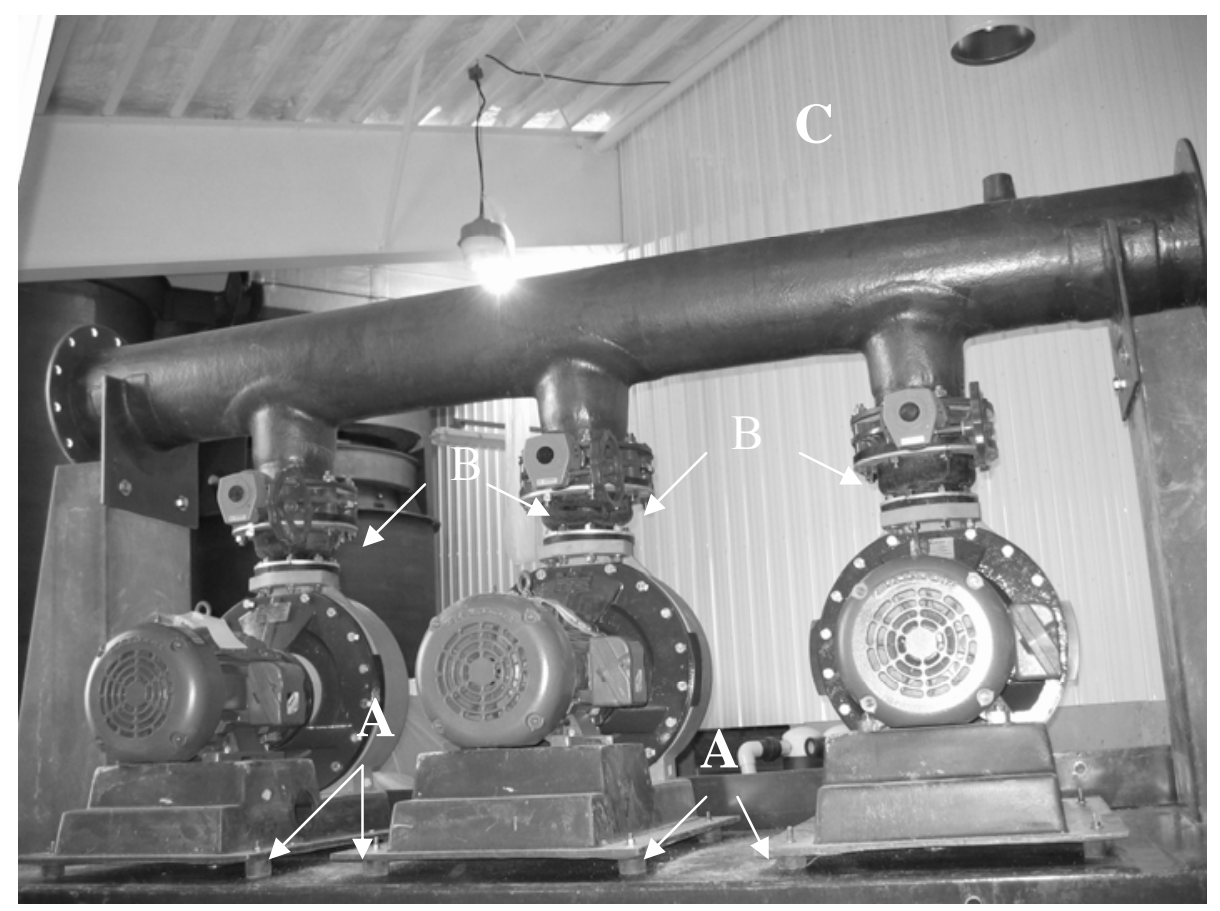

Figure 8. A custom pump stand fabricated by Marine Biotech Inc. (Beverly, MA) installed at the USDA ARS, NCWMAC (Franklin, ME). (A) resilient pump mounts to reduce transmission of motor vibration noise, $(B)$ rubber vibration isolation couplings on both the pump inlet \& outlet piping, and $(\mathrm{C})$ locating the water treatment pumps and equipment in a room separate from the fish culture tanks. 


\section{Chapter 2: The effects of aquaculture production noise on hearing, growth and disease resistance of rainbow trout Oncorhynchus mykiss}

\section{Abstract}

Intensive aquaculture production often utilizes equipment (e.g., aerators, air and water pumps, harvesters, blowers, filtration systems, and maintenance machinery) that increases noise levels in fish culture tanks. Consequently, chronic exposure to elevated noise levels in tanks could negatively impact cultured species. Possible effects include impairment of the auditory system, increased stress, and reduced growth rates. The objective of this study was to evaluate the long term effects of sound exposure on the hearing sensitivity, growth, and survival of cultured rainbow trout (Oncorhynchus mykiss). Two cohorts of rainbow trout were cultured for eight months in replicated tanks consisting of three sound treatments: 115,130 , and $150 \mathrm{~dB}$ re $1 \mu \mathrm{Pa}$ RMS levels. Auditory evoked potential recordings revealed no significant differences in hearing thresholds resulting from exposure to increased ambient sound levels. Although there was no noise-induced hearing loss evident, there were significant differences in hearing thresholds between cohorts. No statistical effect of sound treatment was found for growth rate and mortality for fish within each cohort. There was no significant difference in mortality between sound treatments when fish were exposed to Yersinia ruckeri, but there was significantly different mortality between cohorts. This study indicated that rainbow trout hearing sensitivity, growth, survival, stress, and disease susceptibility were not negatively impacted by noise levels common to recirculating aquaculture systems. These findings should not be generalized to all cultured fish species, however, since many species, including catfish and cyprinids, have much better hearing 
sensitivity than rainbow trout and could be affected differently by noise.

\section{Introduction}

Interest in the effects of environmental noise on fish has grown considerably over the past several years (e.g., Popper, 2003; Popper et al., 2004). While most of the research to date has focused on the impacts of high energy sound sources such as sonar, pile driving, and seismic air guns, there is also interest in potential effects of exposure to chronic lower level sounds.

Potential effects on fish are likely to depend upon the characteristics of the sound including level, duration, and spectrum as well as on the hearing abilities of the fish species concerned. Apparent effects could range from non-detectable, subtle behavioral changes to more dramatic physiological effects including deafness or death.

Exposure to different types of noise (pure tones or broad-band white noise) at sound pressure levels (SPLs) ranging from 142 to $170 \mathrm{~dB}$ re $1 \mu \mathrm{Pa}$ has been shown to induce temporary hearing loss in fishes (Popper and Clarke, 1976; Scholik and Yan, 2001; Amoser and Ladich, 2003; Smith et al., 2004a) and in some cases, damage to portions of the sensory epithelia of the inner ear has been reported after exposing fish to either pure tone stimuli with maximum SPLs of $180 \mathrm{~dB}$ re $1 \mu \mathrm{Pa}$ (Enger, 1981; Hastings et al., 1996), air-gun signals (main energy content from 20 to $1000 \mathrm{~Hz}$ ) with maximum peak-to-peak received levels of $180 \mathrm{~dB}$ (McCauley et al., 2003), or broadband white noise of $170 \mathrm{~dB}$ re $1 \mu \mathrm{Pa}$ SPL (Smith et al., 2006). In addition, endocrinological stress responses to noise have been reported in Atlantic salmon (Salmo salar) exposed to underwater explosions of about $2 \mathrm{MPa}$ in pressure amplitude (Sverdrup et al., 1994), European sea bass (Dicentrarchus labrax) exposed to air-gun blasts (Santulli et al., 1999), and 
goldfish (Carassius auratus) within the first 10 minutes of exposure to broadband white noise of $170 \mathrm{~dB}$ re $1 \mu \mathrm{Pa}$ (Smith et al., 2004a). Endocrinological stress response has also been reported for common carp (Cyprinus carpio), gudgeon (Gobio gobio) and European perch (Perca fluviatilis) exposed to boat noise of $153 \mathrm{~dB}$ re $1 \mu \mathrm{Pa}$ equivalent continuous SPL over 30 minutes (Wysocki et al., 2006). Increased stress levels, especially when chronic, could potentially have detrimental effects on growth, sexual maturation and reproduction, immunological function or disease susceptibility, and survival in fish (Pickering, 1992; McCormick, 1999; Weyts et al., 1999; Pankhurst and Van der Kraak, 2000; Consten et al. 2001a, b, 2002; Huntingford et al., 2006).

Not only are fish in many natural habitats confronted with increasing levels of anthropogenic noise, cultured fish may also be exposed to noise, especially in large, commercial scale aquaculture facilities. Intensive aquaculture production often utilizes equipment such as aerators, air and water pumps, harvesters, blowers, and filtration systems that produce increased ambient noise in culture tanks, especially at low frequencies. Bart et al. (2001) found that mean broad-band sound pressure levels differed across various intensive aquaculture systems. These levels varied from $\leq 100 \mathrm{~dB}$ re $1 \mu \mathrm{Pa}$ in an earthen pond with the aerator turned off, $120 \mathrm{~dB}$ in concrete raceways, and $130 \mathrm{~dB}$ in round fiberglass tanks of various sizes. In the same study, a maximum sound level of $135 \mathrm{~dB}$ re $1 \mu \mathrm{Pa}$ was measured in an earthen pond near an operating aerator, while large fiberglass tanks (14 $\mathrm{m}$ diameter) within a recirculating system had the highest SPLs of $153 \mathrm{~dB}$ re $1 \mu \mathrm{Pa}$.

Consequently, fish culture facilities are chronically exposed to noise levels that are well within the hearing range of many aquaculture species. However, only a few studies have investigated the effects of sound levels relative to aquaculture settings. Lagardère (1982) and 
Regnault and Lagardère (1983) reported that chronic elevation of in-tank noise levels (about 30 $\mathrm{dB}$ higher than levels encountered in their natural habitat) resulted in significant reductions in growth and reproduction rates, increased mortality, and higher metabolic rates, expressed as ammonia excretion rate and oxygen consumption in brown shrimp, Crangon crangon. Additionally, Banner and Hyatt (1973) observed lower egg viability and reduced growth rates of two cyprinodontiform fishes in small glass aquaria when sound pressure levels were approximately $20 \mathrm{~dB}$ higher than levels in the control tanks. While these studies are of interest, there has currently been no investigation that has examined the effects of long term chronic noise exposure throughout the life cycle of fish in aquaculture facilities.

The purpose of the present study was to investigate whether rainbow trout (Oncorhynchus mykiss), raised in tanks with different levels of noise differ in their development. The study considered effects of increased background noise on trout hearing, growth, mortality, stress indicator constituents in the blood (glucose, sodium, chloride), and immuno-competence (mortality following a Yersinia ruckeri pathogen challenge).

\section{Material and methods}

\subsection{Sound treatment tanks}

Prior to the study, sound recordings were taken in a commercial scale (9.1 m diameter, $2.4 \mathrm{~m}$ deep) round fiberglass aquaculture tank within a recirculating system at the Freshwater Institute. Recordings were made using a hydrophone (HTI-94-SSQ, frequency response: $2 \mathrm{~Hz}-$ 
$30 \mathrm{kHz}$, sensitivity: $-170 \mathrm{~dB}$ re $1 \mathrm{~V} / \mu \mathrm{Pa}$, High Tech Inc. Gulfport, MS) connected to a low-pass filter set to $2000 \mathrm{~Hz}$ (Model 91149A, Precision Filters, Inc., Ithaca, NY), a pre-amplifier (Model FP-11, Shure Inc., Niles, IL), and an analog-to-digital converter and data logger (Model USB9215, National Instruments, Austin, TX) connected to a laptop computer. Characterization of sound spectra and corresponding sound pressure levels was performed with NI-DAQmx Base Software using a Labview 7.1 application (National Instruments, Austin, TX). The sound pressure levels in the tank averaged $130 \mathrm{~dB}$ re $1 \mu \mathrm{Pa}$ broadband RMS. A five minute audio recording was created by adding tonal signals to the recording of the ambient noise of a quiet experimental tank to simulate the existing in-water sound characteristics recorded in the commercial scale tank (Fig. 1). The recording was burned to a CD and replicated 14 times without interruption in order to play back sounds of controlled spectra and sound pressure levels in the experimental tanks. The CD was played continuously, 24 hours per day. The sound was transmitted to the tanks via amplifiers (MPA-250, Radio Shack) and tactile speakers (Model AW339, Clark Synthesis Tactile Sound, Littleton, CO) mounted on the outside walls of the tanks $38 \mathrm{~cm}$ from the top and bottom of the water column (Fig. 2).

Six round fiberglass tanks ( $1.5 \mathrm{~m}$ diameter, $0.8 \mathrm{~m}$ deep) were used in the study. Tanks were designed to buffer ambient sound by eliminating contact between vibrating pipes and tank surfaces and by using insulated padding beneath tanks and around PVC pipes (Davidson et al., 2007, i.e. Chapter 1). These modifications were applied to all tanks used in the present study to limit excess background noise, to standardize tanks, and to create relatively quiet control tanks (115 dB re $1 \mu \mathrm{Pa}$ ). Two control tanks, receiving ambient noise only, had a sound level of $115 \mathrm{~dB}$ re $1 \mu \mathrm{Pa}$ broadband RMS. Two experimental tanks had sound levels of $130 \mathrm{~dB}$ re $1 \mu \mathrm{Pa}$ broadband RMS and two had sound levels of $150 \mathrm{~dB}$ re $1 \mu \mathrm{Pa}$ RMS. These treatment categories 
represented levels that were lower than, similar to, and higher than mean sound levels recorded within commercial scale recirculating systems.

RMS sound levels for each tank were measured using a grid system that consisted of 15 locations: five horizontal $(5,38,76,38$, and $5 \mathrm{~cm}$ from the sides of the tank) and locations at 3 different depths $(5,38$, and $71 \mathrm{~cm}$ deep).

Sound pressure level measurements were taken weekly at all locations to ensure that sound levels were consistent throughout the study. Average RMS values were calculated based on the 15 locations recorded in each tank. Sound pressure levels generally varied depending on location within the tanks, with the loudest areas closest to the side walls and the bottom of the tank, and quietest locations near the top and center of the tanks (Fig. 3). In addition, a weekly 15 sec sound recording was taken $38 \mathrm{~cm}$ from the side of the tanks at a depth of $38 \mathrm{~cm}$ to ensure that the spectral composition of the noise remained consistent over time.

\subsection{Animals}

Fertilized rainbow trout eggs (Oncorhynchus mykiss) were obtained from a commercial fish hatchery (Troutlodge, Sumner, WA). All gametes originated from three year old parents from the same gene pool. The zygotes were all female diploids and a cross between rainbow trout (the stationary freshwater form of O. mykiss) and steelhead trout (the anadromous form of O. mykiss). The fertilized eggs were shipped overnight and received at the Freshwater Institute at $3^{\circ} \mathrm{C}$. They were acclimated to hatching system temperatures $\left(13^{\circ} \mathrm{C}\right)$ over a $2 \mathrm{~h}$ time period and then divided into trays within the hatching system. Day 1 of the life cycle (as reference for all following age specifications) was designated six days after arrival when $50 \%$ of the eggs had 
hatched. On day 15 , fish were stocked into a single round tank ( $1.5 \mathrm{~m}$ diameter, $0.8 \mathrm{~m}$ depth). The mean ambient noise level in this tank was $115 \mathrm{~dB}$ re $1 \mu \mathrm{Pa}$ broadband RMS. Water depth was gradually increased as fish grew, to a maximum of $0.8 \mathrm{~m}$ depth. On day 84 , fish were divided into two tanks with the same dimensions and sound pressure levels to reduce fish density. The study officially began on day 92 when fish were randomly divided into three sound treatment tanks $(115,130$, and $150 \mathrm{~dB}$ re $1 \mu \mathrm{Pa}$ RMS $)$ at a density of 700 fish per tank or 10 $\mathrm{kg} / \mathrm{m}^{3}$. The mean weight at stocking for all tanks was $14 \pm 0.1 \mathrm{~g}$.

The second cohort of trout (Troutlodge, Sumner, WA) was also stocked into respective sound treatment tanks $(115,130$, and $150 \mathrm{~dB}$ re $1 \mu \mathrm{Pa}$ RMS $)$ on day 92 of the life cycle and underwent exactly the same procedures and treatments at comparable ages as the abovedescribed cohort 1 animals with the only difference that the fertilized eggs were received and hatched three weeks later.

Throughout the study, all fish were cultured under a constant $24 \mathrm{~h}$ photoperiod at 12.5 $13.5^{\circ} \mathrm{C}$ in a flow through system. They were fed slow-sinking trout feed (Zeigler Brothers Inc., Gardners, PA) with a protein to fat ratio of $42 / 16$ via automated feeders (Sterner Products AB, Sweden) that were programmed to deliver the same amount of feed to each tank and were calibrated weekly.

\subsection{Auditory threshold determination}

Auditory thresholds were determined by recording auditory evoked potentials (AEPs), often called auditory brainstem response, at three different ages: 1) age 17 and 16 weeks for cohort 1 and 2 , respectively ( $\mathrm{n}=10$ per sound treatment, $\mathrm{n}=20$ per cohort), 2) age 33 and 32 
weeks for cohort 1 and 2 , respectively ( $\mathrm{n}=10$ per sound treatment, $n=20$ per cohort), and 3 ) age 41 and 38 weeks for cohort 1 and 2 , respectively ( $n=6$ per sound treatment, $n=12$ per cohort). The main purpose of the third experimental series was to test whether auditory threshold differences between cohorts detected during the previous test series reflected differences in hearing between cohorts or just variations in experimental set up between test dates. Therefore, the third series of auditory threshold determination was conducted for fish from both cohorts on the same date rather than again at comparable ages, but two weeks apart. During the third series of hearing sensitivity tests, fish from both cohorts were measured on the same days to test for differences in hearing sensitivity between cohorts.

During the hearing tests fish were mildly immobilized with an intra-muscular injection of Flaxedil (gallamine triethiodide, Sigma) at doses of $5.8 \pm 0.5 \mu \mathrm{g} \mathrm{g}^{-1}$ body mass for the $15-16$ week old fish and $8.3 \pm 0.2 \mu \mathrm{g} \mathrm{g}^{-1}$ body mass for the $32-41$ week old fish. This dosage allowed the fish to retain slight opercular movement during the experiments, without creating significant myogenic noise to interfere with the recordings.

Test subjects were secured in the center of a rectangular plastic tub $(51 \mathrm{x} 41 \mathrm{~cm}$; water depth: $25 \mathrm{~cm}$ ) that had a $4 \mathrm{~cm}$ thick layer of fine gravel on the bottom. Fish were restrained in a mesh sling and suspended so that the top of the head was $6 \mathrm{~cm}$ below the water surface. A pipette was inserted into the mouth and provided water from a simple temperature-controlled (13 \pm 1 ${ }^{\circ} \mathrm{C}$ ), gravity-fed water circulation system.

The AEPs were recorded using stainless steel electrodes (Rochester Electro-Medical, Inc., Tampa, FL). The recording electrode was placed in the midline of the skull over the medulla region and the reference electrode was placed cranially between the nares. Both electrodes were inserted approximately $2 \mathrm{~mm}$ subdermally. All exposed surfaces of the electrode 
tips that were not in direct contact with the fish were insulated with fingernail polish. A ground electrode was placed in the water.

Sound stimuli presentation and AEP waveform recordings were performed with a modular rack-mount system (TDT System 3, Tucker-Davis Technologies, Gainesville, FL) and TDT BioSig RP Software. Sounds were created using TDT SigGen RP software and fed through a power amplifier (Alesis RA 150, Cumberland, RI) connected to an underwater speaker (UW30, University Sound, Burnsville, MN) placed in the center of the plastic tub. Sound stimuli were presented as repeated tone bursts at a rate of 20 per second. Hearing thresholds were determined at frequencies of $150,250,300$, and $500 \mathrm{~Hz}$, presented in random order. The duration of sound stimuli was 15 milliseconds for 150 and $250 \mathrm{~Hz}$ and $10 \mathrm{~ms}$ for the other frequencies. Rise and fall times were $2 \mathrm{~ms}$. All tone bursts were gated using a Blackman window. Absolute sound pressure levels were measured using a hydrophone $(10 \mathrm{CT}$, frequency response: $30 \mathrm{~Hz}-100$ $\mathrm{kHz}, \pm 3 \mathrm{~dB}$; receiving sensitivity: $-211 \mathrm{~dB} \pm 3 \mathrm{~dB}$ re $1 \mathrm{~V} / \mu \mathrm{Pa}$, G.R.A.S., Holte, Denmark) and a Kistler dual-mode amplifier (5010, Amherst, NY) at the position where the fish was placed in the test tub. For each test condition, stimuli were presented at opposite polarities (180- phase shifted), and the corresponding AEP traces averaged by the Bio-Sig RP software in order to eliminate stimulus artifacts. Up to 500 responses were averaged for each stimulus level and polarity. Sound pressure levels of tone-burst stimuli were reduced in $5 \mathrm{~dB}$ steps until the AEP waveform was no longer apparent. The lowest sound pressure level for which a repeatable AEP trace could be obtained, as determined by overlaying replicate traces, was considered the threshold (Kenyon et al. 1998; Smith et al., 2004a). After determination of hearing thresholds, each fish was euthanized with $200 \mathrm{mg} / 1$ tricaine methanesulfonate (MS-222), inner ears were removed and otolith type was recorded for each individual. Two types of otoliths have been 
observed in salmonids: aragonite and vaterite (Campana, 1999). Aragonite otoliths, which consist of calcium carbonate crystals embedded within a protein matrix, are the normal or wildtype otolith (Campana, 1999; Sweeting et al., 2004) found in teleosts and have an opaque white appearance. Vaterite otoliths are a deviation from the aragonite-type and consist of a crystalline form of calcium carbonate that has a translucent appearance, often with a white, opaque center (Campana, 1999). Oxman et al. (2007) found that Chinook salmon that had at least one vateritetype saccular otolith had significantly lower hearing $(2.5-6.5 \mathrm{~dB})$ compared to salmon with aragonite-type otoliths. Therefore, in the present study otoliths were examined to evaluate potential correlations between otolith structure and hearing threshold.

For technical reasons, hearing thresholds are given in terms of sound pressure, $\mathrm{dB}$ re 1 $\mu \mathrm{Pa}$ (RMS). Since rainbow trout do not possess accessory hearing structures that enhance detection of the pressure component of sound, they are most likely primarily sensitive to particle motion. As a consequence, the thresholds presented here should not be interpreted as absolute values. However, since our main interest was to investigate if there are relative differences in detection of the same stimulus between animals raised under different conditions at different ages, use of a measure of pressure is a valid approach for purely comparative purposes.

\subsection{Growth rates and blood parameter assessment}

Weights and fork lengths of trout from each sound treatment and cohort were measured every two weeks and dead fish were collected and recorded daily. Blood samples were collected from 35 fish from each sound treatment from cohort 1 and 2 on days 309 (week 44) and 315 (week 45), respectively. Preliminary samples indicated that, for each parameter, 35 samples 
would be sufficient so that the $95 \%$ confidence interval for the difference between two means would have a precision equal to one-half of the standard deviation for each mean (Motulsky, 1995). All blood samples for fish within respective cohorts were collected on the same day. Fish were netted individually, sedated by immersion in $75 \mathrm{mg} / \mathrm{l} \mathrm{MS}-222$, and $1 \mathrm{ml}$ of blood was drawn from the caudal vein within $45 \mathrm{~s}$ after introduction to the anesthetic. Samples were centrifuged at $2,400 \mathrm{~g}$ for five minutes at $14^{\circ} \mathrm{C}$. Plasma was stored at $-15^{\circ} \mathrm{C}$ for less than 30 days. Chloride, sodium, and glucose concentrations were analyzed using the Hitachi 917 Chemistry Instrument (Roche Diagnostics, Indianapolis, IN; Animal Health Diagnostic Laboratory, College of Veterinary Medicine, Cornell University, Ithaca, NY).

\subsection{Yersinia ruckeri challenge}

On days 195 (cohort 1) and 197 (cohort 2), 15 fish from each sound treatment (a total 45 fish per cohort) were exposed to a pathogen challenge to determine if sound level affected resistance to enteric redmouth disease in rainbow trout. Fifteen fish from each sound treatment tank were fin clipped for identification and transported to the USDA Agricultural Research Service, National Center for Cool and Coldwater Aquaculture (Leetown, WV). Fish were stocked into a single rectangular fiberglass culture tank $(61 \mathrm{~cm}$ diameter, $38 \mathrm{~cm}$ deep) with a mean sound level of $113 \mathrm{~dB}$ re $1 \mu \mathrm{Pa}$ RMS. Fish were then immersion challenged with $Y$. ruckeri at a concentration of $10^{9} \mathrm{CFU} / \mathrm{ml}$ of tank water. After a one hour immersion, the tanks were returned to normal flow-through conditions. Dead fish were removed daily and fin clips were identified to determine the respective sound treatment categories. 


\subsection{Statistical analyses}

All data sets were tested for normal distribution using the Kolmogorov-Smirnov test. Hearing thresholds between trout raised in $115 \mathrm{~dB}$ tanks and the $150 \mathrm{~dB}$ tanks were compared at each age and frequency using unpaired t-tests. It should be noted that additional measurements were not performed on trout from the $130 \mathrm{~dB}$ tanks. Similarly, hearing thresholds of cohort 1 and 2 trout of the oldest age group measured on the same days were compared at each frequency using unpaired t-tests. Audiograms of trout from both cohorts at the three different ages were compared by a two-way analysis of variance (ANOVA) using a general linear model where one factor was age and the other was frequency. The age factor alone is an indicator for overall differences in the audiograms of the animals at different ages, and in combination with the frequency factor, it indicates whether such differences are the same throughout the whole audiogram or whether the thresholds at the various frequencies changed differently. To determine at which frequency thresholds differ, separate one-way ANOVAs followed by Scheffé's multiple comparison procedure were calculated. The levels of statistical significance were adjusted to the number of frequencies tested $(* \mathrm{P} \leq 0.0125, * * \mathrm{P} \leq 0.0025, * * * \mathrm{P} \leq$ 0.00025). Blood parameters between the different experimental groups within each cohort were compared using Kruskal-Wallis tests followed by Mann-Whitney-U tests since the data were not normally distributed and variances were unequal. All above-mentioned statistical tests were performed using SPSS 12.0 (SPSS Inc., Chicago, IL).

Growth rates were compared using a combination of One-way ANOVA and polynomial regression using SAS version 9.1 (SAS Institute Inc., Cary, NC). Pathogen challenge mortality 
was analyzed using a chi-squared goodness of fit test with a log rank test for equality of survivor functions using Intercooled Stata, version 8.2. (StataCorp, College Station, Texas).

\section{Results}

\subsection{Hearing sensitivity and otolith distribution}

Hearing thresholds of trout within cohort 1 between control $(115 \mathrm{~dB})$ and $150 \mathrm{~dB}$ tanks did not differ at any frequency over the duration of the experiment, and the same was found for cohort 2 trout (unpaired t-tests; $\mathrm{P}>0.05$ for all frequencies; Fig. 4 A-C). Thus, there appeared to be no effect on hearing when comparing fish exposed to increased sound levels to control animals, even as the duration of exposure increased.

Hearing was also examined within cohorts to determine if there are developmental changes in sensitivity with age. The thresholds of fish in cohort 1 animals did not change from 16-41 weeks of age (two-way ANOVA: $\mathrm{F}_{2,222}=0.76, \mathrm{P}=0.47$ ). In contrast, hearing thresholds of cohort 2 trout were significantly different at the various ages tested $\left(\mathrm{F}_{2,208}=23.6, \mathrm{P} \leq 0.001\right)$ and there was a significant interaction between age $\mathrm{x}$ frequency, indicating that the amount of threshold change differed between frequencies $\left(\mathrm{F}_{6,208}=2.57, \mathrm{P} \leq 0.001\right)$. Further analysis indicated that hearing thresholds at 250 and $300 \mathrm{~Hz}$ were higher in the 33 and 38 week old fish than in the 17 week old group

To confirm the differences in hearing sensitivity between cohort 1 and cohort 2 and to rule out that differences found were due to variations in set up at different dates, hearing thresholds from both cohorts were tested on the same experimental day in a third test series 
regardless of the age difference of three weeks between both cohorts. The sensitivity of the two groups differed significantly at 250 and $300 \mathrm{~Hz}$ (unpaired t-tests: $\mathrm{P}=0.004$ and $\mathrm{P}=0.002$, respectively; Fig. 5). Cohort 2 trout had higher hearing thresholds at 250 and $300 \mathrm{~Hz}$.

Inspection of the saccular otoliths from the tested animals showed that they had two types of otoliths, vaterite and aragonite. However, the type was not always the same for both otoliths for an individual fish. Most fish (69\% of those sampled) had vaterite type otoliths in both sacculi (Fig. 6), 26\% had one aragonite and one vaterite type otolith, and only 5\% had aragonite type otoliths in both sacculi. The percentage of vaterite-vaterite sacculi was compared between sound treatments and cohorts. There were relatively small differences in the occurrence of vateritevaterite sacculi between fish cultured at $115 \mathrm{~dB}$ and $150 \mathrm{~dB}$ within each cohort and age group (1$17 \%$ difference). A larger difference in vaterite-vaterite otolith distribution was found between cohorts of the same age group, (16-50\%) (Table 1). When comparing otolith distribution amongst cohorts for 16-17 weeks old and 32-33 week old fish, cohort 1 animals had a higher mean percentage vaterite-vaterite distribution (87.5\%) than cohort 2 animals (50\%). However, this trend was reversed for the 38-41 week old fish (58.5\% for cohort $1,91.5 \%$ for cohort 2$)$.

\subsection{Growth rates and mortality}

Differences in growth rates between sound treatments and cohorts were analyzed using a combination of ANOVA and polynomial regression, which tested for effects of treatment, cohorts, day, and treatment $\mathrm{x}$ day interactions. The treatment $\mathrm{x}$ day interaction tested whether trends across days were the same for each treatment. Results indicated that there was not a significant difference between sound treatments (Fig. 7; $\mathrm{F}_{2,81}=0.60, \mathrm{P}=0.6267$ ). Additionally, 
there was no significant difference in growth between cohorts $\left(\mathrm{F}_{1,81}=3.88, \mathrm{P}=0.1887\right)$. There was a significant difference between days, $\left(\mathrm{F}_{1,81}=4.98, \mathrm{P}=0.0284\right)$, but this is an expected difference since the fish are continuously growing. There was not a significant difference between treatment $\mathrm{x}$ day $\left(\mathrm{F}_{2,81}=0.73, \mathrm{P}=0.4872\right)$, indicating that there were not significant differences in the growth curves between treatments. ${ }^{1}$

One-way ANOVA tests showed that there were no significant differences in overall survival (Table 2) between treatments $\left(\mathrm{F}_{2,6}=3.93, \mathrm{p}=0.145\right)$, or between cohorts $\left(\mathrm{F}_{1,6}=1.52, \mathrm{p}\right.$ $=0.285)$.

\subsection{Blood chemistry and bacterial challenge}

Chloride concentrations did not differ significantly between sound treatments in either cohort (Fig. 8A; cohort 1: $\chi_{2,105}^{2}=3.07, p=0.215$; cohort $2: \chi_{2,105}^{2}=3.51, p=0.173$ ). Similarly the sodium concentrations did not differ between treatment groups for cohort 2 (Fig. $\left.8 \mathrm{~B} ; \chi^{2} 2,105=2.85, \mathrm{p}=0.24\right)$. However, sodium concentrations for cohort 1 were significantly different between treatment groups $\left(\chi^{2} 2,105=19.64, p<0.001\right)$. Subsequent Mann-Whitney-U tests revealed that sodium concentrations in fish from the $115 \mathrm{~dB}$ treatment were significantly higher than the other sound treatments $(\mathrm{p}<0.001$ for the 115 treatment versus $130 \mathrm{~dB}$ and 150 $\mathrm{dB}$ treatments). Glucose levels were significantly different between sound treatment groups in both cohorts (Fig. 8C; cohort 1: $\chi^{2} 2,105=8.49, p=0.014$; cohort $2: \chi^{2} 2,105=30.52, p<0.001$ ). Subsequent Mann-Whitney-U tests showed that fish from cohort 1, $115 \mathrm{~dB}$ treatments had

\footnotetext{
${ }^{1}$ Although no significant differences in growth were detected a plot of percentage difference in mean weight comparing growth of the 115 and $150 \mathrm{~dB}$ treatments over time indicated that rainbow trout growth could have been inhibited in the $150 \mathrm{~dB}$ tanks during the first two weeks of the study after sound was initiated (Appendix, Fig. 1). Sample size $(n=2)$ was likely too small to detect this potential difference.
} 
significantly higher glucose levels than the other sound treatment groups $(\mathrm{p}<0.001)$. In cohort 2 , glucose levels differed between all treatment groups $(\mathrm{p}<0.05$ for all three combinations) with animals from the $130 \mathrm{~dB}$ group having the highest values.

Mortalities resulting from the pathogen challenge did not differ significantly between sound treatment levels $\left(\chi_{2,45}^{2}=1.89, \mathrm{P}=0.3886\right)$, indicating that the sound levels that rainbow trout were subjected to during the study did not increase disease susceptibility. A significant difference in pathogen challenge mortality was detected between cohorts $\left(\chi_{2,90}^{2}=8.21, \mathrm{P}=\right.$ 0.0042). Cohort 1 had lower total mortality than cohort 2: 19 mortalities versus 32, respectively.

\section{Discussion}

\subsection{Auditory thresholds}

No difference in auditory thresholds was found between rainbow trout reared in $115 \mathrm{~dB}$ tanks and $150 \mathrm{~dB}$ tanks for either cohort throughout the entire 6 month observation period. Therefore, chronic exposure to noise levels and sound spectrums similar to those produced within recirculating aquaculture systems did not affect the rainbow trout auditory system. Rainbow trout do not possess specialized accessory hearing structures and generally have a limited hearing bandwidth and sensitivity (such species are often called hearing "generalists") as compared to species with hearing specialized auditory peripheral structures (hearing “specialists") such as carp and catfish (Popper and Fay, 1973; Hawkins, 1993; Ladich and Popper, 2004). 
Data from previous studies confirm that fish species with different overall hearing sensitivity are affected differently by exposure to noise of a given level. Effects range from substantial temporary hearing loss to no effect at all. Substantial noise-induced temporary hearing loss (ranging from 3 days to two weeks) of up to $30 \mathrm{~dB}$ has been described in several hearing specialist fish species possessing a direct connection between the swim bladder and the inner ear (Weberian apparatus), which increases hearing sensitivity and expands hearing bandwidth relative to species without such specializations (Scholik and Yan, 2001; Amoser and Ladich, 2003; Smith et al., 2004a). By contrast, "hearing generalists", species with lower hearing sensitivity as well as a smaller hearing bandwidth, showed no or minimal hearing loss when exposed to comparable noise (Scholik and Yan, 2002; Smith et al., 2004b). Therefore, although rainbow trout were not affected by the noise levels used in the current study, it is possible that other aquaculture species with more sensitive hearing such as catfish or carp could be impacted by noise within aquaculture facilities. Additionally, the natural habitats of rainbow trout have relatively high ambient noise levels (Lugli and Fine, 2003). Sound pressure levels in creeks and streams are usually above $110 \mathrm{~dB}$ re $1 \mu \mathrm{Pa}$ (equivalent continuous broadband level over one minute), whereas ambient noise levels in stagnant habitats with high percentages of hearing specialized fish species such as backwaters and lakes, are typically below $100 \mathrm{~dB}$ re $1 \mu \mathrm{Pa}$ (Wysocki et al., 2007).

Although higher background noise levels did not result in changes in hearing sensitivity with increasing age throughout the study, there was a difference in hearing sensitivity developing with increasing age between cohorts. Hearing thresholds of cohort 1 animals did not change significantly with age except a higher (but not consistently) sensitivity at $400 \mathrm{~Hz}$ in the 33 week old fish. In contrast, hearing sensitivity of cohort 2 animals changed significantly with age. After 
38 weeks of age, cohort 2 trout had significantly higher hearing thresholds at 250 and $300 \mathrm{~Hz}$ than cohort 1 trout (41 weeks) Although the relevant sound characteristic for hearing in trout is primarily particle motion and not sound pressure, this relative difference is between animals receiving the same sound stimulus and thus independent of the proportion between sound pressure and particle motion as well as of the absolute hearing sensitivity to particle motion.

Both cohorts were treated identically throughout the study including: (a) same type and amount of food, (b) same water temperatures and water chemistry, and (c) rearing under identical noise regimes. Therefore, culture conditions and fish husbandry are not a likely cause for the differences observed between cohorts. Additionally, fish originated from the same genetic pool according to the fish supplier. This could not be demonstrated conclusively; therefore, genetic variance could account for the variable development in hearing sensitivity between cohorts.

Several studies have shown the occurrence of different crystalline forms of otoliths within the same population of salmonids. While the aragonite form of calcium carbonate (composed of crystals embedded within a protein matrix) is considered the "wild type", vaterite type (a crystalline form of calcium carbonate) otoliths were found in much higher percentages in hatchery-reared juvenile coho salmon, Oncorhynchus kisutch (Sweeting et al., 2004) and there is recent evidence that auditory thresholds and otolith type correlate for chinook salmon, Oncorhynchus tshawytscha (Oxman et al., 2007). In the present study, otolith types differed between rainbow trout cohorts, however trends within cohorts were not consistent throughout the study. For example, at 32-33 weeks old, the vaterite-vaterite type was much more abundant in cohort 1 and at 38-41 weeks old, when fish from both cohorts were tested simultaneously, vaterite-vaterite otoliths were more abundant in cohort 2 . Therefore, threshold differences could not be conclusively linked to otolith type. In addition, the limited number of aragonite-aragonite 
type otoliths collected was not sufficient to quantitatively compare differences between cohorts. Interestingly, significant differences between cohorts were not only detected for hearing thresholds, but also for pathogen challenge mortality and blood chemistry constituent concentrations.

One factor that could not be controlled was the handling of the fertilized eggs during and before shipping until arrival at the Freshwater Institute. Fertilized eggs are commonly shipped on ice in coolers to maintain optimal temperatures and to prevent accelerated development. Since our trout presumably came from parents of the same gene pool but arrived three weeks apart at the study site, it is possible that cohort 2 eggs were chilled for a longer period than cohort 1 eggs. Thermal control is widely used in aquaculture as a means of influencing the hatching time of the larvae. A recent study on juvenile steelhead trout found evidence that cryopreservation of milt can lead to differences in weight and length as well as in overall stress levels relative to siblings produced from untreated milt (Hayes et al., 2005). Similarly, several factors in the environment of fish eggs such as the surrounding temperature and the speed of development between fertilization and hatching could impact the later development of the fish and this is certainly a topic which needs further investigation.

\subsection{Health parameters}

Although elevated noise levels could potentially impair various health parameters, i.e., reduced growth rates, increased aggression, reduced food uptake but higher metabolic rates such as has been observed in brown shrimp (Lagardère, 1982; Regnault and Lagardère, 1983), 
significant differences in growth rates were not detected between trout reared under the noise regimes used during this study.

Decreases in chloride and sodium plasma concentrations, as well as increases in plasma glucose concentrations are part of the secondary stress response in teleost fish (Barton and Iwama, 1991; Wendelaar Bonga, 1997). Blood chemistry concentrations for all treatments (Fig. 8) were within "normal" levels as reported in the literature for rainbow trout, i.e. $84-132$ meq/L of chloride, 41-151 mg/dL of glucose (Wedemeyer, 1996), and 123-164 meq/L for sodium (Stoskopf, 1993). Chloride concentrations were not different between fish subjected to different sound treatments in either cohort, nor were sodium concentrations in cohort 2. In cohort 1, however, fish reared in the 130 and $150 \mathrm{~dB}$ tanks had significantly lower sodium concentrations compared to fish reared in the $115 \mathrm{~dB}$ tank. The significantly lower sodium levels in fish from the 130 and $150 \mathrm{~dB}$ tanks could indicate that these fish were more stressed by these noise conditions compared to fish in the $115 \mathrm{~dB}$ tank since freshwater fish tend to overhydrate to compensate for stress, which results in dilution of ions in the blood such as sodium. Glucose concentrations between sound treatments differed within both cohorts, although there was not a common trend. For example, for cohort 1, fish from the $115 \mathrm{~dB}$ tank had the highest glucose concentrations amongst treatments and cohort 2 fish from the $130 \mathrm{~dB}$ tanks had the highest glucose concentrations. Blood chemistry data and analysis did not result in specific trends to conclude that elevated noise levels in the rearing tanks presented a chronic stressor to the fish.

Noise has the potential to induce stress responses in the few fish species that have been studied (Smith et al., 2004a; Wysocki et al, 2006). However, research suggests that induction of a stress response could depend on the type of noise. For example, boat engine noise, which was variable in level, time, and frequency domain elicited increased secretion of the primary stress 
hormone cortisol in three species of European freshwater fishes with different hearing sensitivities. In contrast, continuous Gaussian noise of comparable intensity did not elicit a stress response in the same individuals (Wysocki et al., 2006). It has been speculated that that fish are able to habituate to a continuous stimulus. The ability to adapt to continuous noise is important since many fish species, such as gobies and trout, live and reproduce in inherently noisy natural habitats such as rocky creeks, torrents and seashores (Lugli and Fine, 2003) and must therefore be able to maintain their normal activities despite high levels of background noise. The noise encountered during this study and in aquaculture tanks in general is also continuous. Therefore the rainbow trout could have adapted to the noise presented in this study over time.

\section{Conclusions}

Noise in aquaculture production systems is unlikely to be a limiting factor affecting growth, health and hearing ability for rainbow trout. Variability in hearing sensitivity and disease resistance between different groups of trout could be related to factors such as genetic variability or egg treatment. Although rainbow trout were not affected by the noise levels used in this study, these results should not be generalized to all cultured fish species. "Hearing specialist" species such as catfish or carp could be affected differently, especially in their sensory development. Due to the high diversity of hearing abilities and other environmental adaptations in fishes, more data are needed to confirm potential effects of noise in aquaculture facilities on other fish species. 


\section{Literature Cited}

Amoser, S., Ladich, F., 2003. Diversity in noise-induced temporary hearing loss in otophysine fishes. J. Acoust. Soc. Am. 113, 2170-2179.

Banner, A., Hyatt, M., 1973. Effects of noise on eggs and larvae of two estuarine fishes. Trans. Am. Fish. Soc. 1, 134-136.

Bart, A.N., Clark J., Young J, Zohar Y., 2001. Underwater ambient noise measurements in aquaculture systems: a survey. Aquac. Eng. 25, 99-110.

Barton, B.A., Iwama, G.K., 1991. Physiological changes in fish from stress in aquaculture with emphasis on the response and effects of corticosteroids. Ann. Rev. Fish Diseases 1, 3-26.

Campana, S.E. 1999. Chemistry and composition of fish otoliths: pathways, mechanisms, and applications. Mar. Ecol. Prog. Ser. 188: 263-297.

Consten, D., Lambert, J.G., Goos, H.J., 2001a. Cortisol affects testicular development in male common carp, Cyprinus carpio L., but not via an effect on LH secretion. Comp. Biochem. Physiol. B-Biochem. Mol. Biol. 129, 671-677.

Consten, D., Bogerd, J., Komen, J., Lambert, J.G., Goos, H.J., 2001b. Long-term cortisol treatment inhibits pubertal development in male common carp, Cyprinus carpio L. Biol. Reprod. 64, 1063-1071.

Consten, D., Lambert, J.G., Komen, H., Goos, H.J., 2002. Corticosteroids affect the testicular androgen production in male common carp (Cyprinus carpio L.). Bio. Reprod. 66, 106111.

Davidson, J., Frankel, A.S, Ellison, W., Summerfelt, S.T., Popper, A.N., Mazik, P., Bebak, J. 2007. Minimizing noise in fiberglass aquaculture tanks: Noise reduction potential of various retrofits. Aquacultural Eng. 137, 125-131.

Enger, P.S., 1981. Frequency discrimination in teleosts -- central or peripheral? In: Tavolga, W.N., Popper, A.N., Fay, R.R. (Eds.), Hearing and Sound Communication in Fishes. Springer, New York pp. 243-255.

Hastings, M.C., Popper, A.N., Finneran, J.J., and Lanford, P.J., 1996. Effect of low frequency underwater sound on hair cells of the inner ear and lateral line of the teleost fish Astronotus ocellatus. J. Acoust. Soc. Am. 99, 1759-1766.

Hawkins, A.D., 1993. Underwater sound and fish behaviour. In: Pitcher, T.J. (Ed.), Behaviour of Teleost Fishes., Chapman and Hall, London, pp. 129-169. 
Hayes, M.C., Rubin, S.P., Hensleigh, J.E., Reisenbichler, R.R., Wetzel, L.A., 2005. Performance of juvenile steelhead trout (Oncorhynchus mykiss) produced from untreated and cryopreserved milt. Aquaculture 249, 291-302.

Huntingford, F.A., Adams, C., Braithwaite, V.A., Kadri, S., Pottinger, T.G., Sandøe, P., Turnbull, J. F., 2006. Current issues in fish welfare. J. Fish Biol. 68, 332-372.

Kenyon, T.N., Ladich, F., and Yan, H.Y., 1998. A comparative study of hearing ability in fishes; the auditory brainstem response approach. J. Comp. Physiol. A 182, 307-318.

Ladich, F., Popper, A.N., 2004. Parallel evolution in fish hearing organs. In: Manley, G., Fay, R.R., Popper A.N. (Eds.), Evolution of the Vertebrate Auditory System. Springer, New York, pp. 95-127.

Lagardère, J.P., 1982. Effects of noise on growth and reproduction on Crangon crangon in rearing tanks. Mar. Biol. 71, 177-185.

Lugli, M., Fine, M.L., 2003. Acoustic communication in two freshwater gobies: ambient noise and short-range propagation in shallow streams. J. Acoust. Soc. Am. 114, 512-521.

McCauley, R.D., Fewtrell, J., Popper, A.N., 2003. High intensity anthropogenic sound damages fish ears. J. Acoust. Soc. Am. 113, 638-642.

McCormick, M.I., 1999. Experimental test of the effect of maternal hormones on larval quality of a coral reef fish. Oecologia 118, 412-422.

Motulsky, H., 1995. Intuitive Biostatistics. Oxford University Press, Inc., New York, pp. 195 ff.

Oxman, D.S., Barnett-Johnson, R., Smith, M.E., Coffin, A., Miller, D.L., Josephson, R., Popper, A.N. 2007. The effect of vaterite deposition on sound reception, otolith morphology, and inner ear sensory epithelia in hatchery-reared Chinook salmon (Oncorhynchus tshawytscha). Can. J. Fish Aquat. Sci. 64: 1469-1478.

Pankhurst, N.W., Van der Kraak, G., 2000. Evidence that acute stress inhibits ovarian steroidogenesis in rainbow trout in vivo, through the action of cortisol. Gen.Comp. Endocrinol. 117, 225-37.

Pickering, A.D., 1992. Rainbow trout husbandry: management of the stress response. Aquaculture 100, 125-139.

Popper, A.N., 2003. Effects of anthropogenic sound on fishes. Fisheries 28, 24-31.

Popper, A.N., Fay, R.R., 1973. Sound detection and processing by teleost fishes: a critical review. J. Acoust. Soc. Am. 53, 1515- 1529. 
Popper, A.N., Clarke, N.L., 1976. The auditory system of the goldfish (Carassius auratus): Effects of intense acoustic stimulation. Comp. Biochem. Physiol. A 53, 11-18.

Popper, A.N., Fewtrell, J., Smith, M.E., and McCauley, R.D., 2004. Anthropogenic sound: Effects on the behavior and physiology of fishes. Mar. Technol. Soc. J. 37, 35-40.

Regnault, M., Lagardère, J.P., 1983. Effects of ambient noise on the metabolic levels of Crangon crangon (Decapoda, Natantia). Mar. Ecol. Prog. Ser. 11, 71-78.

Santulli, A., Modica, A., Messina, C., Ceffa, L., Curatolo, A., Rivas, G., Fabis, G., Damelio, V., 1999. Biochemical responses of European sea bass (Dicentrarchus labrax L.) to the stress induced by of shore experimental seismic prospecting. Mar. Pollut. Bull. 38, 1105-1114.

Scholik, A.R., Yan, H.Y., 2001. Effects of underwater noise on auditory sensitivity of a cyprinid fish. Hear. Res. 152, 17-24.

Scholik, A.R., Yan, H.Y., 2002. Effects of boat engine noise on the auditory sensitivity of the fathead minnow, Pimephales promelas. Environ. Biol. Fishes 63, 203-209.

Smith, M.E., Kane, A.S., Popper, A.N., 2004a. Noise-induced stress response and hearing loss in goldfish (Carassius auratus). J.Exp. Biol. 207, 427-435.

Smith, M.E., Kane, A.S., and Popper, A.N., 2004b. Acoustical stress and hearing sensitivity in fishes: Does the linear threshold shift hypothesis hold water? J. Exp. Biol. 207, 35913602 .

Smith, M.E., Coffin, A.B., Miller, D.L., and Popper, A.N., 2006. Anatomical and functional recovery of the goldfish (Carrasius auratus) ear following noise exposure. J. Exp. Biol. 207, 4193-4202.

Stoskopf, M. 1993. Fish Medicine. W.B. Saunders Company, Philadelphia, 882 pp.

Sverdrup, A., Kjellsby, E., Krüger, P.G., Floysand, R., Knudsen, F.R ., Enger, P.S., SerckHanssen G, Helle K.B., 1994. Effects of experimental seismic shock on vasoactivity of arteries, integrity of the vascular endothelium and on primary stress hormones of the Atlantic salmon. J. Fish Biol. 45, 973-995.

Sweeting, R.M., Beamish, R.J., Neville, C.M., 2004. Crystalline otoliths in teleosts: Comparisons between hatchery and wild coho salmon (Oncorhynchus kisutch) in the Strait of Georgia. Rev. Fish. Biol. Fish. 14, 361-369.

Wedemeyer, G.A., 1996. Physiology of Fish in Intensive Culture Systems. Chapman and Hall, New York.

Wendelaar Bonga, S.E., 1997. The stress response in fish. Physiol. Rev. 77, 591-625. 
Weyts, F.A.A., Cohen, N., Flik, G., Verburg-van Kemenade, B., 1999. Interactions between the immune system and the hypothalamo-pituitary-interrenal axis in fish. Fish Shellfish Immunol. 9, 1-20.

Wysocki, L.E., Dittami, J.P., Ladich, F., 2006. Ship noise and cortisol secretion in European freshwater fishes. Biol. Cons. 128, 501-508.

Wysocki, L.E, Amoser, S., Ladich, F., 2007. Diversity in ambient noise in European freshwater habitats: Noise levels, spectral profiles, and impact on fishes. J. Acoust. Soc. 121, 25592566. 


\section{Tables}

Table 1. Percentage distribution of various saccular otolith crystalline structures from fish that were tested for hearing thresholds.

\begin{tabular}{ccccc}
\hline \multirow{2}{*}{ Age } & Cohort & \multicolumn{3}{c}{ Otolith type } \\
& & AA & AV & VV \\
\hline 17 weeks & Cohort 1 & $4.8 \%$ & $9.5 \%$ & $85.7 \%$ \\
16 weeks & Cohort 2 & $20 \%$ & $30 \%$ & $50 \%$ \\
\hline 33 weeks & Cohort 1 & -- & $10.5 \%$ & $89.5 \%$ \\
32 weeks & Cohort 2 & -- & $55 \%$ & $45 \%$ \\
\hline 41 weeks & Cohort 1 & $8.3 \%$ & $33.3 \%$ & $58.3 \%$ \\
38 weeks & Cohort 2 & -- & $8.3 \%$ & $91.7 \%$ \\
\hline
\end{tabular}

AA - both ears aragonite-type saccular otoliths

$\mathrm{AV}$ - saccular otolith of one ear aragonite and of the other ear vaterite

VV - both ears vaterite-type saccular otoliths

Table 2. Percentage survival of trout from each sound treatment tank during the entire study period.

\begin{tabular}{cccc}
\hline \% Survival & \multicolumn{3}{c}{ Sound treatment } \\
& $115 \mathrm{~dB}$ & $130 \mathrm{~dB}$ & $150 \mathrm{~dB}$ \\
\hline Cohort 1 & $99.1 \%$ & $97.7 \%$ & $98.5 \%$ \\
Cohort 2 & $98.4 \%$ & $96.9 \%$ & $97.8 \%$ \\
\hline
\end{tabular}




\section{Figures}

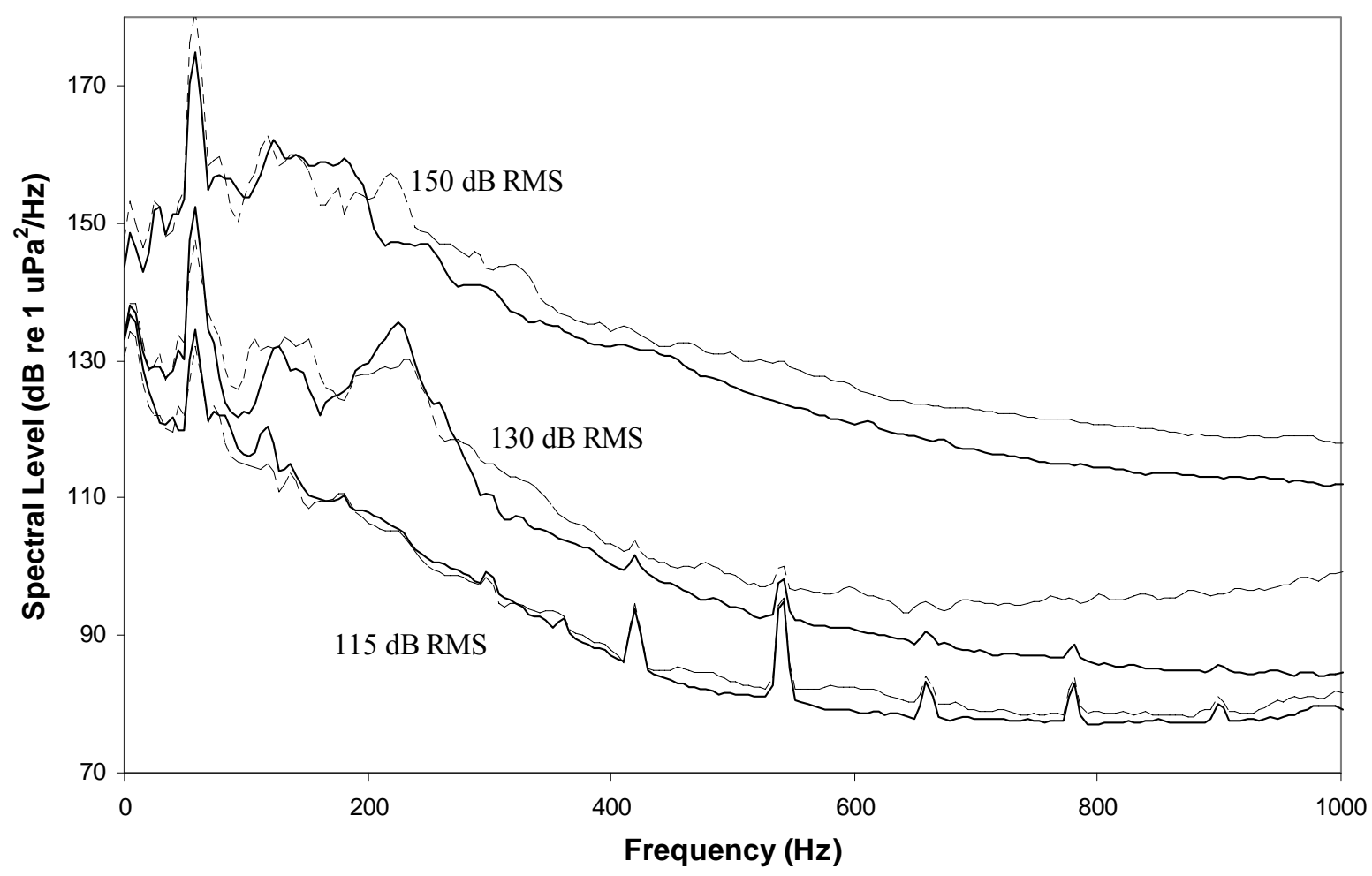

Figure 1. Average sound density spectra of the three sound treatment tanks for cohort 1 (solid lines) and cohort 2 (dotted lines). 


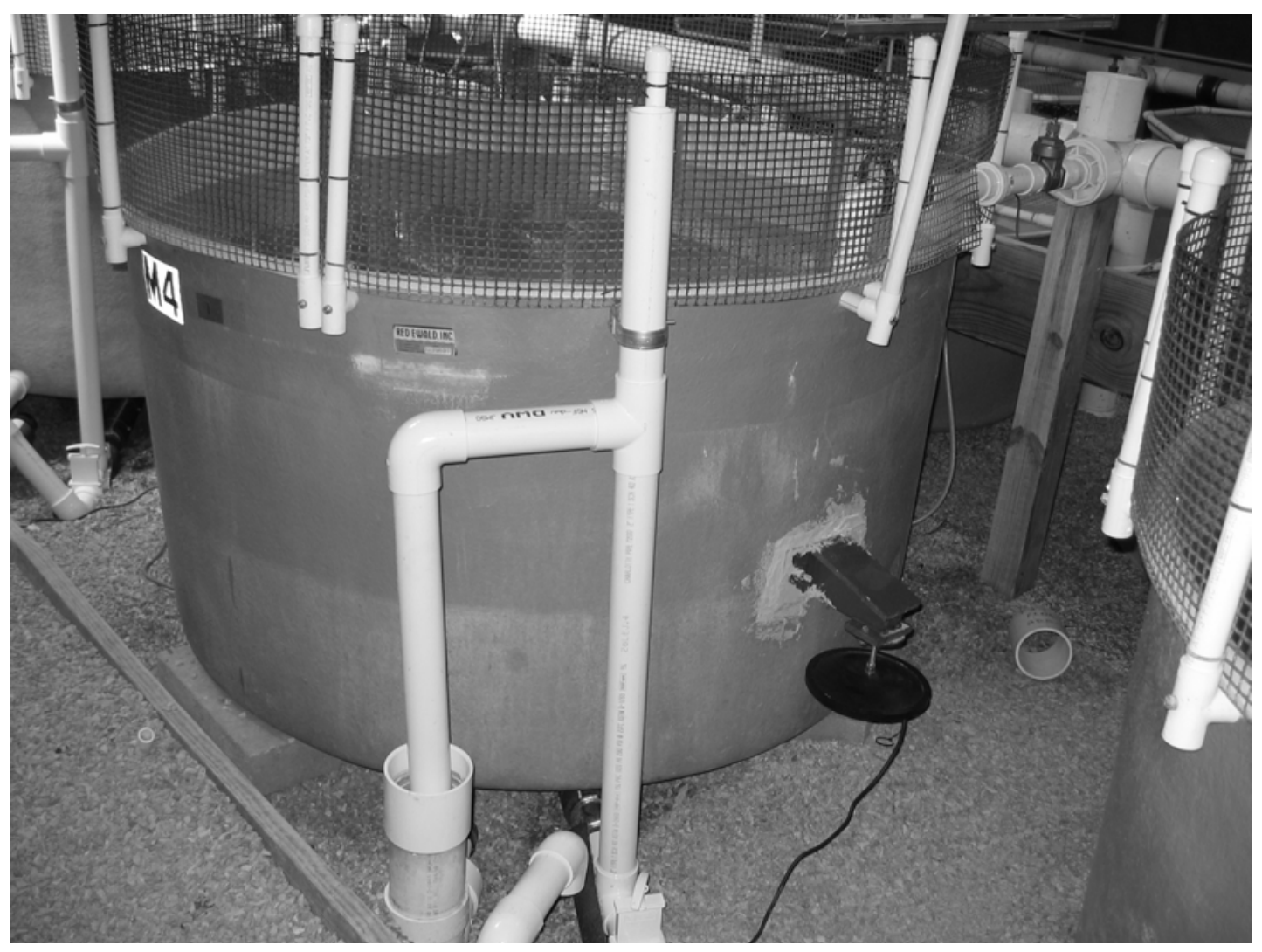

Figure 2. Tactile speaker attached to side wall of an experimental tank used to transmit aquaculture production noise into the tank. 


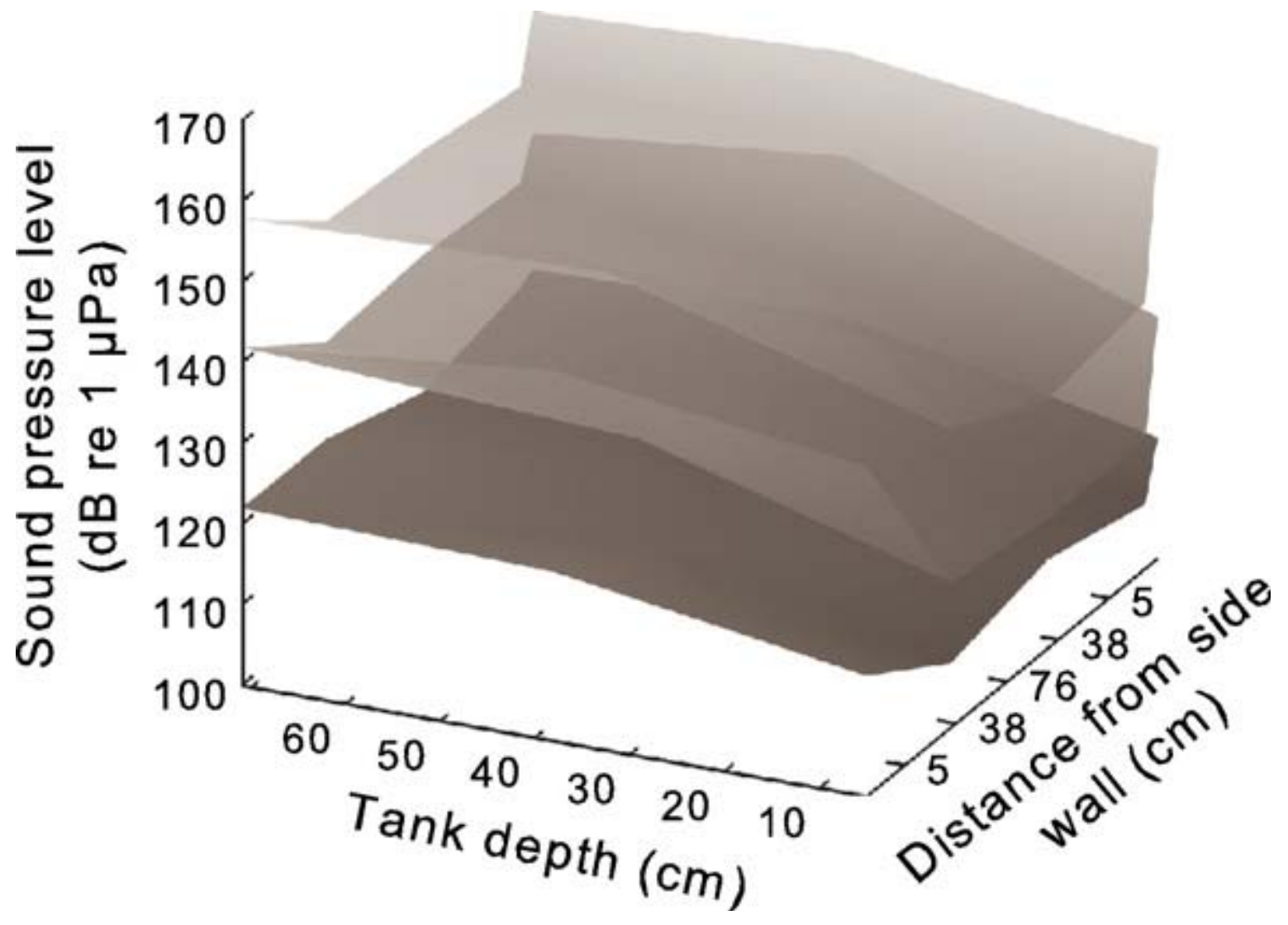

Figure 3. Variability of sound pressure levels (dB re $1 \mu \mathrm{Pa}$ broadband [2 Hz to $20 \mathrm{kHz}] \mathrm{RMS}$ ) within the different sound treatment tanks. Sound levels represent mean RMS measurements taken at various locations within each sound treatment tank for Cohort 1 and Cohort 2 over the course of the study. Figure courtesy of Popper Lab (University of Maryland). 

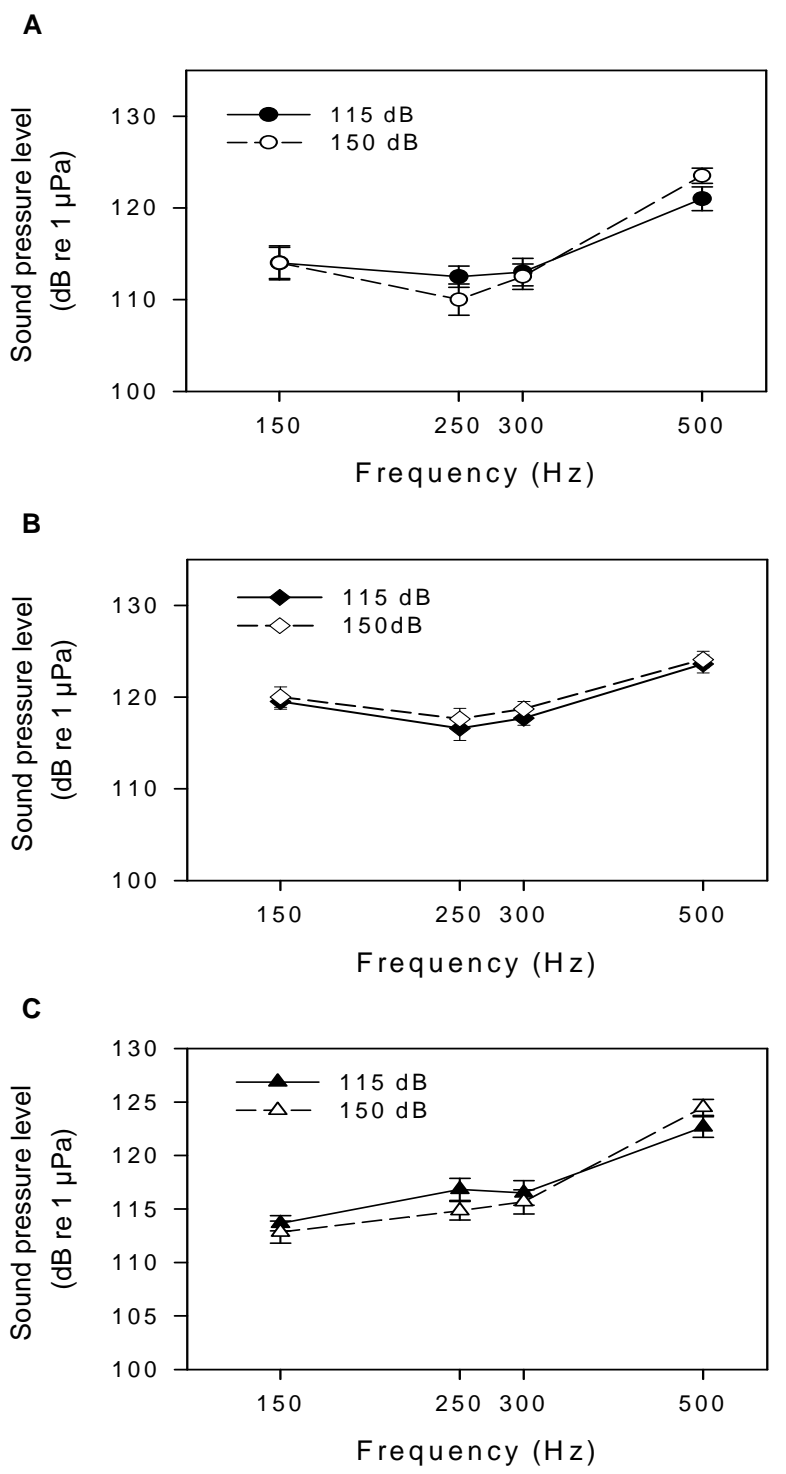

Figure 4. Hearing thresholds of cohort 2 trout raised in $115 \mathrm{~dB}$ tanks (solid lines) and in $150 \mathrm{~dB}$ tanks (dashed lines) at the age of 16 weeks (A), 32 weeks (B), and 38 weeks (C). 


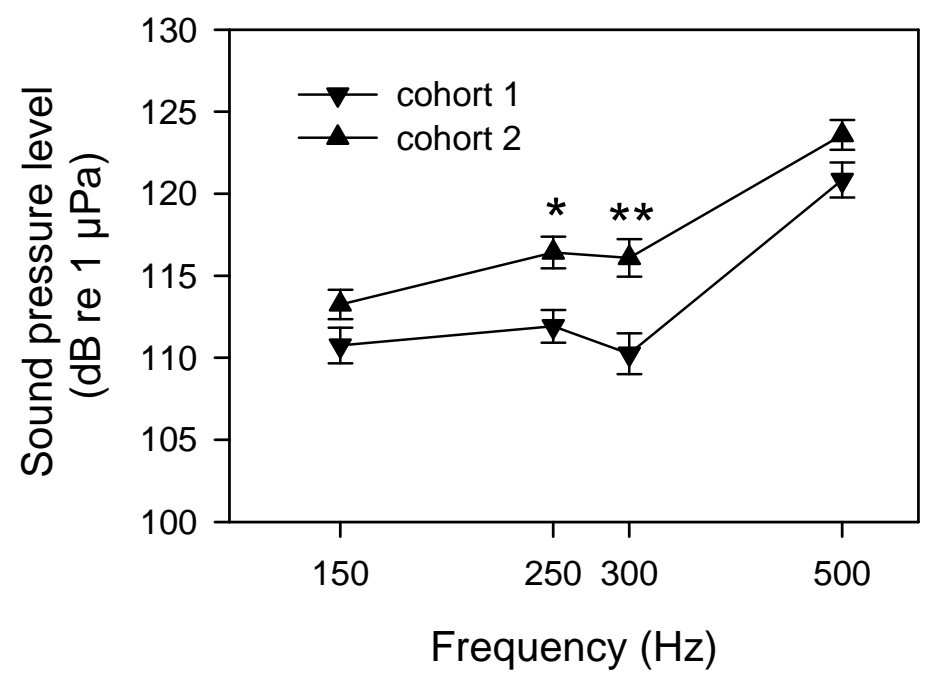

Figure 5. Hearing thresholds of cohort 1 trout (age: 41 weeks) and cohort 2 trout (age: 38 weeks) measured on the same test days. Asterisks indicate significant differences between both cohorts $(* \mathrm{P} \leq 0.0125, * * \mathrm{P} \leq 0.0025)$.

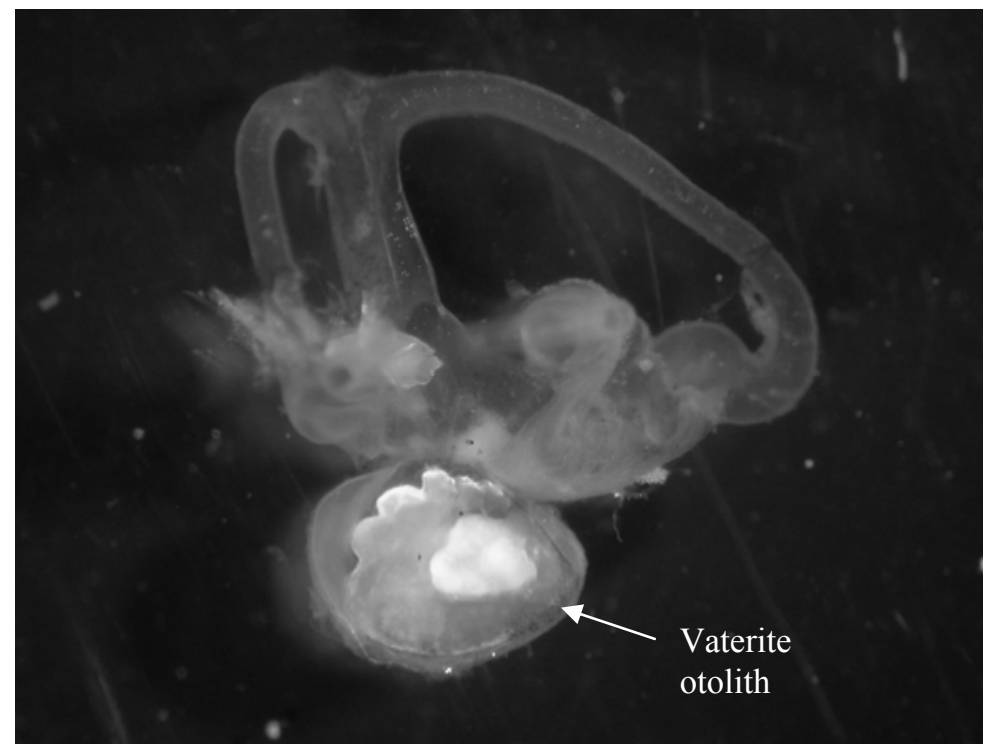

Figure 6. Microscope photograph of a dissected fish ear with vaterite otolith. Photo courtesy of Popper Lab (University of Maryland) and dissection by Michael Gearhart. 


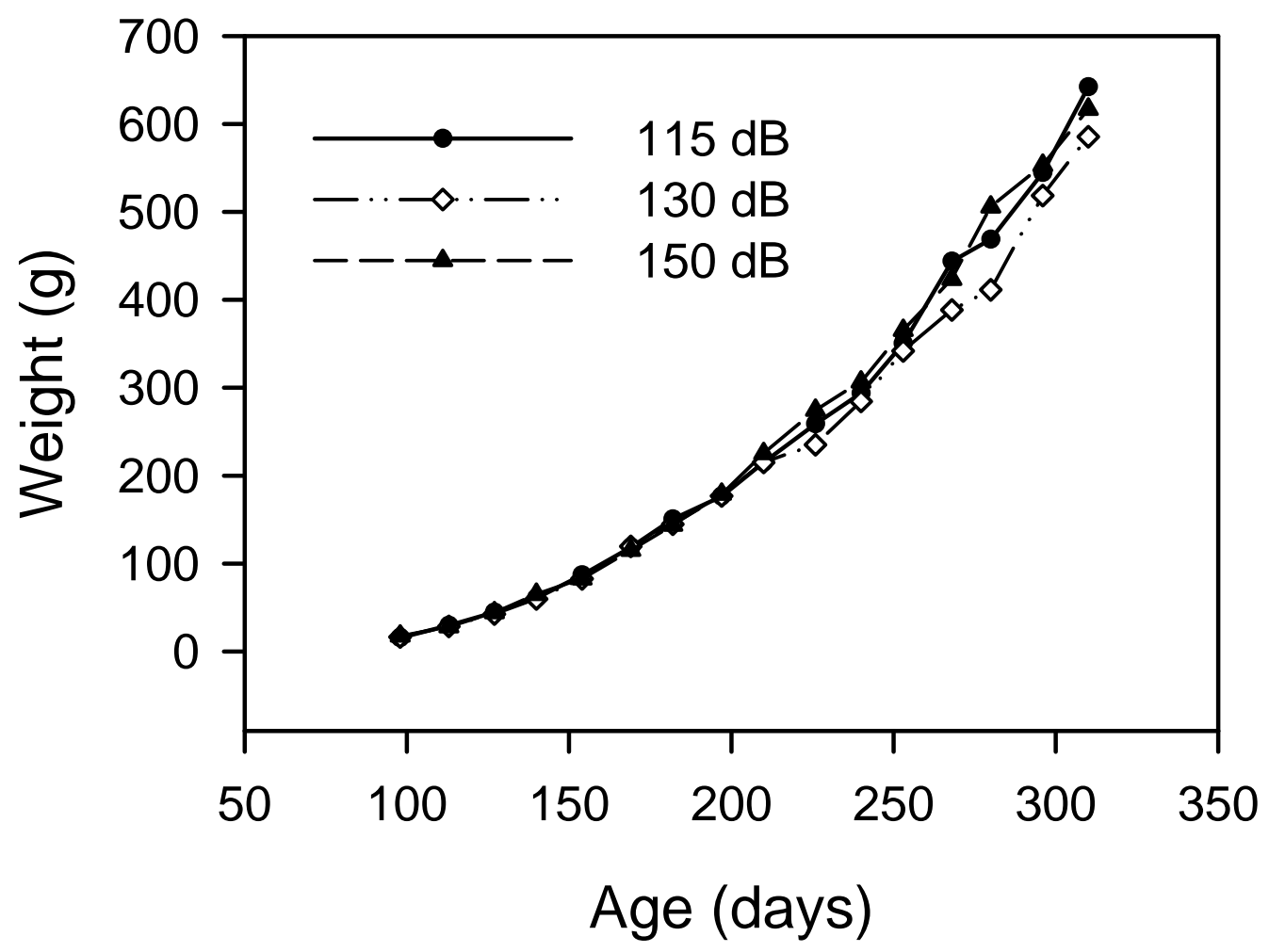

Figure 7. Growth curves of cohort 1 trout raised in the three different sound treatment tanks. 


\section{A}

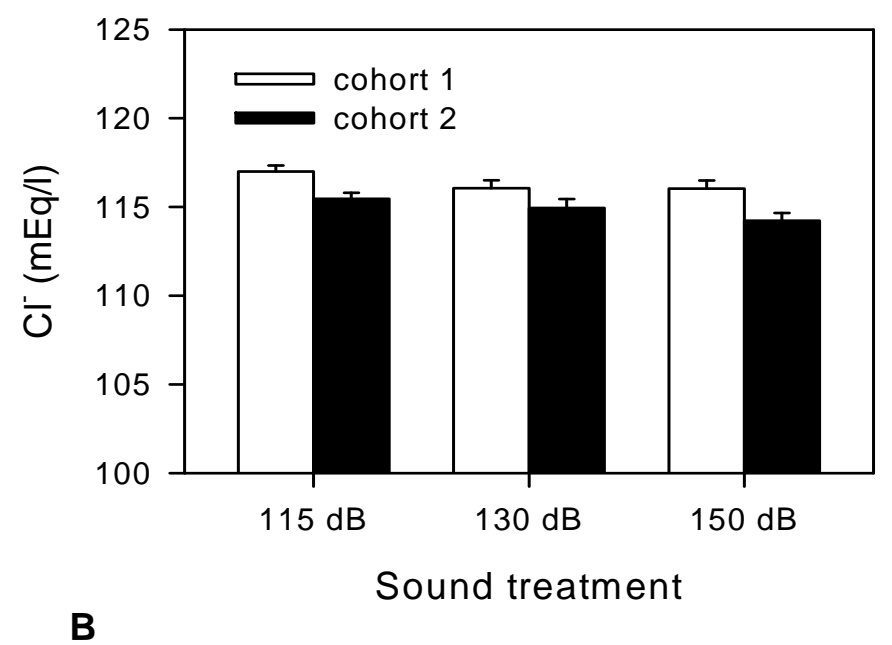

B

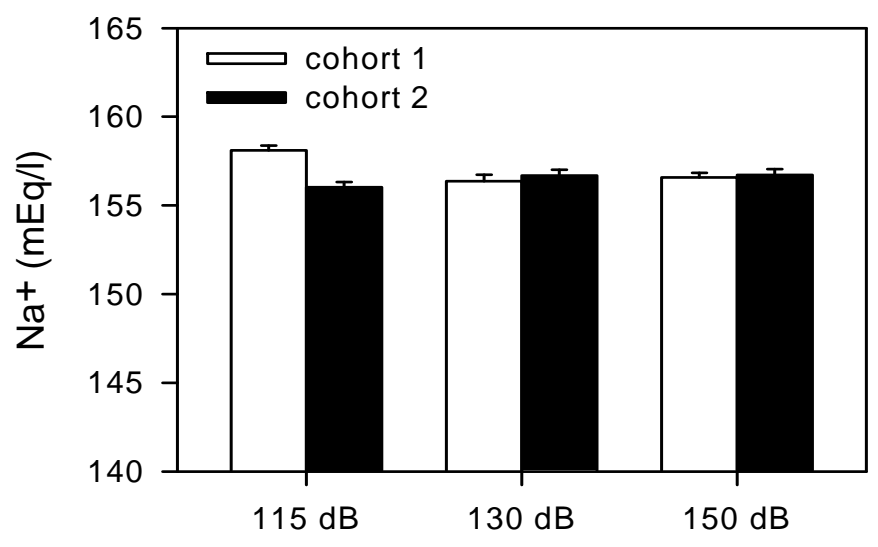

C

Sound treatment

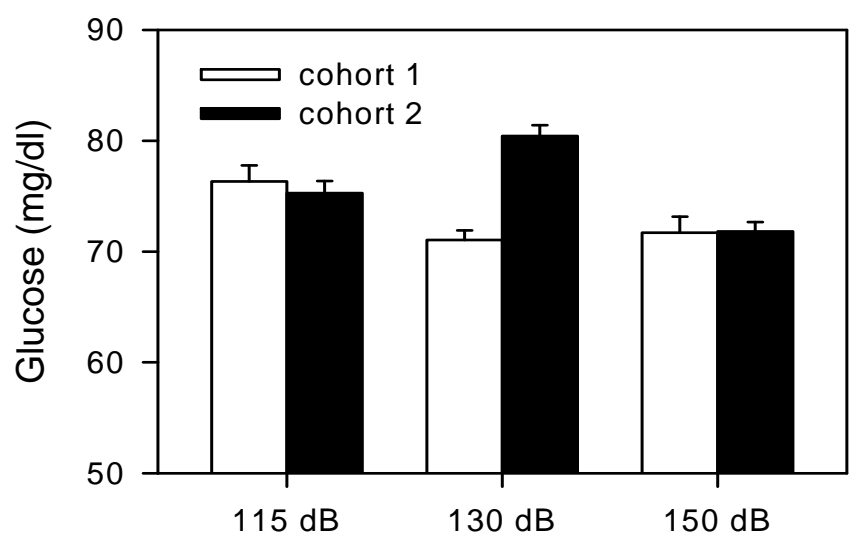

Sound treatment

Figure 8. Chloride (A), sodium (B), and glucose (C) blood concentrations of trout from cohort 1 (white bars) and cohort 2 (black bars) trout raised in different sound treatment tanks. 


\section{Chapter 3. The Effects of Aquaculture Production Noise on the Growth, Condition Factor, Feed Conversion, and Survival of Rainbow Trout, Oncorhynchus mykiss}

\section{Abstract}

Intensive aquaculture systems, particularly recirculating systems, utilize equipment such as aerators, air and water pumps, blowers, and filtration systems that increase noise levels in fish culture tanks. Sound levels and frequencies measured within intensive aquaculture systems are within the range of fish hearing, but species-specific effects of aquaculture production noise are not well defined. Field and laboratory studies have shown that fish behavior and physiology can be negatively impacted by intense sound. Therefore, chronic exposure to aquaculture production noise could cause increased stress, reduced growth rates and feed conversion efficiency, and decreased survival. The objective of this study was to provide an in-depth evaluation of the long term effects of aquaculture production noise on the growth, condition factor, feed conversion efficiency, and survival of cultured rainbow trout, Oncorhynchus mykiss. Rainbow trout were cultured in replicated tanks using two sound treatments: $117 \mathrm{~dB}$ re $1 \mu \mathrm{Pa}$ RMS which represented sound levels lower than those recorded in an intensive recycle system and $149 \mathrm{~dB}$ re $1 \mu \mathrm{Pa}$ RMS, representing sound levels near the upper limits known to occur in recycle systems. To begin the study mean fish weights in the 117 and $149 \mathrm{~dB}$ tanks were 40 and $39 \mathrm{~g}$, respectively. After five months of exposure no significant differences were identified between treatments for mean weight, length, specific growth rates, condition factor, feed conversion, or survival $(n=4)$. Mean final weights for the 117 and $149 \mathrm{~dB}$ treatments were $641 \pm 3$ and $631 \pm$ 
$10 \mathrm{~g}$, respectively. Overall specific growth rates were equal, i.e. $1.84 \pm 0.00$ and $1.84 \pm 0.01$. Analysis of growth rates of individually tagged rainbow trout indicated that fish from the $149 \mathrm{~dB}$ tanks grew slower during the first month of noise exposure $(p<0.05)$; however, fish acclimated to the noise thereafter. This study further suggests that rainbow trout growth and survival are unlikely to be affected over the long term by noise levels common to intensive aquaculture systems.

\section{Introduction}

Recently, there has been increasing concern regarding the effects of anthropogenic noise on marine life, including fish (Popper, 2003). A number of field and laboratory studies evaluating the effects of sound on fish have shown that increased ambient sound levels can alter habitat selection, behavior, and ecology, and could cause negative effects on fish physiology such as hearing damage, stress response, and reduced growth and reproduction rates (Popper, 2003). However, only a limited number of studies have investigated the effects of noise on fish physiology, growth, and survival within fish culture systems, particularly recycle systems which are known to produce relatively loud ambient sound levels.

Many field and laboratory studies have shown that fish are capable of hearing within a species-specific range and will often exhibit behavioral and physiological responses to increased ambient noise. Seismic prospecting using air guns which produce high intensity pulses of sound up to $230 \mathrm{~dB}$ re $1 \mu \mathrm{Pa}$ have caused startle response of rockfish, Sebastes spp., (Pearson et al., 1992), reduced local abundance and catch rates of cod, Gadus morhua and haddock 
Melanogrammus aeglefinus (Engås et al., 1996), biochemical stress response in European sea bass, Dicentrarchus labrax (Santulli et al., 1999), and damage to sensory epithelia of the inner ear in pink snapper, Pagrus auratus (McCauley et al., 2003). Additionally, offshore sounds produced by shipping, seismic air guns, or sonar could confuse larval fish by masking biotic reef sounds, which pelagic larval fish use as a homing device (Tolimieri et al., 2002; 2004), thus preventing fish from locating the reef (Popper, 2003). Several studies have shown that infrasound $(<20 \mathrm{~Hz})$ can impact fish behavior and potentially alter migration routes. Startle and avoidance behavior was observed in response to infrasound in downstream migrating Atlantic salmon smolt, Salmo salar (Knudsen et al., 1994), Pacific salmon juveniles, Oncorhynchus spp. (Knudsen et al., 1997), and migrating European silver eels, Anguilla anguilla (Sand et al., 2000). Sun et al. (2001) showed that drilling noise and vibration from petroleum reconnoitering caused reduced growth rates of grass carp, Ctenopharyngodon idellus. In addition, Atlantic salmon exposed to intense underwater explosions of about $2 \mathrm{MPa}$ exhibited biochemical stress responses and injury to the endothelium of the aorta and arteries (Sverdrup et al., 1994).

Several studies also indicate that boat engine noise can negatively impact fish physiology. Fathead minnows, Pimephales promelas, exposed to recorded boat engine noise (0.3-4.0 kHz at a mean sound level of $142 \mathrm{~dB}$ re $1 \mu \mathrm{Pa}$ ) experienced temporary hearing loss (Scholik and Yan 2001; 2002), and underwater ambient noise produced by ships (153 dB re $1 \mu \mathrm{Pa}$ continuous SPL over 30 mins) elicited a biochemical stress response in common carp, Cyprinus carpio, the gudgeon, Gobio gobio, and the European perch, Perca fluviatilis (Wysocki et al., 2006). Other laboratory studies have shown that increased ambient sound can damage sensory organs of fish (Enger, 1981; Hastings et al., 1996) and thus cause hearing loss (Popper and Clarke, 1976; Amoser and Ladich, 2003; Smith et al., 2004). Hearing loss was observed in 
goldfish, Carassius auratus, and the vocalizing catfish, Pimelodus pictus, following exposure to intense white noise (158 dB re $1 \mu \mathrm{Pa}$ ) for 12-24 hours (Amoser and Ladich, 2003). Smith et al. (2004) found that goldfish exhibited increased cortisol and glucose levels indicative of a stress response and experienced a temporary reduction in hearing following exposure to white noise (0.1-10 kHz and 160-170 $\mathrm{dB}$ re $1 \mu \mathrm{Pa}$.$) .$

Cultured fish could also be exposed to increased ambient noise, especially in large, commercial scale aquaculture facilities that utilize recirculating systems. In many aquaculture operations fish are confined to individual culture tanks where they cannot escape from areas with less than optimal sound conditions. Therefore, chronic exposure to elevated sound levels in aquaculture is a concern. However, only a few studies have investigated the effects of sound on cultured species. Banner and Hyatt (1973) observed lower egg viability and reduced growth rates for longnose killifish, Fundulus similis, and the sheepshead minnow, Cyprinodon variegates, when sound levels within aquarium tanks were approximately $20 \mathrm{~dB}$ higher than sound levels in control tanks. Lagardère (1982) and Regnault and Lagardère (1983) reported reduced growth and reproductive rates and decreased survival of cultured brown shrimp, Crangon crangon, when ambient sound pressure levels (SPL's) were $30 \mathrm{~dB}$ higher than SPL's common to the natural habitat of the brown shrimp. Additionally, Terhune et al. (1990) observed decreased growth and smoltification rates of Atlantic salmon in fiberglass tanks that had underwater sound levels 2-10 $\mathrm{dB}$ re $1 \mu \mathrm{Pa}$ higher at $100-500 \mathrm{~Hz}$ than concrete tanks.

Recently, Wysocki and Davidson et al. (2007b), i.e., Chapter 2, found that the hearing, growth, survival, and disease resistance of rainbow trout (Oncorhynchus mykiss), which are commonly cultured within potentially noisy recycle systems, were not negatively impacted by long- term exposure to intensive aquaculture production noise $(115,130$, and $150 \mathrm{~dB}$ re $1 \mu \mathrm{Pa}$ 
RMS). However, anecdotal evidence from Chapter 2, such as decreased feeding and slightly slower growth rates, particularly at the onset of exposure to the $150 \mathrm{~dB}$ treatment, warranted further investigation into the effects of aquaculture production noise on rainbow trout growth. These observations were not specifically reported in Chapter 2 since a small sample size $(n=2)$ made it difficult to determine if the suspected effects on growth were real. Therefore, the objective of the present study was to further evaluate the potential impacts of intensive aquaculture production noise on rainbow trout growth and survival. The present study evaluated the 115 and $150 \mathrm{~dB}$ treatments, and excluded the $130 \mathrm{~dB}$ treatment since there was no evidence of an effect in the previous study (Wysocki and Davidson et al., 2007b). The 115 and $150 \mathrm{~dB}$ treatments represented sound levels that were much lower than those recorded within recirculating systems (Bart et al., 2001; personal experience) and sound levels that were near the upper limits known to occur in intensive aquaculture production systems (Clark et al., 1996; Bart et al., 2001). The present study was complementary to Wysocki and Davidson et al. (2007b), i.e. Chapter 2, and was conducted to provide a comprehensive assessment of the effects of aquaculture production noise on rainbow trout growth and survival including an evaluation of monthly and long term growth, specific growth rates, feed conversion efficiency, condition factor, and fish size distribution.

\section{Materials and Methods}

Methods for the current study resembled those used in Chapter 2. To summarize, sound recordings were taken in a commercial scale $(9.1 \mathrm{~m}$ diameter, $2.4 \mathrm{~m}$ deep) round fiberglass aquaculture tank within a recirculating system at the Freshwater Institute (Shepherdstown, WV). 
The recordings were representative of the sound characteristics that fish are exposed to within intensive recycle systems. A five minute audio recording was then created to simulate underwater sound characteristics recorded in the commercial scale tank and was burned to a CD. The audio recording was transmitted to the experimental tanks continuously, 24 hours per day, via amplifiers (MPA-250, Radio Shack), a stereo sound mixer (Model 32-2057, Radio Shack), and tactile speakers (Model AW339, Clark Synthesis Tactile Sound, Littleton, CO) mounted on the outside walls of the tanks at mid depth (i.e. $38 \mathrm{~cm}$ from the top of the water column).

Eight round fiberglass tanks ( $1.5 \mathrm{~m}$ diameter, $0.8 \mathrm{~m}$ deep) were used in the current study. The study design consisted of four control tanks which received ambient noise only and had a mean sound level of $117 \pm 1 \mathrm{~dB}$ re $1 \mu \mathrm{Pa}$ RMS and four experimental tanks in which the sound system was tuned to produce mean sound levels of $149 \pm 0 \mathrm{~dB}$ re $1 \mu \mathrm{Pa}$ RMS. These treatment categories represented sound levels that were lower than those recorded within recirculating systems and sound levels that were near the upper limits known to occur in intensive aquaculture production systems.

Fertilized rainbow trout eggs (Oncorhynchus mykiss) were obtained from a commercial fish hatchery and egg supplier (Troutlodge, Sumner, WA). The fish were all female diploids and the progeny of a cross between rainbow trout (the stationary freshwater form of O. mykiss) and steelhead trout (the anadromous form of O. mykiss), i.e. the same strain that was used in Wysocki et al. (2007b). The fertilized eggs were received at the Freshwater Institute at $3^{\circ} \mathrm{C}$, acclimated to hatching system temperatures $\left(12^{\circ} \mathrm{C}\right)$, and then divided into Heath incubator trays. Day 1 of the life cycle was designated when $50 \%$ of the eggs had hatched, six days after arrival. When fish had absorbed the majority of the yolk sac they were stocked into a single round tank $(1.1 \mathrm{~m}$ diameter, $0.5 \mathrm{~m}$ maximum depth) also designed to buffer ambient sound to ensure that fish were 
not predisposed to "loud" conditions. Fish were fed a standard trout diet (Zeigler Brothers Inc., Gardners, PA) during the pre-study period. Daily feed rations and feed size were determined using standard trout feeding charts as well as observations of feeding activity. As the fish grew, water depth was gradually increased and fish were split into three identical tanks. The sound spectrum for the holding tanks was similar to the $117 \mathrm{~dB}$ re $1 \mu \mathrm{Pa}$ RMS control tanks used during the study (Fig. 1).

To begin the study 200 fish $(39 \pm 0.2 \mathrm{~g})$ were randomly divided into the experimental tanks at a density of $5.6 \mathrm{~kg} / \mathrm{m}^{3}$. Passive integrated transponder (PIT) tags (Biomark Inc., Boise, ID) were implanted in 100 fish from each tank in order to track individual growth rates during the study. Preliminary tagging studies at the Freshwater Institute and other recent studies suggest that rainbow trout retain tags well and have unaffected growth and survival rates (Acolas et al., 2007). The $11 \mathrm{~mm}, 125 \mathrm{kHz}$ tags were implanted in the peritoneal cavity using hypodermic needles inserted behind the right pelvic fin of each fish. Needles were disinfected in an iodine solution after each use. To avoid bias, fish that were not implanted with PIT tags were punctured with the tagging syringes in the same location. Fish were allowed a one week acclimation period to adjust to the new tanks before the sound was initiated. A $1 \%$ salt treatment was administered for 30 minutes as a static bath one time per day for four days following tagging and stocking. Fish were kept off feed over the four day period as an additional measure to minimize stress.

Sound levels to the tanks were tuned prior to stocking to achieve approximately $150 \mathrm{~dB}$ re $1 \mu \mathrm{Pa}$ then equipment was turned off with the desired settings in place. The sound recording was turned on to the tanks sequentially so that video could be collected for each tank to observe initial fish response to the sound. Sound pressure level (SPL's) measurements were taken weekly to ensure that sound levels were consistent throughout the study. SPL's were extrapolated from 
millivolt readings which were collected using a calibrated hydrophone (HTI-94-SSQ, frequency response: 2-30 kHz, sensitivity: $-170 \mathrm{~dB}$ re $1 \mathrm{~V} / \mu \mathrm{Pa}$, High Tech Inc. Gulfport, MS) connected to a voltmeter. Raw voltage values were converted to broadband sound levels and expressed as $\mathrm{dB}$ re $1 \mu \mathrm{Pa}$ root mean squared (RMS). Sound levels (RMS) for each tank were measured using a grid system that consisted of 15 locations: five horizontal $(5,38,76,38$, and $5 \mathrm{~cm}$ from the sides of the tank) and locations at 3 depths $(5,38$, and $71 \mathrm{~cm}$ deep). In addition, a weekly 15 sec sound recording was taken $38 \mathrm{~cm}$ from the side of the tanks at a depth of $38 \mathrm{~cm}$ to ensure that the spectral composition of the noise remained consistent over time. Recordings were made using the hydrophone connected to a low-pass filter set to $2000 \mathrm{~Hz}$ (Model 91149A, Precision Filters, Inc., Ithaca, NY), a pre-amplifier (Model FP-11, Shure Inc., Niles, IL), and an analog-to-digital converter and data logger (Model USB-9215, National Instruments, Austin, TX) connected to a laptop computer. Characterization of sound spectra and corresponding sound pressure levels were performed with NI-DAQmx Base Software using a Labview 7.1 application (National Instruments, Austin, TX).

The study was conducted over a five month period and concluded when the fish reached maximum densities, approximately $80 \mathrm{~kg} / \mathrm{m}^{3}$. Fish were cultured well beyond the generally accepted market size of $340+$ grams to simulate a complete production cycle and beyond (Fornshell, 2002). Throughout the study, all fish were cultured under a constant $24 \mathrm{~h}$ photoperiod at $13.0 \pm 0.0{ }^{\circ} \mathrm{C}$ in a flow through system. Fish were fed slow-sinking trout feed (Zeigler Brothers Inc., Gardners, PA) with a protein-to-fat ratio of 42/16 via automated feeders (Sterner Products AB, Sweden) programmed to deliver the same amount of feed to each tank and were calibrated weekly. The feeding schedule consisted of 24-30 small feed events per day at equally spaced intervals around the clock. Flow rates were adjusted to maintain equal flow between 
treatments. Mean flow rates for the 117 and $149 \mathrm{~dB}$ treatments were $37.6 \pm 0.3$ and $36.9 \pm 0.1$ $\mathrm{L} / \mathrm{min}$, respectively. Water samples were collected on a monthly basis and analyzed for alkalinity, carbon dioxide, nitrite, total ammonia nitrogen, and total suspended solids. Dissolved oxygen and temperature were measured three times per week. Weights and fork lengths of all trout from each tank were measured monthly. During sampling events each fish was scanned using a PIT tag reader (Destron Mini Portable Reader, Destron Fearing Corporation, St. Paul, MN). Tag codes were stored within the PIT tag reader, downloaded to an excel file, and matched with respective length and weight data to track individual growth rates. In order to retrieve data for all tagged fish, every fish in each tank was sampled; therefore population means for length and weight were obtained as opposed to sample means. Individual weights were not collected during the third monthly length and weight sample due to problems with the PIT tag reader. Statistical analyses were performed using Systat 11 software (Systat Software, Inc., 2004). Multivariate repeated measures analysis of variance (MANOVA) was used to test for differences in weight, length, condition factor, and feed conversion ratios between treatments. Each tank was considered an experimental unit, therefore tank means $(n=4)$ were used to test for differences between treatments. To further investigate potential subtle differences in growth between treatments, growth rates of individually tagged fish from each treatment were pooled and also compared using MANOVA $(\mathrm{n}=342,325)$. Post hoc analysis for individual growth rates was conducted using separate t-tests for each weight sample with a Bonferroni adjustment. A Mann-Whitney U-test was used to test for differences in survival between treatments. Survival efficiencies were transformed for statistical analysis using an arcsine square-root transformation (Sokal and Rohlf, 1981). A probability level $(\alpha)$ of 0.05 was used to determine significance for each statistical test, with the exception of the post hoc analysis of individual growth rates $(\alpha=$ 
0.01). In addition, $95 \%$ confidence intervals were applied to monthly weight and length measurements. The following criteria were calculated and used for analysis: 1) Percentage difference in mean weights and lengths between treatments $(\mathrm{PD} \%)=\left(\left(\mathrm{Wt}_{117 \mathrm{~dB}}-\mathrm{Wt}_{149 \mathrm{~dB}}\right) / \mathrm{Wt}\right.$ $117 \mathrm{~dB}) * 100$; specific growth rates $(\mathrm{SGR}, \% /$ day $)=\left(\left(\mathrm{LN}\left(\mathrm{Wt}_{\mathrm{f}}\right)-\mathrm{LN}\left(\mathrm{Wt}_{\mathrm{i}}\right)\right) /\right.$ days between samples $) * 100$; Fulton's condition factor $(\mathrm{CF})=\left(10^{5} * \mathrm{Wt} \mathrm{(g}_{(\mathrm{g})}\right) / \mathrm{L}_{(\mathrm{mm})}^{3}($ Lagler, 1956); and feed

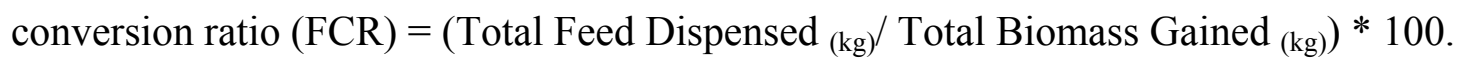

\section{Results}

\subsection{Experimental Conditions}

Mean sound levels for the control tanks and the experimental tanks were $117 \pm 1 \mathrm{~dB}$ re 1 $\mu \mathrm{Pa}$ RMS and $149 \pm 0 \mathrm{~dB}$ re $1 \mu \mathrm{Pa}$ RMS, respectively. Sound pressure levels generally varied depending on location within the tanks, with the loudest areas closest to the side walls and the bottom of the tank, and quietest locations near the top and center of the tanks (Table 1,2). Mean spectral plots for each treatment are presented in Fig. 2. All water quality parameters were relatively equal between treatments and were within safe limits (Table 3).

\subsection{Observations}

When the $149 \mathrm{~dB}$ treatment was initiated the fish responded with an initial alarm reaction and appeared to be stressed, scattering throughout the tank and swimming erratically. Fish began swimming in normally distributed patterns within a few hours following the onset of the sound. 


\subsection{Growth (Weight)}

Rainbow trout weights at the beginning of the study were relatively equal following random stocking, $39 \pm 0$ and $40 \pm 0 \mathrm{~g}$, for the $117 \mathrm{~dB}$ and $149 \mathrm{~dB}$ tanks, respectively (Fig.3). Fish from the $117 \mathrm{~dB}$ tanks were $1.5 \%$ larger than fish from the $149 \mathrm{~dB}$ tanks to begin the study (Fig. 4). Following one month of noise exposure (sample 2), 95\% confidence intervals for the 117 and the $149 \mathrm{~dB}$ treatments were 90-92 and 79-91 g, respectively, and barely overlapped. The 95\% confidence intervals for specific growth rate also exhibited only slight convergence, i.e. 2.90-3.07 \%/day for the $117 \mathrm{~dB}$ treatment vs. 2.64-2.93\%/day for the $149 \mathrm{~dB}$ treatment (Fig. 5). Following one month of exposure to experimental conditions mean weights were $91 \pm 0 \mathrm{~g}$ in the $117 \mathrm{~dB}$ tanks and $85 \pm 2 \mathrm{~g}$ in the $149 \mathrm{~dB}$ tanks (Fig. 3). Fish in the $117 \mathrm{~dB}$ tanks were 6.8\% larger than the $149 \mathrm{~dB}$ tanks after one month, which was a notable increase from the $1.5 \%$ difference observed at the beginning of the study (Fig. 4).

There was no long term effect of noise exposure on rainbow trout growth. There were no significant differences in mean growth between the 117 and $149 \mathrm{~dB}$ treatments $(p=0.204)$ and no significant differences relative to a time $\mathrm{x}$ treatment interaction $(p=0.062)$. In addition, overall specific growth rates for the 117 and the $149 \mathrm{~dB}$ treatments were equal, $1.84 \pm 0.00$ and $1.84 \pm 0.01$, respectively (Table 3 ). Calculation of $95 \%$ confidence intervals indicated that weight intervals for the 117 and the $149 \mathrm{~dB}$ treatments overlapped at the conclusion of the study (i.e. 630-652 and 600-661 g, respectively) and for each monthly weight sample (Table 4; Fig. 3). The mean weight for the $117 \mathrm{~dB}$ treatment $(641 \pm 3 \mathrm{~g})$ was $1.6 \%$ greater than the $149 \mathrm{~dB}$ treatment $(631 \pm 10 \mathrm{~g})$, a difference that essentially existed to begin the study (Table 4; Fig. 4). The $149 \mathrm{~dB}$ treatment had a notably greater size variation at the end of the study as suggested by 
standard error and variance values for weight. Standard error for the 117 and $149 \mathrm{~dB}$ treatments was 3 and $10 \mathrm{~g}$, respectively; while variance was 48 and 363, respectively.

\subsection{Individual Growth (Weight)}

To further investigate potential subtle differences in growth between treatments, growth rates of individually tagged fish from each treatment were pooled and compared using MANOVA. A significant difference existed for individual growth rates between the 117 and 149 $\mathrm{dB}$ treatments $(p=0.035)$, as well as the time $\mathrm{x}$ treatment interaction $(p=0.000)$. Post hoc analysis, testing against an $\alpha=0.01$ indicated that the difference in the time $\mathrm{x}$ treatment interaction occurred during sample $2(p=0.000)$. Mean weights for sampling events $1,4,5$ and 6 were not significantly different $(p=0.024,0.107,0.019,0.188$, respectively).

\subsection{Growth (Length)}

Rainbow trout lengths at the beginning of the study were equal between treatments, $142 \pm$ $0 \mathrm{~mm}$. Following one month of exposure to experimental conditions mean lengths were $175 \pm 1$ $\mathrm{mm}$ in the $117 \mathrm{~dB}$ tanks and $178 \pm 1 \mathrm{~mm}$ in the $149 \mathrm{~dB}$ tanks (Fig. 6). Similar to the trend for fish weight, percentage difference in length peaked after the first month of the study and decreased during each subsequent sample (Fig. 4). There was no long term effect of noise exposure on rainbow trout growth relative to length. There were no significant differences in length between the 117 and $149 \mathrm{~dB}$ treatments $(p=0.260)$ and no significant differences relative to a time $\mathrm{x}$ treatment interaction $(p=0.358)$. Fish lengths at the end of the study for the 117 and the $149 \mathrm{~dB}$ tanks were $333 \pm 2$ and $334 \pm 1 \mathrm{~mm}$, respectively (Table 4; Fig.6). 


\subsection{Condition Factor}

There were no significant differences in condition factor between treatments $(p=0.431)$ and no time $\mathrm{x}$ treatment interaction $(p=0.804)$ throughout the study. Rainbow trout condition factors for the $117 \mathrm{~dB}$ and the $149 \mathrm{~dB}$ tanks to begin the study were $1.36 \pm 0.01$ and $1.37 \pm 0.01$, respectively. Rainbow trout condition factors at the end of the study were $1.71 \pm 0.01$ for the 117 $\mathrm{dB}$ treatment and $1.70 \pm 0.01$ for the $149 \mathrm{~dB}$ treatment (Table 4).

\subsection{Feed Conversion}

There were no significant differences in FCR between treatments $(p=0.141)$, and no significant differences relative to a time $\mathrm{x}$ treatment interaction $(p=0.106)$. Similar to the aforementioned parameters, the greatest difference in FCR between treatments occurred during the first month of the study. After one month of noise exposure, FCR's were $0.88 \pm 0.02$ in the $117 \mathrm{~dB}$ tanks and $1.01 \pm 0.04$ in the $149 \mathrm{~dB}$ tanks. Feed conversion ratios for the $117 \mathrm{~dB}$ and the $149 \mathrm{~dB}$ treatments throughout the study were $1.07 \pm 0.01$ and $1.09 \pm 0.02$, respectively (Table 4).

\subsection{Size Distribution}

A distribution plot of fish weights showed that size distribution was relatively equal to begin the study (Fig. 7). After one month of noise exposure, the size distribution had shifted slightly, indicating greater numbers of $149 \mathrm{~dB}$ fish to the left of the median (75-100 g) and greater numbers of $117 \mathrm{~dB}$ fish to the right of the median (Fig. 8). For example, a relatively distinct difference in number of fish per sound treatment was evident for the 50-75 g distribution, i.e. $28 \pm 4$ fish in the $117 \mathrm{~dB}$ tanks and $46 \pm 6$ fish in the $149 \mathrm{~dB}$ tanks. The $100-125 \mathrm{~g}$ distribution consisted of $56 \pm 2$ fish for the $117 \mathrm{~dB}$ tanks and $37 \pm 5$ fish for the $149 \mathrm{~dB}$ tanks. 
Distribution plot of mean weight for subsequent sampling events and at the conclusion of the study indicated relatively similar size distributions for 117 and $149 \mathrm{~dB}$ treatments (Fig. 9).

\subsection{Survival}

There was no significant difference in percentage survival between the 117 and $149 \mathrm{~dB}$ treatments, i.e. $98.6 \pm 0.4$ and $99.0 \pm 0.2 \%$, respectively $(p=0.661)$ (Table 4). Mean total mortality for the $117 \mathrm{~dB}$ was $3 \pm 1$ fish and $2 \pm 0$ fish for the $149 \mathrm{~dB}$ treatment. The sum of mortalities across all replicated tanks was 11 fish for the $117 \mathrm{~dB}$ treatment and 8 fish for the 149 $\mathrm{dB}$ treatment.

\section{Discussion}

Intensive aquaculture systems, particularly recycle systems, often utilize equipment such as aerators, air and water pumps, harvesters, blowers, and filtration systems that could increase ambient sound levels within culture tanks. Davidson et al. (2007), i.e., Chapter 1, found that low frequency tonal sounds created by pumps $(59 \mathrm{~Hz})$ and blowers $(29 \mathrm{~Hz})$ were transmitted into fish culture tanks and contributed to the loudest portion of the sound spectrum $(105-130 \mathrm{~dB}$ re 1 $\mu \mathrm{Pa})$. Bart et al. (2001) found that mean broadband sound pressure levels (SPL's) differed between various intensive aquaculture systems. Mean SPL's ranged from $\leq 100 \mathrm{~dB}$ re $1 \mu \mathrm{Pa}$ in an earthen pond with the aerator turned off, $120 \mathrm{~dB}$ in concrete raceways, and $130 \mathrm{~dB}$ in round fiberglass tanks of various sizes. In the same study, SPL's were generally higher at relatively low frequencies $(125-135 \mathrm{~dB}$ re $1 \mu \mathrm{Pa}$ at $25-1000 \mathrm{~Hz})$ and ranged from $100-115 \mathrm{~dB}$ re $1 \mu \mathrm{Pa}$ at $1-2$ $\mathrm{kHz}$. Additionally, a maximum sound level of $135 \mathrm{~dB}$ re $1 \mu \mathrm{Pa}$ was recorded in an earthen pond 
near an operating aerator, while the highest SPL's, $153 \mathrm{~dB}$ re $1 \mu \mathrm{Pa}$, were measured within $14 \mathrm{~m}$ fiberglass tanks within a recirculating system (Bart et al., 2001). The highest sound levels reported within aquaculture systems are $160 \mathrm{~dB}$ re $1 \mu \mathrm{Pa}$ (Clark et al., 1996). Consequently, cultured fish are chronically exposed to noise levels that are well within the hearing range of many aquaculture species. Sound pressure levels within aquaculture systems are likely greater than underwater sound levels of most natural habitats. For example, Lugli et al. (2003) reported maximum sound pressure levels in streams and rivers of $85-110 \mathrm{~dB}$ re 1 from $60-500 \mathrm{~Hz}$. Mean sound levels of $119 \mathrm{~dB}$ re $1 \mu \mathrm{Pa}$ have also been measured in creeks known to sustain rainbow trout (Wysocki et al. 2007a). Therefore, stream dwelling fish such as trout that are cultured within intensive recycle systems could be exposed to sound levels that are 40-75 $\mathrm{dB}$ re $1 \mu \mathrm{Pa}$ greater than sound levels experienced in a natural environment.

In the current study increased sound pressure levels and the spectral components representative of intensive recirculating aquaculture systems (149 $\mathrm{dB})$ did not inhibit long term growth and survival of rainbow trout. No significant differences were detected between the 117 and the $149 \mathrm{~dB}$ treatments for mean weights, lengths, specific growth rates, condition factors, and feed conversion ratios. Additionally, the percent difference in mean weight between treatments was essentially the same at the beginning and end of the study, and the final size distributions for the 117 and $149 \mathrm{~dB}$ treatments were similar. Therefore, results from this study supported the overall findings of Chapter 2, which also showed that long term rainbow trout growth was not significantly impacted by aquaculture production noise.

However, initial effects on growth, observed as anecdotal evidence in the Chapter 2 study were evident again during this study. Although significant differences were not detected for most growth parameters over the long term, data analysis indicated that rainbow trout in the $149 \mathrm{~dB}$ 
treatment could have been negatively affected during the first month of noise exposure and then acclimated to the increased sound over the remainder of the study. Observations of an initial startle response, confidence intervals for weight, plots of percent difference in length and weight, a shift in size structure, and higher FCR's for the $149 \mathrm{~dB}$ treatment each indicate that fish were negatively impacted during the first month of exposure to the $149 \mathrm{~dB}$ treatment. Due to a relatively small sample size $(n=4)$, which was limited due to availability of resources, the study design was not powerful enough to statistically detect very small differences. To further simulate the potential difference in growth between treatments, growth rates of individually tagged fish from each treatment were pooled and compared using MANOVA. Results indicated a significant difference between treatment and a difference in the time $\mathrm{x}$ treatment interaction. Post hoc analysis indicated that the only significant difference in fish weight occurred for sample 2, after the first month of noise exposure. Therefore, analysis of individual growth rates provides further evidence of a subtle negative effect on growth for the $149 \mathrm{~dB}$ treatment over the first month of noise exposure. Individual fish typically are not analyzed as units of replication. Therefore, these results were not used in drawing overall conclusions, but to further analyze potentially small differences between treatments.

Additionally, the $149 \mathrm{~dB}$ treatment had a notably greater degree of size variation at the conclusion of the study. The increased variation in weight for the $149 \mathrm{~dB}$ treatment was likely caused during the first month of the study as indicated by size distribution (Fig. 8). It is possible that a portion of the population was not able to compensate for the potential inhibition of growth during the first month, thus resulting in greater long term variation. Although the mean weights to end the study were not significantly different $(n=4)$, the difference in variation could be a cause for concern for a trout farmer. Trout growers are often expected to provide a size specific 
product within a specific time frame, and fish that are too small at harvest could convey a lower market price or even be rejected, ultimately reducing profitability.

The subtle differences in growth and comparatively higher FCR's measured for the 149 $\mathrm{dB}$ treatment could be explained by several theories: 1) fish were not feeding as well as the 117 $\mathrm{dB}$ controls due to potentially stressful acoustic conditions or 2) fish were consuming similar amounts of food as control fish but utilizing some energy towards a physiological stress response rather than complete growth. Stress response is defined as the sum of physiological changes that result when fish are challenged by physical, chemical, or biological conditions (Wedemeyer et al., 1990; Wedemeyer, 1996). Increased stress levels in fish, especially when chronic, could adversely effect growth, sexual maturation and reproduction, immune response, and survival in fish (Wedemeyer et al., 1990; Wedemeyer, 1996; Pickering, 1992; Wendelaar-Bonga, 1997; Weyts et al., 1999; Pankhurst and Van der Kraak, 2000). Physiological compensation for stressful challenges requires caloric energy thereby making it unavailable for other functions such as growth (Beitinger and McCauley, 1990; Wedemeyer et al., 1996). Barton and Schreck (1987) found that salmonids utilize up to $25 \%$ of total energy towards coping with mild stressors. Thus, impaired growth typically accompanies a stress response.

Rainbow trout apparently were successful in physiological adaptation to any stress response caused by the $149 \mathrm{~dB}$ treatment as evidenced by the increased growth rates during the remainder of the study and excellent survival. Following the first month of noise exposure, specific growth rates for the $149 \mathrm{~dB}$ fish increased and were slightly faster than growth rates for the $117 \mathrm{~dB}$ treatment (sample 3 and 4, Fig. 5), indicating that the fish had adapted to potentially stressful conditions caused by the sound. The growth response of the $149 \mathrm{~dB}$ fish following the first month of noise exposure is similar to a compensatory growth response that is often observed 
when feed rations are restricted for a period of time and then increased (Jobling and Johansen, 1999). In the case of the current study feed rations were not restricted, but feeding could have been reduced due to stress response. Thus, following acclimation fish could have increased feeding resulting in hyperphagia, which is a common response during a compensatory growth cycle.

Minimal effects on rainbow trout growth evidenced in the current study and in Chapter 2 are likely related to the hearing capability of rainbow trout. Previous studies have shown that salmonids do not have a wide hearing bandwidth or sensitivity to sound pressure levels and are therefore not as likely to be impacted by increased ambient sound. Hawkins and Johnstone (1978) discovered that Atlantic salmon, a hearing generalist, responded only to frequencies below $380 \mathrm{~Hz}$, and Chapter 2 found that rainbow trout responded to sound stimuli up to $500 \mathrm{~Hz}$. Additionally, Chapter 2 found that hearing thresholds of rainbow trout cultured under similar conditions, i.e. in tanks with SPL's of $150 \mathrm{~dB}$ re $1 \mu \mathrm{Pa}$ RMS, did not experience a shift in hearing threshold that would indicate hearing damage. Rainbow trout have been characterized as hearing generalists since they do not possess specialized hearing structures and therefore have a limited range of hearing sensitivity (Popper et al., 2003). Hearing generalists typically can only detect frequencies below $500 \mathrm{~Hz}$ and are not as sensitive to sound pressure levels (Popper, 2003). Many teleost species, such as carp and catfish possess physiological adaptations called Weberian ossicles, a bony connection that bridges the swim bladder and the inner ear that enhances hearing capability (Popper and Fay, 1973; Popper et al., 2003; and Ladich and Popper, 2004). Most hearing specialists can detect sound pressure levels as low as 50-75 $\mathrm{dB}$ re $1 \mu \mathrm{Pa}$, and frequencies ranging from 100-2,000 Hz (Popper, 2003; Popper et al., 2003). Although rainbow trout growth and survival were not impacted over the long term during the present study these results should 
not be generalized to all cultured species. Hearing specialist species such as catfish, goldfish, and carp are sometimes cultured in intensive aquaculture systems, including recycle systems (Broussard et al., 1976; Bovenduer et al., 1987; Ng et al., 1992; McVeigh, 2004; Halachmi, 2006). The effects of aquaculture production noise on the growth, physiology, and survival of such hearing specialist species is unknown.

\section{Conclusions}

In conclusion, intensive aquaculture production noise, particularly sound levels associated with recirculating systems, did not inhibit rainbow trout growth and survival over the greater part of a production cycle. Thus, results from the current study corroborate the findings of Chapter 2, which analyzed the effects of aquaculture production noise on rainbow trout hearing, but provided a less comprehensive analysis of the effects of production noise relative to rainbow trout growth. Although significant differences in rainbow trout growth were not detected in the current study, comprehensive data analysis showed that rainbow trout did appear to exhibit a stress response when the $149 \mathrm{~dB}$ sound was initiated. Rainbow trout acclimated to the increased sound, appeared to achieve compensatory growth, and ultimately grew at the same overall rate as fish in relatively quiet control tanks. Any effects of noise during the study appear to be subtle; however, management of noise associated with intensive aquaculture systems should still be considered. In standard aquaculture production fish could experience circumstances similar to those that were presented during this study in which they are suddenly exposed to increased sound levels. For example, fish are typically moved between various culture systems as they progress through the life cycle. At the Freshwater Institute, fish are 
transferred from a relatively quiet flow through fry system with sound levels similar to the 117 $\mathrm{dB}$ treatment, to recirculating systems with increased ambient sound levels. Although fish in the current study acclimated to the increased sound, decreased immune efficiency and disease could have resulted in the presence of additional stressors, such as poor water quality, poor handling, or crowded conditions. Successful fish culturists proactively manage production systems to ensure that stressful conditions are minimized. Production system noise should also be considered a variable that requires control. Chapter 1 suggests some practical and inexpensive methods to reduce sound levels within fish culture tanks.

This study evaluated a continuous, i.e. unchanging sound stimulus, to which rainbow trout appeared to acclimate. Rainbow trout could have responded differently to irregular sound patterns, such as loud bursts of sound, which often occur in aquaculture facilities due to construction, use of power tools, and the operation of equipment related to harvesting and cleaning. Therefore, additional research simulating intense bursts of aquaculture noise would be beneficial.

Results from this study should not be generalized to all cultured species since hearing abilities vary widely between species. Cultured species with specialized hearing such as catfish and goldfish could respond much differently to elevated sound levels associated with intensive production systems. Additionally, this study did not evaluate the effects of production noise on rainbow trout during the early developmental life stages. Therefore, additional research is necessary to determine the long term effects of aquaculture production noise on rainbow trout eggs and larvae as well as many other cultured species. 


\section{Literature Cited}

Acolas, M.L., Roussel, J.M., Lebel, J.M., Bagliniere, J.L., 2007. Laboratory experiment on survival, growth, and tag retention following PIT injection into the body cavity of juvenile brown trout (Salmo trutta). Fish. Res. 86, 280-284.

Amoser, S., Ladich, F., 2003. Diversity in noise-induced temporary hearing loss in otophysine fishes. J. Acoust. Soc. Am. 113, 2170-2179.

Banner, A., Hyatt, M., 1973. Effects of noise on eggs and larvae of two estuarine fishes. Trans. Am. Fish. Soc. 1, 134-136.

Bart, A.N., Clark, J., Young, J., Zohar, Y., 2001. Underwater ambient noise measurements in aquaculture systems: a survey. Aquac. Eng. 25, 99-110.

Barton, B.A., Schreck, C.B., 1987. Metabolic cost of acute physical stress in juvenile steelhead. Trans. Am. Fish. Soc. 116, 257-263.

Beitinger, T.L., McCauley, R.W., 1990. Whole animal physiological processes for the assessment of stress in fishes. Journal of Great Lakes Research 16, 542-575.

Bovendeur, J., Eding, E.H., Henken, A.M., 1987. Design and performance of a water recirculation system for high density culture of African catfish, Clarias gariepinus. Aquaculture 63, 329-353.

Broussard, M.C. Jr., Simco, B.A., 1976. High density culture of channel catfish in a recirculating system. Prog. Fish Cult. 38 (3), 138-141.

Clark, J., Young, J., Bart, A.N., Zohar, Y., 1996. Underwater ambient noise measurements. In: $30^{\text {th }}$ Proceedings of the Acoustical Society of America, St. Louis, MO. Nov. 27, p. 13.

Davidson, J., Frankel, A.S, Ellison, W., Summerfelt, S.T., Popper, A.N., Mazik, P., Bebak, J., 2007. Minimizing noise in fiberglass aquaculture tanks: Noise reduction potential of various retrofits. Aquac. Eng. 137, 125-131.

Engås, A., Lokkeborg, S., Ona, E., Soldal, A.V., 1996. Effects of seismic shooting on local abundance and catch rates of cod (Gadus morhua) and haddock (Melanogrammus aeglefinus). Can. J. Fish. Aqua. Sci. 53, 2238-2249.

Enger, P.S., 1981. Frequency discrimination in teleosts -- central or peripheral? In: Tavolga, W.N., Popper, A.N., Fay, R.R. (Eds.), Hearing and Sound Communication in Fishes. Springer, New York pp. 243-255.

Fornshell, G., 2002. Rainbow Trout—Challenges and Solutions. Rev. Fish. Sci. 10, 545-557. 
Halachmi, I., 2006. Systems engineering for ornamental fish production in a recirculating aquaculture system. Aquaculture 259, 300-314.

Hastings, M.C., Popper, A.N., Finneran, J.J., Lanford, P.J., 1996. Effect of low frequency underwater sound on hair cells of the inner ear and lateral line of the teleost fish Astronotus ocellatus. J. Acoust. Soc. Am. 99, 1759-1766.

Hawkins, A.D., Johnstone, A.D.F., 1978. The hearing of the Atlantic Salmon, Salmo salar. J.Fish Biol. 13, 655-673.

Jobling, M., Johansen, S.J.S., 1999. The lipostat, hyperphagia and catch-up growth. Aquacult. Res. 30 (7), 473-478.

Knudsen, F.R., Enger, P.S., Sand. O., 1994. Avoidance responses to low frequency sound in downstream migrating Atlantic salmon smolt, Salmo salar. J. Fish Biol. 45, 227-233.

Knudsen, F.R., Schreck, C.B., Knapp, S.M., Enger, P.S., and Sand, O., 1997. Infrasound produces flight and avoidance responses in Pacific juvenile salmonids. J. Fish Biol. 51, 824-829.

Lagler, K.F., 1956. Freshwater Fishery Biology. Second edition. W.C. Brown Publishers, Dubuque, Iowa.

Ladich, F., Popper, A.N., 2004. Parallel evolution in fish hearing organs. In: Manley, G., Fay, R.R., Popper A.N. (Eds.), Evolution of the Vertebrate Auditory System. Springer, New York, pp. 95-127.

Lagardère, J.P., 1982. Effects of noise on growth and reproduction on Crangon crangon in rearing tanks. Mar. Biol. 71, 177-185.

Lugli, M., Yan, H.Y., Fine, M.L., 2003. Acoustic communication in two freshwater gobies: the relationship between ambient noise, hearing thresholds and sound spectrum. J. Comp. Physiol. A 189, 309-320.

McCauley, R.D., Fewtrell, J., Popper, A.N., 2003. High intensity anthropogenic sound damages fish ears. J. Acoust. Soc. Am. 113, 638-642.

McVeigh, S., 2004. African catfish grow in solar heated recirculating system. Hatchery International 5 (5), 24-25.

Ng, W.J., Kho, K., Ho, L.M., Ong, S.L., Sim, T.S., Tay, S.H., Goh, C.C., Cheong, L., 1992. Water quality within a recirculating system for tropical ornamental fish culture. Aquaculture 103 (2), 123-124. 
Pankhurst, N.W., Van der Kraak, G., 2000. Evidence that acute stress inhibits ovarian steroidogenesis in rainbow trout in vivo, through the action of cortisol. Gen.Comp. Endocrinol. 117, 225-37.

Pearson, W.H., Skalski, J.R., Malme, C.I., 1992. Effects of sound from a geophysical survey device on behavior of captive rockfish. Can. J. Fish. Aqua. Sci. 49, 1343-1356.

Pickering, A.D., 1992. Rainbow trout husbandry: management of the stress response. Aquaculture 100, 125-139.

Popper, A.N., Fay, R.R., 1973. Sound detection and processing by teleost fishes: a critical review. J. Acoust. Soc. Am. 53, 1515-1529.

Popper, A.N., Clarke, N.L., 1976. The auditory system of the goldfish (Carassius auratus): Effects of intense acoustic stimulation. Comp. Biochem. Physiol. A 53, 11-18.

Popper, A.N., 2003. Effects of anthropogenic sound on fishes. Fisheries 28, 24-31.

Popper, A.N., R.R. Fay, C. Platt, O. Sand., 2003. Sound detection mechanisms and capabilities of teleost fishes. Pages 3-38 in S.P. Collin and N.J. Marshall, eds. Sensory processing in aquatic environments. Springer-Verlag, New York.

Regnault, M., Lagardère, J.P., 1983. Effects of ambient noise on the metabolic levels of Crangon crangon (Decapoda, Natantia). Mar. Ecol. Prog. Ser. 11, 71-78.

Sand, O., Enger, P.S., Karlsen, H.E., Knudsen, F., Kvernstuen, T. 2000. Avoidance responses to infrasound in downstream migrating silver eels, Anguilla anguilla. Environmental Biology of Fishes 57 (3), 327-336.

Santulli, A., Modica, A., Messina, C., Ceffa, L., Curatolo, A., Rivas, G., Fabis, G., Damelio, V., 1999. Biochemical responses of European sea bass (Dicentrarchus labrax L.) to the stress induced by of shore experimental seismic prospecting. Mar. Pollut. Bull. 38, 1105-1114.

Scholik, A.R., Yan, H.Y., 2001. Effects of underwater noise on auditory sensitivity of a cyprinid fish. Hear. Res. 152, 17-24.

Scholik, A.R., Yan, H.Y., 2002. Effects of boat engine noise on the auditory sensitivity of the fathead minnow, Pimephales promelas. Environ. Biol. Fishes 63, 203-209.

Smith, M.E., Kane, A.S., Popper, A.N., 2004. Noise-induced stress response and hearing loss in goldfish (Carassius auratus). J.Exp. Biol. 207, 427-435.

Sokal, R.R., Rohlf, F.S., 1981. Biometry. W.H. Freeman. New York.

Sverdrup, A., Kjellsby, E., Krüger, P.G., Floysand, R., Knudsen, F.R., Enger, P.S., SerckHanssen G, Helle K.B., 1994. Effects of experimental seismic shock on vasoactivity of 
arteries, integrity of the vascular endothelium and on primary stress hormones of the Atlantic salmon. J. Fish Biol. 45, 973-995.

Sun, Y., Song, Y., Zhao, J., Chen, J., Yuan, Y., Jiang, S., Zhang, D., 2001. Effect of drilling noise and vibration on growth of carp (Cyprinus carpio) by cut-fin marking. Mar. Fish. Res./ Haiyang Shiuchan Yanjiu 22 (1), 62-68.

Systat Software, Inc. 2004. Systat 11 for Windows. Chicago, IL.

Terhune, J.M., Friars, G.W., Bailey, J.K., O’Flynn, F.M., 1990. Noise levels may influence Atlantic salmon smolting rates in tanks. J. Fish Biol. 37, 185-197.

Tolimieri, N., Haine, O., Montgomery, J.C., Jeffs, A., 2002. Ambient sound as a navigational cue for larval reef fish. Bioacoustics 12, $214-217$.

Tolimieri, N., Haine, O., Jeffs, A., McCauley, R., Montgomery, J., 2004. Directional orientation of pomacentrid larvae to ambient reef sound. Coral Reefs 23 (2), 184-191.

Wedemeyer, G.A., Barton, B.A., McLeay, D.J., 1990. Stress and acclimation: Pages 451-489 in C. Schreck and P. Moyle (eds.), Methods for Fish Biology. American Fisheries Society, Bethesda, MD.

Wedemeyer, G.A., 1996. Physiology of Fish in Intensive Culture Systems. Chapman and Hall, New York.

Wendelaar-Bonga, S.E., 1997. The stress response in fish. Physiol. Rev. 77, 591-625.

Weyts, F.A.A., Cohen, N., Flik, G., Verburg-van Kemenade, B., 1999. Interactions between the immune system and the hypothalamo-pituitary-interrenal axis in fish. Fish Shellfish Immunol. 9, 1-20.

Wysocki, L.E., Dittami, J.P., Ladich, F., 2006. Ship noise and cortisol secretion in European freshwater fishes. Biol. Cons. 128, 501-508.

Wysocki, L.E., Amoser, S., Ladich, F. 2007a. Diversity in ambient noise in European freshwater habitats: Noise levels, spectral profiles, and impact on fishes. J. Acoust. Soc. Am. 121 (5), 2559-2566.

Wysocki, L.E., Davidson, J.W.3 ${ }^{\text {rd }}$, Smith, M.E., Frankel, A.S., Ellison, T.E., Mazik, P.M., Popper, A.N., Bebak, J., 2007b. The effects of aquaculture production noise on hearing, growth, and disease resistance of rainbow trout, Oncorhynchus mykiss. Aquaculture 272, 687-697. 


\section{Tables}

Table 1. Mean sound levels (dB re $1 \mu \mathrm{Pa}$ RMS) for the $117 \mathrm{~dB}$ treatment.

\begin{tabular}{c|ccccc|}
\multicolumn{1}{c}{} & \multicolumn{5}{c}{ Distance from Tank Side $(\mathrm{cm})$} \\
\multirow{2}{*}{$\begin{array}{c}\text { Depth }(\mathrm{cm}) \\
5\end{array}$} & 5 & 38 & 76 & 38 & 5 \\
\cline { 2 - 6 } 38 & $\mathbf{1 2 0}$ & $\mathbf{1 1 0}$ & $\mathbf{1 1 0}$ & $\mathbf{1 1 0}$ & $\mathbf{1 2 0}$ \\
& $\mathbf{1 2 2}$ & $\mathbf{1 1 5}$ & $\mathbf{1 1 3}$ & $\mathbf{1 1 5}$ & $\mathbf{1 2 4}$ \\
76 & $\mathbf{1 2 3}$ & $\mathbf{1 1 6}$ & $\mathbf{1 1 5}$ & $\mathbf{1 1 7}$ & $\mathbf{1 2 4}$ \\
\hline
\end{tabular}

Table 2. Mean sound levels (dB re $1 \mu \mathrm{Pa}$ RMS) for the $149 \mathrm{~dB}$ treatment.

\begin{tabular}{|c|c|c|c|c|c|}
\hline \multirow{3}{*}{$\begin{array}{c}\text { Depth }(\mathrm{cm}) \\
5\end{array}$} & \multicolumn{5}{|c|}{ Distance from Tank Side $(\mathrm{cm})$} \\
\hline & 5 & 38 & 76 & 38 & 5 \\
\hline & 157 & 135 & 133 & 139 & 164 \\
\hline 38 & 157 & 143 & 140 & 147 & 163 \\
\hline 76 & 157 & 142 & 142 & 146 & 163 \\
\hline
\end{tabular}

Table 3. Mean water quality concentrations \pm 1 standard error for each sound treatment.

\begin{tabular}{lcc}
\hline Parameter & $\mathbf{1 1 7} \mathbf{~ d B}$ & $\mathbf{1 4 9} \mathbf{~ d B}$ \\
\hline Alkalinity (mg/L) & $272 \pm 2$ & $266 \pm 3$ \\
Carbon dioxide (mg/L) & $21 \pm 1$ & $21 \pm 0$ \\
Dissolved Oxygen (mg/L) & $10.2 \pm 0.0$ & $10.6 \pm 0.1$ \\
Nitrite (mg/L) & $0.00 \pm 0.00$ & $0.01 \pm 0.00$ \\
Total Ammonia Nitrogen (mg/L) & $0.38 \pm 0.00$ & $0.36 \pm 0.00$ \\
Total Suspended Solids (mg/L) & $1.30 \pm 0.10$ & $0.87 \pm 0.04$ \\
\hline
\end{tabular}


Table 4. Mean \pm 1 standard error for various growth criteria for the 117 and $149 \mathrm{~dB}$ treatments following five months of noise exposure $(n=4)$.

\begin{tabular}{lll}
\hline Parameter & $\mathbf{1 1 7} \mathbf{~ d B}$ & $\mathbf{1 4 9} \mathbf{~ d B}$ \\
\hline Weight (g) & $641 \pm 3$ & $631 \pm 10$ \\
95\% CI Weight (g) & $630-652$ & $601-662$ \\
Length (mm) & $333 \pm 2$ & $334 \pm 1$ \\
Specific Growth Rate (\%/day) & $1.84 \pm 0.00$ & $1.84 \pm 0.01$ \\
95\% CI SGR (\%/day) & $1.83-1.86$ & $1.82-1.87$ \\
Feed Conversion Ratio & $1.07 \pm 0.01$ & $1.09 \pm 0.02$ \\
Condition Factor & $1.71 \pm 0.01$ & $1.70 \pm 0.01$ \\
Survival (\%) & $98.6 \pm 0.4$ & $99.0 \pm 0.2$ \\
\hline
\end{tabular}




\section{Figures}

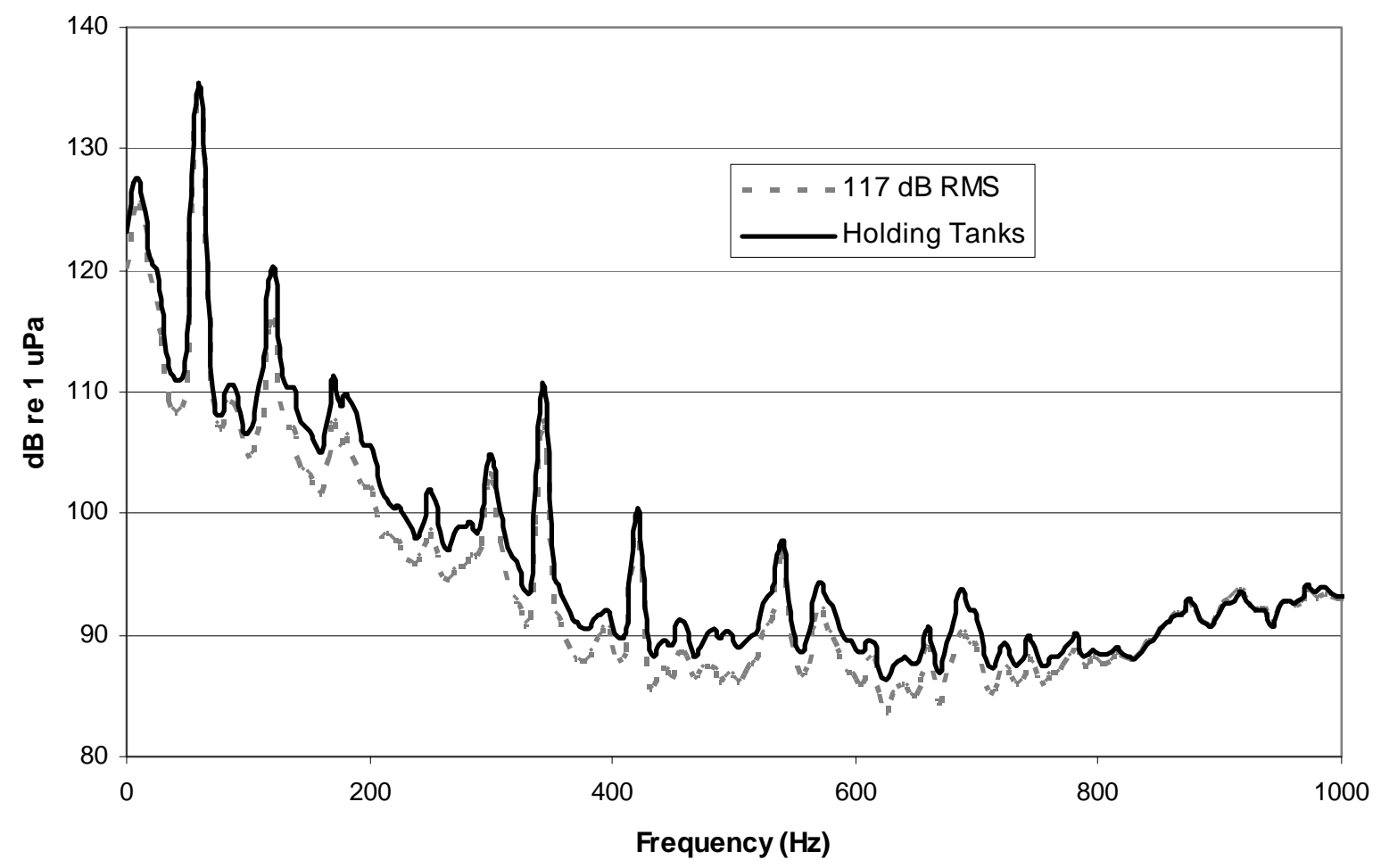

Figure 1. Sound spectrum comparison of the holding tanks and the experimental control tanks used during the study ( $117 \mathrm{~dB}$ re $1 \mu \mathrm{Pa}$ RMS).

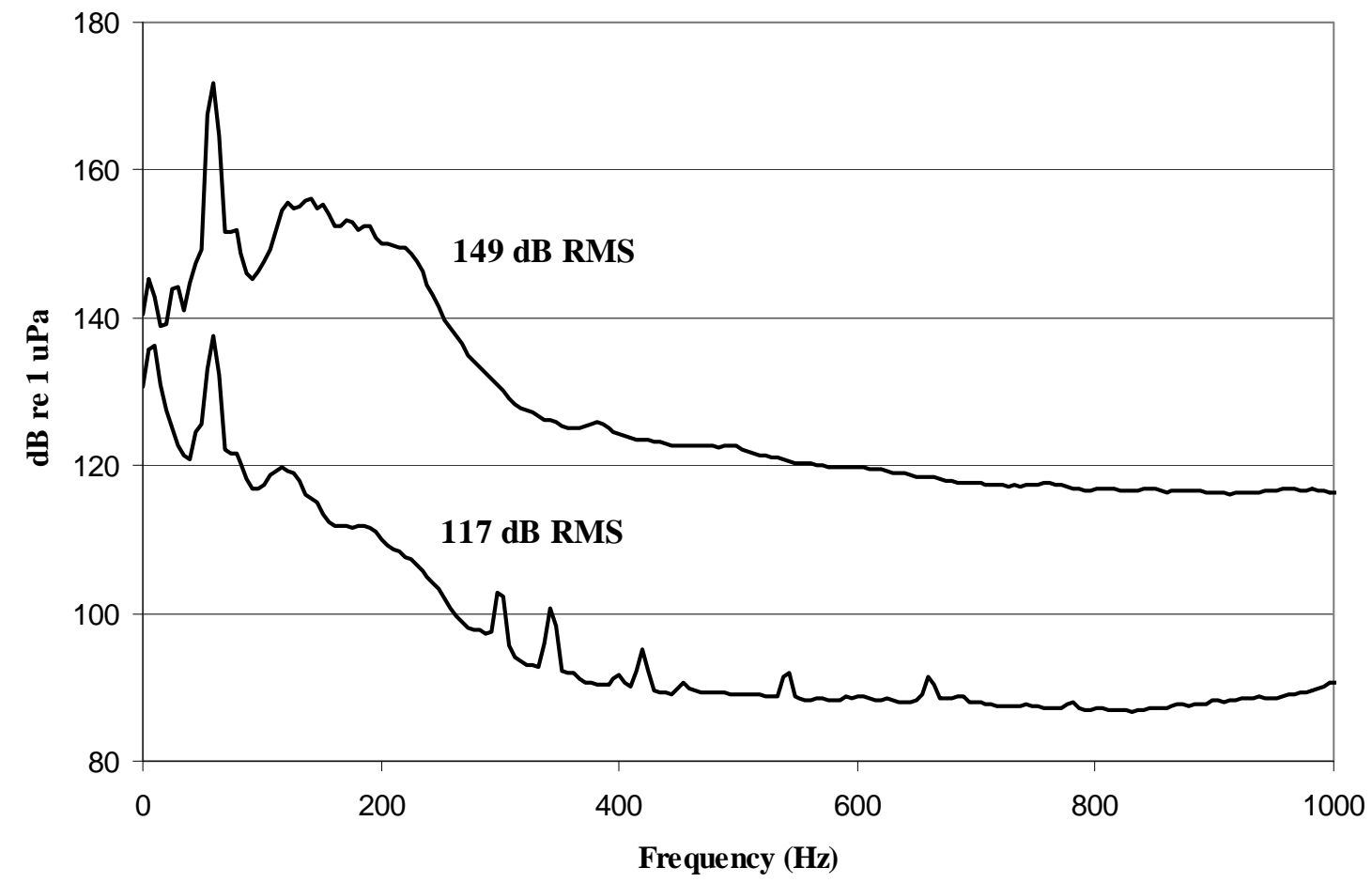

Figure 2. Mean sound spectrum levels for the two sound treatments. 


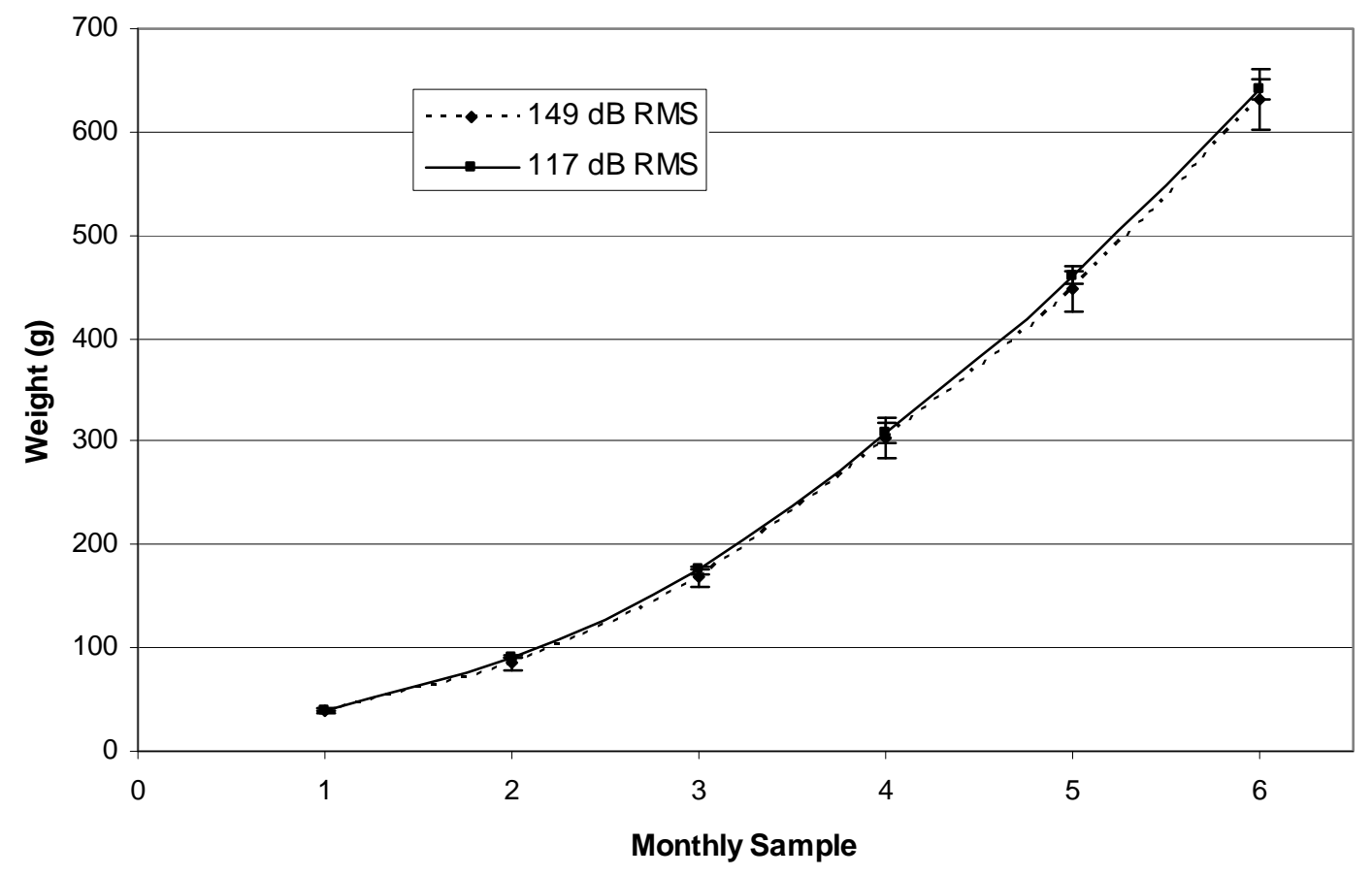

Figure 3. Mean growth rates (g) for the 149 and $117 \mathrm{~dB}$ treatments throughout the study with $95 \%$ confidence intervals.

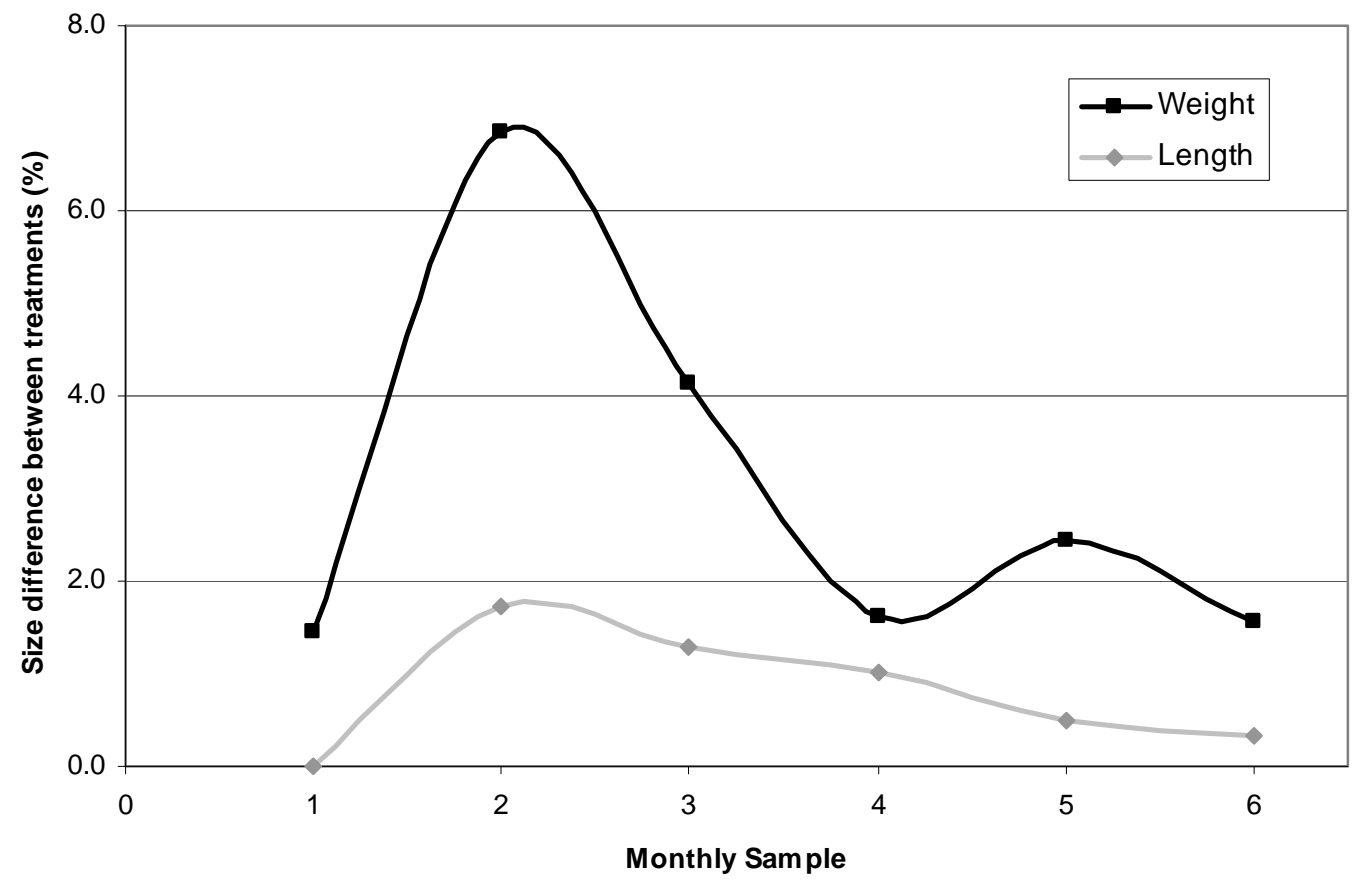

Figure 4. Percentage difference in mean weights and lengths between treatments for each monthly sample. 


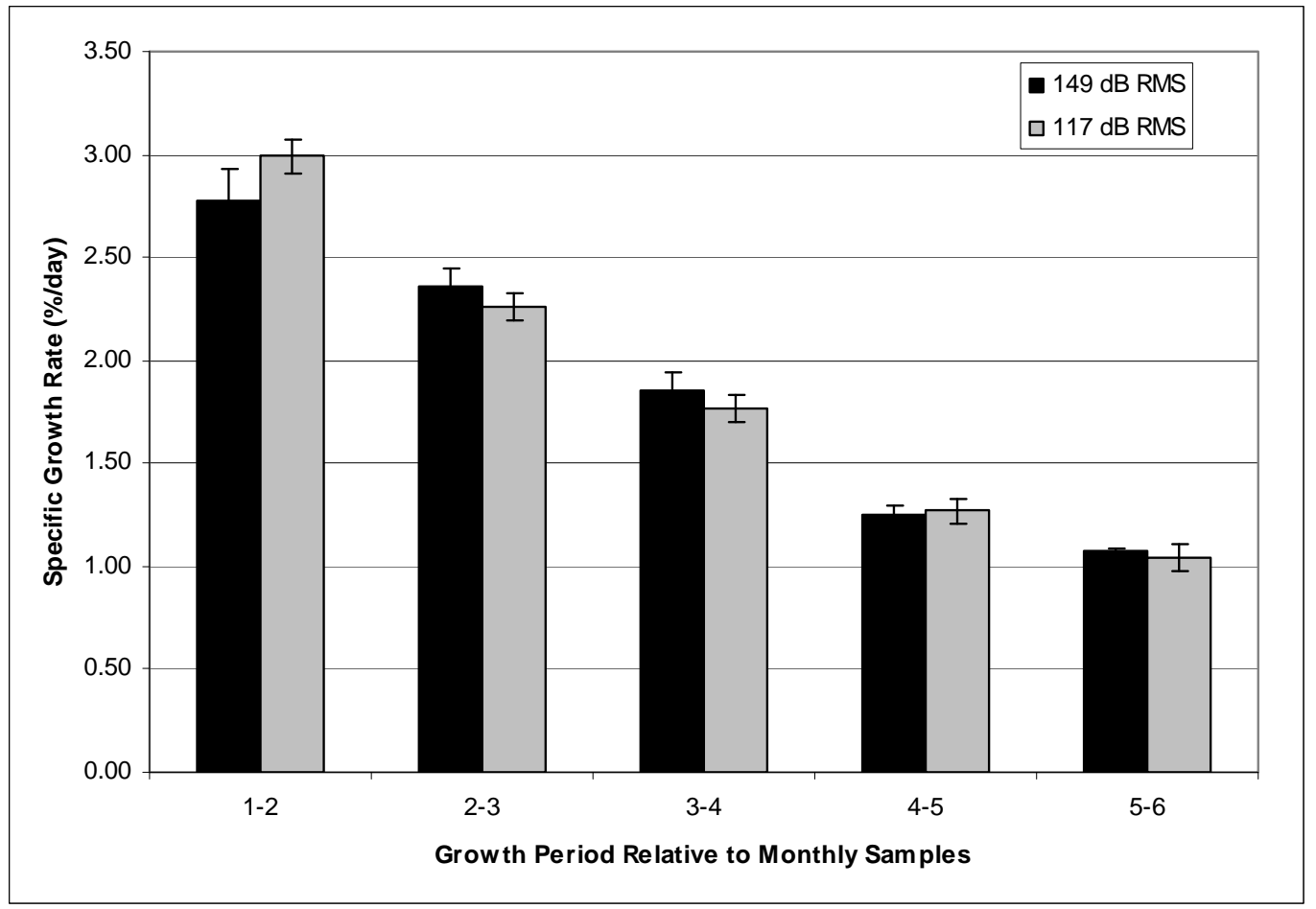

Figure 5. Specific growth rates (\% growth/day) between each monthly sample for the 149 and $117 \mathrm{~dB}$ treatments with $95 \%$ confidence intervals.

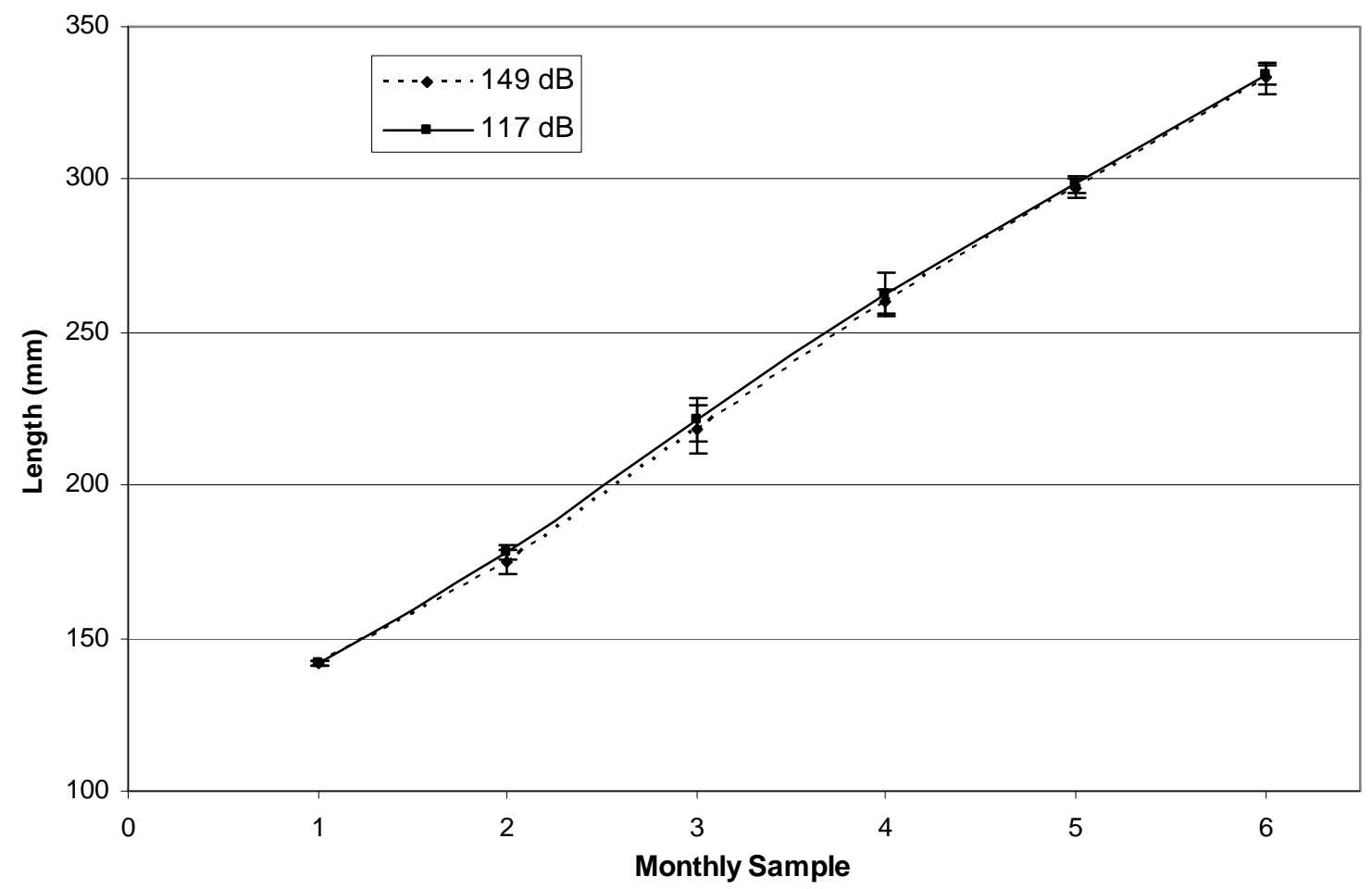

Figure 6. Mean length (mm) for the 149 and $117 \mathrm{~dB}$ treatments throughout the study with $95 \%$ confidence intervals. 


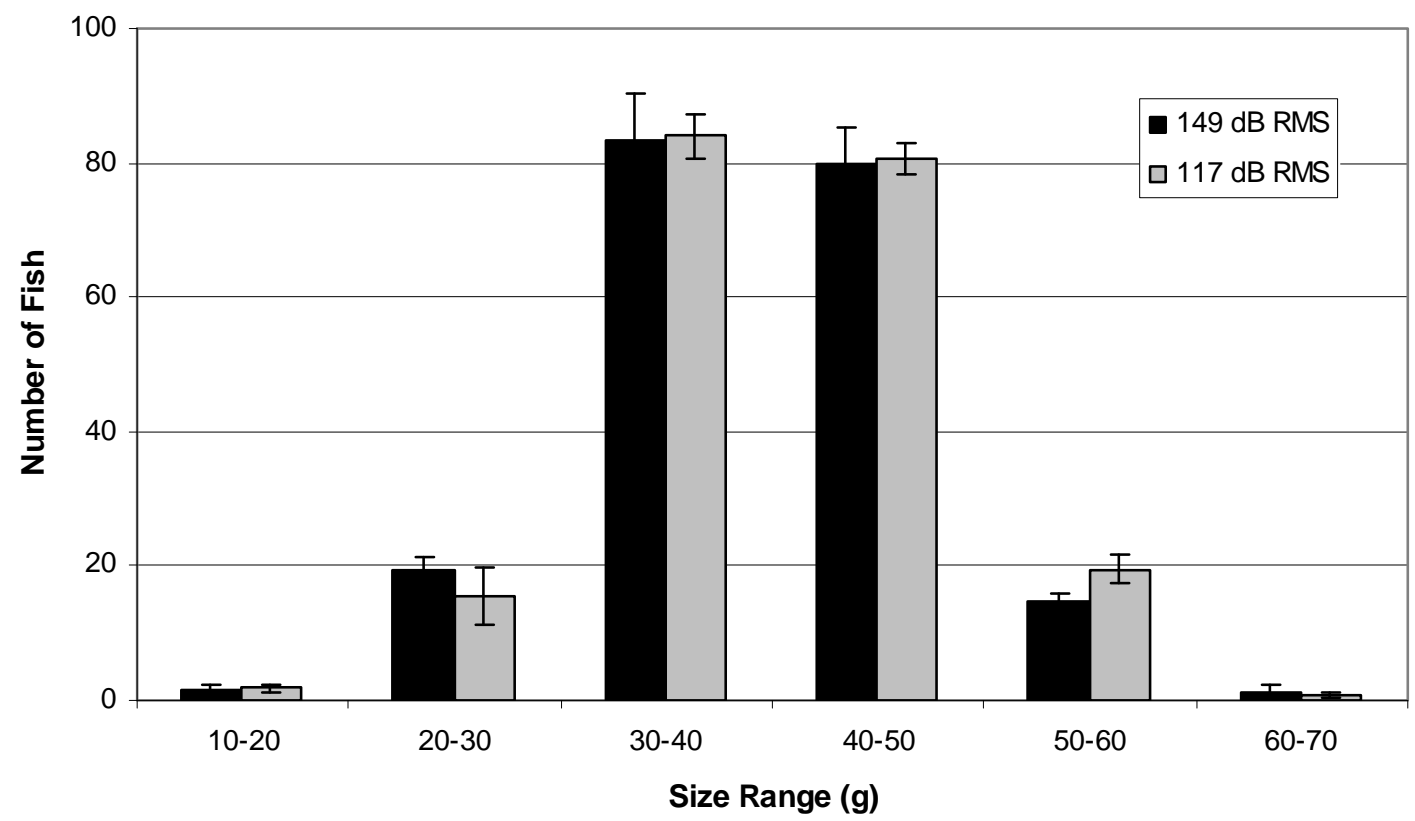

Figure 7. Mean size distribution for each sound treatment at the beginning of the study.

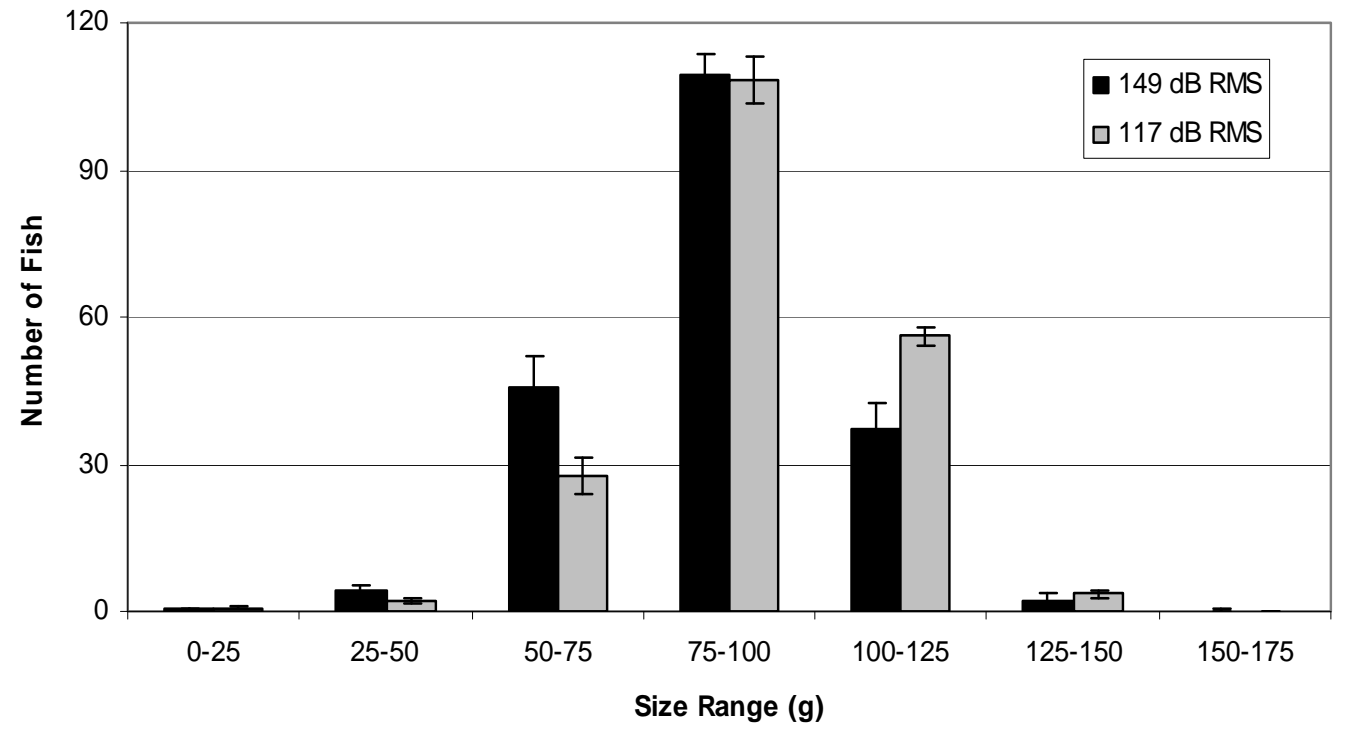

Figure 8. Mean size distribution for each sound treatment after one month of exposure to experimental conditions. 


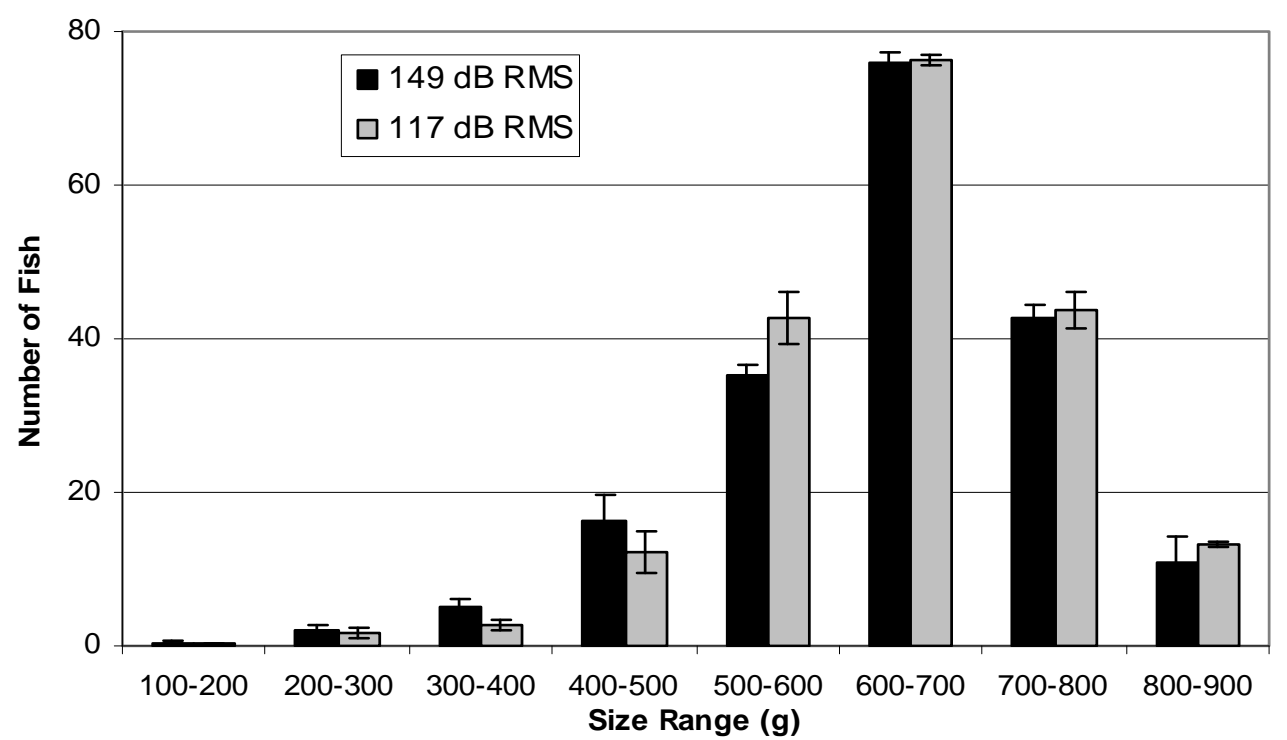

Figure 9. Mean size distribution for each sound treatment at the end of the study. 


\section{Appendix}

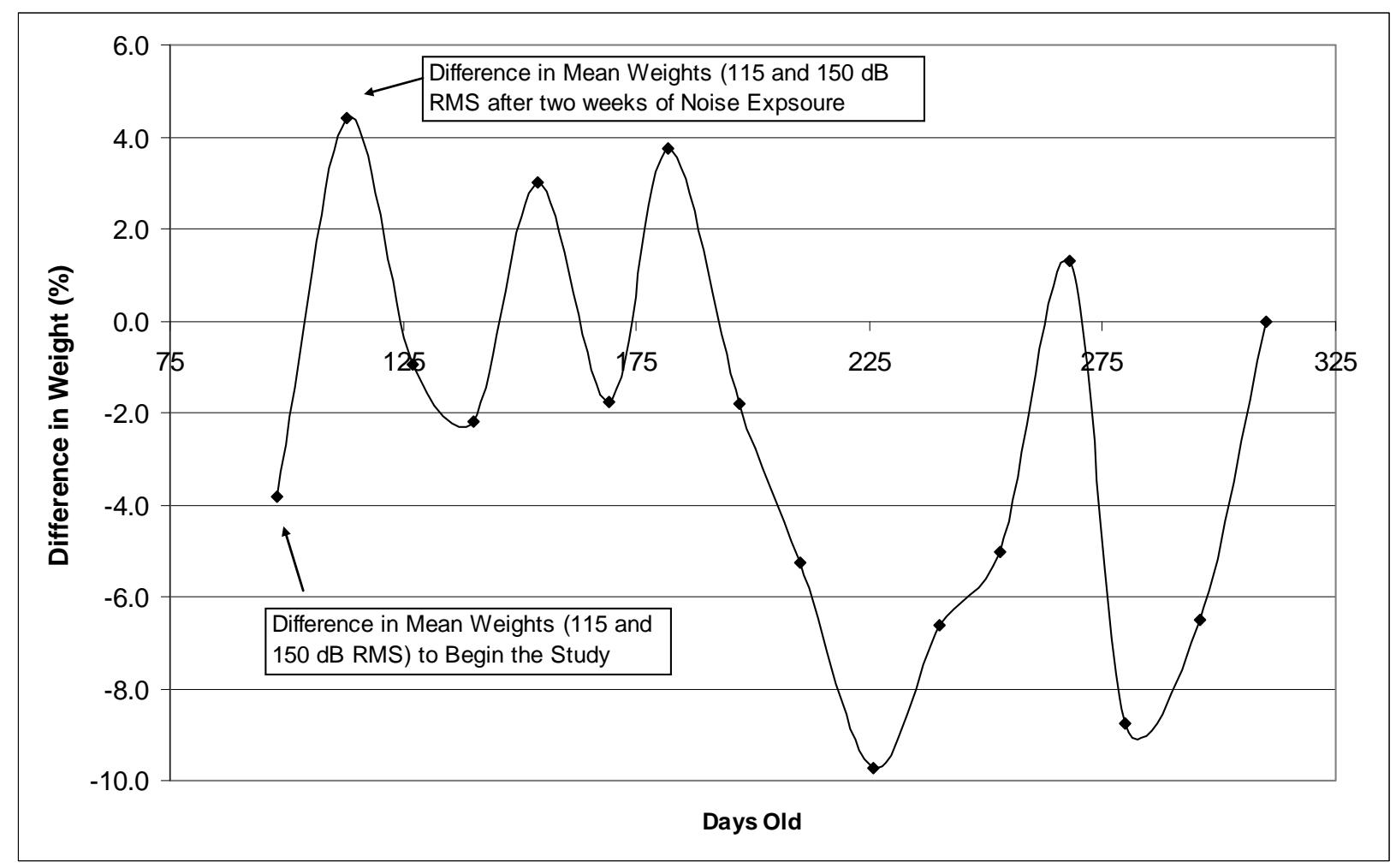

Figure 1. Difference in mean weight (\%) between the 115 and the $150 \mathrm{~dB}$ re $1 \mu \mathrm{Pa}$ RMS treatments during each sampling event over the course of the study. Percent difference in mean weight was calculated as: $\mathrm{PD}=\left(115 \mathrm{~dB}_{\mathrm{wt}}-150 \mathrm{~dB}_{\mathrm{wt}} / 115 \mathrm{~dB}_{\mathrm{wt}}\right) * 100$. Positive measures of percent difference, i.e. $0+\%$, represents larger fish within the $115 \mathrm{~dB}$ treatment, while a negative percent difference represents larger fish within the $150 \mathrm{~dB}$ treatment. Note that the largest difference occurred after two weeks of noise exposure. 


\title{
Curriculum Vitae
}

\author{
John W. Davidson III \\ 1098 Turner Road, Shepherdstown, West Virginia 25443 \\ ph. 304-876-2815 xt.221 j.davidson@,freshwaterinstitute.org
}

\section{EDUCATION}

Shepherd College (Shepherdstown, WV) graduated 1998, Bachelor of Science in Biology Relevant classes: Animals as Organisms, Animal Physiology, Invertebrate Natural History, Chemistry I and II, Physics I and II, Plants as Organisms, Plant Pathology, Genetics

West Virginia University, pursuing Master's of Science Degree in Wildlife and Fisheries Management, will graduate in 2009

Relevant classes: Fish Ecology, Advanced Fisheries Management, Data Analysis I and II, Ichthyology, Aquatic Toxicology

Classes to be taken: Advanced GIS, Fish Physiology

\section{OTHER TRAINING \& CONTINUING EDUCATION}

Coldwater Fish Culture. National Conservation Training Center (Shepherdstown, WV). 1999.

Water Reuse Systems Short Course. Sponsored by The Freshwater Institute and Cornell University (Shepherdstown, WV). 2001

Electrical Troubleshooting for Wastewater Systems. West Virginia Environmental Training Center and West Virginia Department of Education. 2002

Basic Course in HACCP (Hazard Analysis and Critical Control Point) sponsored by the Association of Food and Drug Officials/ Seafood HACCP Alliance (Hampton, VA). 2002

Introduction to GIS for Conservation Professionals. National Conservation Training Center (Shepherdstown, WV). 2007 


\section{PROFESSIONAL EXPERIENCE}

The Conservation Fund's Freshwater Institute (Shepherdstown, WV)

1997 - Internship: “An optimal dosage of chitosan for the removal of suspended solids from a recirculating water system for rainbow trout"

Nov. 1998- Jan.1999 - Part-time, Research Technician

Feb. 1999- Present: Research Associate

Research focus: Recirculating aquaculture system technologies and waste management technologies for aquaculture

Job Description and Skills:

-Animal husbandry and recirculating aquaculture system management

-Carry out and oversee aquaculture research projects

-Organize and summarize data using charts and figures, and conduct statistical analyses

-Write scientific manuscripts for professional publication for industry related journals

-Water sample collection and analysis

-Minor construction and repairs of recirculating fish culture systems

-Assist engineering staff with consulting projects for the US Fish \& Wildlife Service

-Operate and maintain specialized equipment: oxygen, $\mathrm{pH}$, water flow meters, etc.

\section{CAREER HIGHLIGHTS}

\section{Lead author and technical researcher for the following publications:}

Davidson, J.W., Good, C. Welsh, C., Brazil, B., and Summerfelt, S.T. 2008 (In Press). Water quality and treatment efficiency in replicated recirculating systems operated under 1) high feed and low flushing conditions or 2) low flushing with or without ozonation. Proceedings of the $7^{\text {th }}$ International Conference on Recirculating Aquaculture.

Davidson, J.W., Helwig, N., and Summerfelt, S.T. 2008 (In Press). Fluidized sand biofilters used to remove ammonia, biochemical oxygen demand, total coliform bacteria, and suspended solids form an intensive aquaculture effluent. Aquacultural Engineering.

Davidson, J.W. and Summerfelt, S.T. 2008. U.S. researchers study effectiveness of fluidized sand biofilters. Hatchery International March/April: 37.

Davidson, J.W., Frankel, A.S., Ellison, W., Summerfelt, S.T., Popper, A.N., Mazik, P., and Bebak, J. 2007. Minimizing noise in fiberglass aquaculture tanks: Noise reduction potential of various tank retrofits. Aquacultural Engineering 125-131. 
Davidson, J.W. and Summerfelt, S.T. 2005. Settler Evaluation: Radial Flow vs. Tangential Flow. Global Aquaculture Advocate 8 (3): 56-57.

Davidson, J.W. and Summerfelt, S.T. 2005. Solids Removal from a Coldwater Recirculating System - Comparison of a Swirl Separator to a Radial-Flow Settler. Aquacultural Engineering 33: 47-61.

Davidson, J.W. Waldrop, T., Summerfelt, S.T., and Bebak-Williams, J. 2004. Arctic char performance at 13-14 degrees Celsius using recirculating technologies. World Aquaculture 35 (1): 48.51 .

Davidson, J.W. and Summerfelt, S.T. 2004. Solids flushing, mixing, and water velocity profiles within large (10 and 150 cubic meter) circular 'Cornell-type' dual-drain tanks. Aquacultural Engineering 32: 245-271.

Davidson, J.W., Masters, A., Vinci, B., and Summerfelt, S.T. 2004. Testing dual drain tanks for improved waste removal at Craig Brook NFH. Hatchery International 5 (3): 22-23, 34.

\section{Co-first author and technical researcher for the following publication:}

Wysocki, L.E., Davidson, J.W. $3^{\text {rd }}$, Smith, M.E., Frankel, A.S., Ellison, W.T., Mazik, P.M., Popper, A.N., and Bebak, J. 2007. Effects of aquaculture production noise on hearing, growth, and disease resistance of rainbow trout, Oncorhynchus mykiss. Aquaculture 272: 687-297.

\section{Coauthor and technical researcher for the following publications:}

Wysocki, L.E., Smith, M.E., Popper, A.N., Davidson, J., Frankel, A., Ellison, W., Ford, F., and Bebak-Williams, J. 2006. Effects of environmental noise on hearing capabilities of fish. $29^{\text {th }}$ Mid Winter Meeting of the Association for Research in Otolaryngology, February 5-9, Baltimore, MD (poster).

Summerfelt, S., Davidson, J., Waldrop, T., Tsukuda, S., and Bebak-Williams, J. 2005. PartialReuse Systems: Offer Benefits for Coldwater, Seawater Aquaculture. Global Aquaculture Advocate 8 (1): 68-69.

Summerfelt, S.T., Davidson, J., Waldrop, T., Tsukuda, S., and Bebak-Williams, J. 2004. A partial-reuse system for coldwater aquaculture. Aquacultural Engineering 31: 157-181.

Tsukuda, S.M., Davidson, J., Adkins, A. and Summerfelt, S.T. 2003. Evaluation of Dissolved Chitosan for Suspended Solids Removal. International Journal of Recirculating Aquaculture 4: 33-46.

Summerfelt, S.T., Davidson, J. and Waldrop, T. 2003. Evaluation of full-scale carbon dioxide stripping columns in a coldwater recirculating system. Aquacultural Engineering 28, 155-169. 


\section{Professional Presentations}

Water Quality and Treatment Efficiency in Recirculating Systems Operated Under High Feed and Low Flushing Conditions. Aquaculture America Conference. Orlando, FL. 2008.

Fluidized Sand Biofilters Remove Ammonia and Biochemical Oxygen Demand from an Intensive Aquaculture Effluent. $6^{\text {th }}$ International Conference on Recirculating Aquaculture. Roanoke, VA. 2006.

Minimizing Noise in Fiberglass Aquaculture Tanks: Noise Reduction Potential of Various Tank Retrofits. Aquaculture America Conference. Las Vegas, NV. 2006.

The Effects of Aquaculture Noise on the Growth and Survival of Rainbow Trout. Aquaculture America Conference. Las Vegas, NV. 2006.

Commercial Scale Growout of Arctic char using Recirculating Systems Technology.

Aquaculture America Conference. Honolulu, HI. 2004

Solids Removal from a Coldwater Recirculating System: Comparison of a Swirl Separator and a Radial Flow Settler. $5^{\text {th }}$ International Conference on Recirculating Aquaculture. Roanoke, VA. 2004.

Solids Flushing, Mixing, and Water Velocity Profiles within Large Circular Dual Drain Tanks for Salmonid Culture. Aquaculture Engineering Society Issues Forum. Seattle, WA. 2003

Growth Performance of a Yukon Gold x Tree Rivers Arctic Char and a Yukon Gold Arctic Char at $12-14{ }^{\circ}$ C. Aquaculture America, San Diego, CA. 2002.

\section{Other Accomplishments}

Identified and coordinated donations of food-size rainbow trout and Arctic char to local rescue missions in Martinsburg (WV), Winchester (VA), Hagerstown (MD), and Frederick (MD), which led to collaboration with the Federation of Virginia Food Banks and the donation of over 200,000 pounds of fish to feed the hungry. 